\title{
Simulação de fenômenos óticos e fisiológicos do sistema de visão humana
}

\author{
Leandro Henrique Oliveira Fernandes
}

Orientador: Prof ${ }^{\circ} r^{\circ}$ Odemir Martinez Bruno

\author{
Dissertação apresentada ao Instituto de Ciências Matemáticas e \\ de Computação - ICMC-USP, como parte dos requisitos para \\ obtenção do título de Mestre em Ciências - Ciências de \\ Computação e Matemática Computacional.
}

USP - São Carlos

Janeiro/2008 

Simulação de fenômenos óticos e fisiológicos do sistema de visão humana.

Leandro Henrique Oliveira Fernandes 

Em memória à Ana Carolina, amorosa sobrinha, o vazio deixado é enorme e a saudade infinita ... 



\section{Agradecimento}

Agradeço as pessoas que se fizeram presentes em minha vida.

Meus pais, Wilmar e Liany, inspirações desde os primeiros e vacilantes passos até os mais ousados. Incentivaram-me e sempre acreditaram em mim. Efusiva homenagem e uma gratidão sem fim.

A Daniela, adorável e querida companheira, que com sua presença afetuosa e constante, tornou suave este empreendimento tão árduo.

Professor Doutor Odemir Martinez Bruno, meu orientador. A eficiência com que acompanhou o desenvolvimento das pesquisas e à maneira jeitosa de guiar minhas idéias desde as mais ingênuas até as mais atrevidas, concorreram, imprescindivelmente, para a organização geral desta reflexão. Minha admiração e respeito.

Professor Doutor Luis Gustavo Nonato e Professor Doutor Luis Alberto Vieira de Carvalho. Grato pela generosidade, valiosas foram as muitas orientações e magistrais sugestões. Meu especial reconhecimento pela atensão magnânima, motivo de estímulo em todas as fases de investigação.

Amigos. Àqueles que me apoiaram o débito é imenso e o espaço diminuto para expressar toda a minha alegria por esta realização.

E finalmente à CNPQ, o apoio financeiro foi indispensável para conclusão deste trabalho. 



\section{Resumo}

O ganho crescente de desempenho nos computadores modernos tem impulsionado os trabalhos científicos nas áreas de simulação computacional. Muitos autores utilizam em suas pesquisas ferramentas comerciais que limitam seus trabalhos ao esconder os algoritmos internos destas ferramentas e dificultam a adição de dados in-vivo nestes trabalhos. Este trabalho explora esta lacuna deixada por aqueles autores. Elaboramos um arcabouço computacional capaz de reproduzir os fenômenos óticos e fisiológicos do sistema visual. Construímos com superfícies quádricas os modelos esquemáticos do olho humano e propomos um algoritmo de traçado de raio realístico. Então realizamos um estudo nos modelos esquemáticos e a partir deles mais a adição de dados in-vivo obtidos de um topógrafo de córnea extraímos informações óticas destes modelos. Calculamos os coeficientes e Zernike dos modelos para tamanhos diversos de pupila e obtivemos medidas de aberração do olho humano. Os resultados encontrados estão de acordo com os trabalhos relacionados e as simulações com dados in-vivo estão consoantes com as produzidas por um aparelho de frente de onda comerciais. Este trabalho é um esforço em aproveitar as informações adquiridas pelos equipamentos modernos de oftalmologia, além de auxiliar o entendimento de sistemas visuais biológicos acabam também em auxiliar a elaboração de sistemas de visão artificial e os projetistas de sistemas óticos. 



\section{Abstract}

The increase in performance of the modern computers has driven scientific work in the areas of computer simulation. Many authors use in their research commercial tools that use embedding algorithms, which sources are not provided, and it makes harder and sometimes impossible, the development of novel theories or experiments. This work explores this gap left for those authors. We present a computational framework capable to reproduce the optical and physiological phenomena of the human visual system. We construct schematical models of the human eye from quadrics surfaces and consider an algorithm of realistic ray tracing. Afterward, we performed a study on schematics models and in addition we introduce, in these models, in-vivo data obtained from corneal topography machine and extract optical information. We calculate the Zernike coefficients in the models for different sizes of pupil and measures of aberration of the human eye. The results are in agreement with related work and simulations with in-vivo data are according with the produced by a commercial wave-front device. This work is an effort in using to advantage the information acquired for the modern equipment of ophthalmology, besides assisting the understanding of biological visual systems, it also helps the development of artificial vision systems and the designing of optical systems. 



\section{Sumário}

Sumário $\quad$ i

Lista de Figuras $\quad$ v

Lista de Tabelas $\quad$ ix

1 Introdução 1

1.1 Objetivos e Organização . . . . . . . . . . . . . . . . . 2

2 Ótica fisiológica $\quad 5$

2.1 Ótica geométrica . . . . . . . . . . . . . . . . . 5

2.1 .1 Lei de Snell . . . . . . . . . . . . . . . . . . . . . . . . 7

2.1.2 Propagação em meios inomogêneos . . . . . . . . . . . . . . . 8

2.1.3 Sistemas óticos . . . . . . . . . . . . . . . . . . 8

2.1.4 Aproximação paraxial . . . . . . . . . . . . . . . . . . 10

2.1 .5 Aberrações . . . . . . . . . . . . . . . . . . . 13

2.2 Ótica de Fourier . . . . . . . . . . . . . . . . . . . . . . . . 18

2.2.1 Sistemas óticos como sistema linear . . . . . . . . . . . . . . . . 19

2.2.2 Teoria ondulatória de aberração . . . . . . . . . . . . . . . . . . 19

2.2.3 Polinômios de Zernike . . . . . . . . . . . . . . . . . . . . . . 21

2.2.4 Função de espalhamento de ponto e função de tranferência de modulação . . . . . . . . . . . . . . . . 22 
2.3 Formação de imagens em sistemas óticos . . . . . . . . . . . . . . . . . . . 24

3 Olho humano $\quad 25$

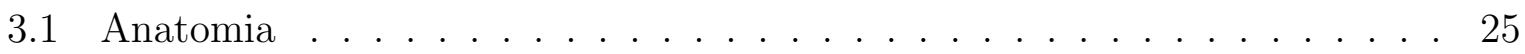

3.2 Funções dos olhos . . . . . . . . . . . . . . . . . . . . . . . 27

3.3 Eixos do olho humano . . . . . . . . . . . . . . . . . . . . . . . . . . 28

3.4 Modelos óticos . . . . . . . . . . . . . . . . . . . . 30

4 Acomodação no olho humano $\quad 31$

4.1 Processo de acomodação . . . . . . . . . . . . . . . . . . . . . 31

4.2 Ponto remoto e ponto próximo . . . . . . . . . . . . . . . . 32

4.3 Convergência binocular . . . . . . . . . . . . . . . . . . . . . 33

4.4 Medidas de acomodação . . . . . . . . . . . . . . . . . 34

4.5 Teoria de acomodação . . . . . . . . . . . . . . . . . 35

5 Olho Virtual $\quad 39$

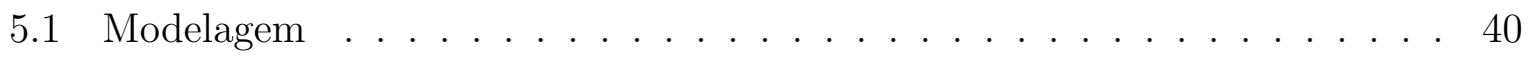

5.1 .1 Modelagem teórica . . . . . . . . . . . . . . . . . . 40

5.1 .2 Modelagem dado in-vivo . . . . . . . . . . . . . . . . . 41

5.1 .3 Geração de malhas . . . . . . . . . . . . . . . . . . . . . . 42

5.2 Simulação: traçado de raios . . . . . . . . . . . . . . . . . . . 44

5.2.1 Cálculo de intersecção e normal . . . . . . . . . . . . . 45

5.2 .2 Propagação dos raios . . . . . . . . . . . . . . . . . . . . 49

5.3 Visualização . . . . . . . . . . . . . . . . . . . . . . 53

5.4 Acomodação no VEye . . . . . . . . . . . . . . . . . 54

5.5 Cálculo das propriedades paraxiais . . . . . . . . . . . . . . . . 55

5.6 Aberração esférica: longitudinal e transversal . . . . . . . . . . . . . . . 57

5.7 Simulação de frente de onda . . . . . . . . . . . . . . . . . 59

5.8 Projeção de cones . . . . . . . . . . . . . . . . . . . . . . . 61

6 Simulações e resultados $\quad 65$

6.1 Propriedades gaussianas . . . . . . . . . . . . . . . . 66 
6.2 Simulação do processo de acomodação . . . . . . . . . . . . . . . 68

6.3 Aberração esférica . . . . . . . . . . . . . . . . . . . . 69

6.4 Simulação frente de onda . . . . . . . . . . . . . . . . . . . . 72

6.4 .1 Validação . . . . . . . . . . . . . . . . . . . . 73

6.4 .2 Frente de Onda . . . . . . . . . . . . . . . . . 75

6.4.3 Coeficientes de Zernike . . . . . . . . . . . 76

6.4.4 Função de espalhamento de pontos e função de trasferência de modulação . . . . . . . . . . . . . . . . . . 80

6.5 Formação de imagens . . . . . . . . . . . . . . . . . . . . . . 82

6.6 Diagrama de pontos . . . . . . . . . . . . . . . 85

6.7 Análise de erros . . . . . . . . . . . . . . . . . . . . 87

$\begin{array}{lll}7 & \text { Conclusão e perspectivas futuras } & 91\end{array}$

$\begin{array}{ll}\text { A Convenção e símbolos } & 93\end{array}$

A.1 Notação e sinal de distâncias . . . . . . . . . . . . . . . . . . . . . 93

A.2 Unidades e suas abreviações . . . . . . . . . . . . . . . . . . . 93

A.3 Modelos e abreviações . . . . . . . . . . . . . . . . . . . 94

A.4 Símbolos . . . . . . . . . . . . . . . . . . . . . 94

$\begin{array}{ll}\text { B Modelos do olho humano } & 97\end{array}$

B.1 Unidades . . . . . . . . . . . . . . . . . . . . . . . . 97

B.2 Emsley . . . . . . . . . . . . . . . . . . . 97

B.3 Gullstrand-LeGrand . . . . . . . . . . . . . . . . . . . . . . 98

B.3.1 (Não-acomodado) . . . . . . . . . . . . . 98

B.3.2 (Acomodado) . . . . . . . . . . . . . . . 99

B.4 Le Grand . . . . . . . . . . . . . . . . . . . . . . . . . . . . . 99

B.4.1 (Não-acomodado $\ldots \ldots \ldots \ldots . \ldots \ldots$

B.4.2 (Acomodado) . . . . . . . . . . . . . 100

B.5 Lotmar $(1971) \ldots \ldots \ldots \ldots$. . . . . . . . . . . . . . . . . . . . . . . . .

B.6 Kooijman(1983) . . . . . . . . . . . . . . . . 100

B.7 Navarro . . . . . . . . . . . . . . . . . . . . . . . . . 101 
Sumário

B.8 Liou-Brennan . . . . . . . . . . . . . . . . . . . . . . . . . 103

Referências Bibliográficas

105 


\section{Lista de Figuras}

2.1 Ilustração interface de refração. . . . . . . . . . . . . . . . . . . 6

2.2 Ilustração lei de Snell. . . . . . . . . . . . . . . . . . . . . 7

2.3 Propagação em meio inomogêneo. . . . . . . . . . . . . . . . . . 8

2.4 Ilustração de sistema ótico. O ponto $P^{\prime}$ é a imagem do ponto $P$. . . . . . 10

2.5 Ilustração dos pontos cardinais de um sistema ótico centrado. . . . . . . . 11

2.6 Combinação de dois sistemas óticos centrados. . . . . . . . . . . . . . . . 13

2.7 Ilustração frente de onda e aberração. . . . . . . . . . . . . . . . . . . . . 14

2.8 Traçado realístico e aberração geométrica. . . . . . . . . . . . . . 15

2.9 Aberração esférica geométrica. . . . . . . . . . . . . . . . 17

2.10 Aberração distorção geométrica. . . . . . . . . . . . . . . . . . 18

2.11 Aberração cromática. . . . . . . . . . . . . . . . . . 18

2.12 Aberração segundo ótica ondulatória. . . . . . . . . . . . . . . 20

3.1 Diagrama esquemático do olho humano. Figura extraída de (27) . . . . . . 27

3.2 Eixos do olho humano. . . . . . . . . . . . . . . . . . 29

4.1 Representação esquemática do olho focando no infinito. . . . . . . . . . . 33

4.2 Zona de acomodação. . . . . . . . . . . . . . . . . . . . . 33

4.3 Ilustração convergência binocular. . . . . . . . . . . . . . . . . . 34

4.4 Fibras zônulas e cristalino. . . . . . . . . . . . . . . . . 36

4.5 Acomodação segundo Helmholtz. . . . . . . . . . . . . . . . . . . . 37 


\section{Lista de Figuras}

4.6 Acomodação segundo Schachar. . . . . . . . . . . . . . . . . . . 38

5.1 Sistema de coordenadas do VEye . . . . . . . . . . . . . . . . . . . . 40

5.2 Modelagem da córnea a partir de dados in-vivo . . . . . . . . . . . . . . . . 41

5.3 Geração de malha: etapa inicial. . . . . . . . . . . . . . . . . . . . . . . 42

5.4 Malha $m$ em construção. . . . . . . . . . . . . . . . . . . . . . . . . 43

5.5 Esuqema de refinamento da malha $m \ldots \ldots \ldots$. . . . . . . . 43

5.6 Camadas com dois níveis de refinamento distintos. . . . . . . . . . . . . . . 44

5.7 Exemplo de malha utilizada no VEye . . . . . . . . . . . . . . . 45

5.8 Ilustração "Door-in Door-out". . . . . . . . . . . . . . . . . . . . . . 47

5.9 Traçado paraxial. . . . . . . . . . . . . . . . . . . . 51

5.10 Visualização em wire-frame. . . . . . . . . . . . . . . . . . 54

5.11 Visualização em shading. . . . . . . . . . . . . . . . . . . . . 54

5.12 Formação da entrada $E$ e saída $E^{\prime}$ da pupila em um modelo hipotético. . . 57

5.13 Aberração esférica longitudinal e transversal. . . . . . . . . . . . . . . . . . 58

5.14 Simulação frente de onda. . . . . . . . . . . . . . . . . . 60

5.15 Simulação projeção de cones. . . . . . . . . . . . . . . . . . . 63

6.1 Acomodação no VEye . . . . . . . . . . . . . . . . . . . . 70

6.2 Gráfico círculo de confusão por Gráfico acomodação. . . . . . . . . . . . 71

6.3 Aberração esférica longitudinal $L S A$. $<L S A>$ é dado pela Equação (6.3). 71

6.4 Aberração esférica transversal TSA. . . . . . . . . . . . . . . . 72

6.5 Coeficientes de Zernike extraídos de aparelho comercial de frente de onda Wave-Scan. . . . . . . . . . . . . . . . . . 73

6.6 Esquema de validação dos algoritmos de frente de onda . . . . . . . . . . 74

6.7 Curvas de níveis (em $\mathrm{mm}$ ) da frente de onda que emerge do modelo $l g r_{u}$. . 76

6.8 Curvas de níveis (em $\mathrm{mm}$ ) da frente de onda que emerge do modelo $\mathrm{lbr} \ldots 76$

6.9 Curvas de níveis (em $\mathrm{mm}$ ) da frente de onda que emerge do modelo hibrido

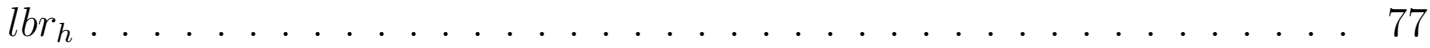

6.10 Frente de onda do modelo $\lg _{u} \ldots \ldots$. . . . . . . . . . . . . . 77

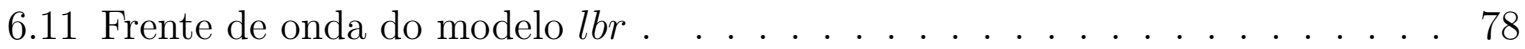

6.12 Coeficientes de Zernike obtidos do VEye (dados in-vivo ). . . . . . . . . 78 


\section{Lista de Figuras}

6.13 Coeficientes de Zernike do modelo $l b r$ e cristalino de $l b r$. . . . . . . . . . 79

6.14 Modelo $l g r_{u}$ e $l b r$.Coeficiente $c_{4}$ e $c_{12}$ em função de $R$. . . . . . . . . . . 79

6.15 Funções: de espalhamento de pontos e de transferência de modulação modelo $l b r \ldots \ldots \ldots$. . . . . . . . . . . . . . . . . . . 80

6.16 Função de espalhamento de pontos e função de transferência de modulação modelo $l b r_{h} \ldots \ldots \ldots \ldots \ldots$. . . . . . . . . . . . . . . 82

6.17 Experimento de convolução com $G_{\sigma}$ : a) imagem original b) $\sigma=1,0$ e c)

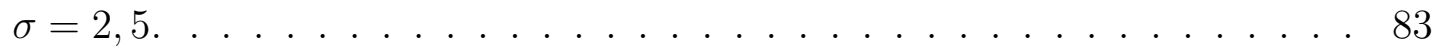

6.18 Imagem e histograma formada por $l g r_{a} R=1,0 \mathrm{~mm} \ldots \ldots$. . . . . . . . 83

6.19 Imagem e histograma formada por $\lg _{a} R=2,5 \mathrm{~mm} \ldots \ldots . . \ldots 84$

6.20 Imagem e histograma formada por $\operatorname{lgr}_{a} R=4,0 \mathrm{~mm} \ldots \ldots$. . . . . . . . 84

6.21 Diagrama de pontos $l g r_{u}$ e airy disc . . . . . . . . . . . . . 86

6.22 Diagrama de pontos $l g r_{a}$ e airy disc . . . . . . . . . . . . . . 87

6.23 Diagrama de pontos $l b r$ para $\alpha=0$ o e airy disc . . . . . . . . . . . 88

6.24 Diagrama de pontos $l b r$ para $\alpha=5^{\circ}$ e airy disc . . . . . . . . . . . . . 88

6.25 Análise de erro. . . . . . . . . . . . . . . . . . . . . . . . . 89

6.26 Propagação de erro. . . . . . . . . . . . . . . . . . . . . 89

A.1 Convenção de sinal raio de curvatura. . . . . . . . . . . . . . . . . . . . 94 
Lista de Figuras 


\section{Lista de Tabelas}

2.1 Primeiros 6 polinômios de Zernike e as respectivas aberrações associadas a

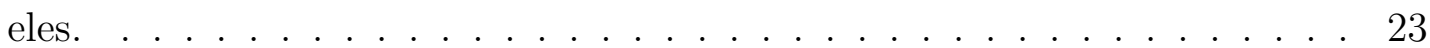

6.1 Propriedades gaussianas dos modelos:lgr $r_{u}, l g r_{a}, g u l_{u}$ e $g u l_{a} \ldots \ldots$. . . 67

6.2 Propriedades gaussianas dos modelos: lot, koo e $l b r \ldots \ldots$. . . . . . 68

6.3 Propriedades gaussianas do modelo de nav : nav $v_{0,0}, n^{2} v_{5,0}$ e nav $v_{10,0}$. . . 69

$6.4 L S A$ termos da Equação (5.40) para os modelos $l g r_{u}$ e lot . . . . . . . . . 72

6.5 LSA termos da Equação (5.40) para os modelos nav $v_{0,0}$ e $l b r$. . . . . . . . 72

6.6 Eixo astigmatismo. Em todos os casos a medida de astigmatismo foi $\phi_{A}=$

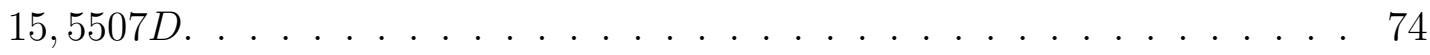

6.7 Cálculos de dioptria. Raio da pupila $R=1.70 \mathrm{~mm}$. . . . . . . . . . . 75

A.1 Lista de unidades e símbolos. . . . . . . . . . . . . . . . . . . . 94

A.2 Abreviações dos modelos esquemáticos do VEye . . . . . . . . . . . . . 95

A.3 Lista de símbolos. . . . . . . . . . . . . . . . . . . . . . . 95

B.1 Constantes da Equação (B.1) que descreve a distribuição do índice de refração na porção anterior $n_{A}$ e posterior $n_{P}$ do cristalino. . . . . . . . . . . 104 
Lista de Tabelas 


\section{Lista de Algoritmos}

5.1 Traçado de raios . . . . . . . . . . . . . . . . . . . . 46

5.2 Malha: intersecção e normal . . . . . . . . . . . . . . . . . . . 50

5.3 Cálculo propriedades gaussianas. . . . . . . . . . . . . 56

5.4 Cálculo da entrada e saída da pupila. . . . . . . . . . . . . . . . . . . 58

5.5 Simulação frente de onda: Amostragem . . . . . . . . . . . . . . . 61

5.6 Simulação frente de onda: polinômios de Zernike . . . . . . . . . . . . 62

5.7 Projeção de cones . . . . . . . . . . . . . . . . . . . 64 



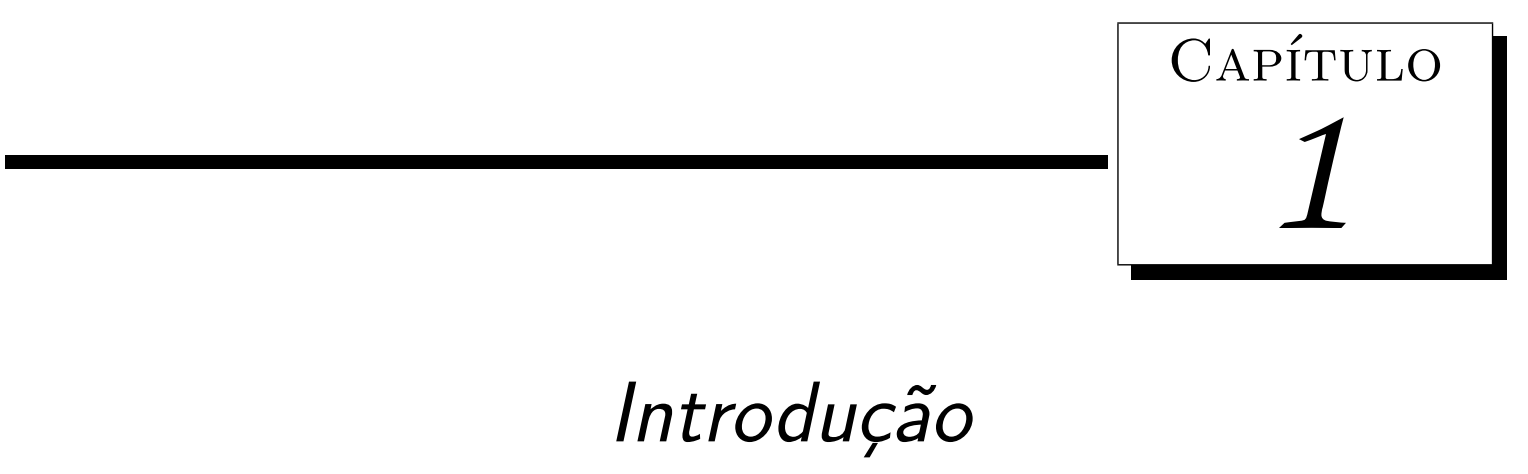

O interesse em entender os aspectos que influenciam a qualidade visual, propriedades óticas do olho humano e a relação com seus componentes fisiológicos apareceram em 1619. Uns dos grandes tratados da área foi escrito por Helmholtz (1909) (19). Desde então, uma grande variedade de técnicas e instrumentos auxilia o oftalmologista a diagnosticar seus pacientes. A modelagem computacional tem sido estudada por diferentes setores da comunidade científica. Com o aperfeiçoamento das técnicas de computação gráfica e o ganho crescente de desempenho dos computadores modernos, aumentou o interesse nesta área, principalmente na possibilidade de reproduzir as propriedades óticas do olho humano. Os resultados dessa intensa pesquisa já podem ser observados nos equipamentos oftalmológicos, como os topógrafos de córnea e os aparelhos modernos de frente de onda que sofreram uma rápida evolução nos últimos anos. Como pode ser notado na literatura: Gullstrand (1), Emsley (20), Kooijaman (8), Thibos (25), a maioria dos trabalhos descritos ainda empregam modelos puramente teóricos nas suas simulações, desperdiçando as informações adquiridas pelos equipamentos modernos de oftalmologia. Muitos dos trabalhos recentes utilizam aplicações comerciais voltadas para desenho ótico de propósito geral e não permitem um controle detalhado amarrando as mãos do pesquisador.

Neste trabalho são comuns dois termos: sistema visual humano para designar carac- 


\section{Introdução}

terísticas relacionadas ao olho e cérebro humano, e sistema ótico para designar o caráter ótico-físico do olho humano

\subsection{Objetivos e Organização}

Modelagens computacionais podem substituir e/ou auxiliar os aparelhos oftalmológicos atuais. Este projeto de mestrado explora exatamente esse aspecto. Em conjunto com membros do grupo de ótica oftalmológica do Departamento de Física da USP de São Carlos, o projeto propõe um arcabouço computacional que viabiliza a utilização de dados reais na modelagem e simulação dos fenômenos óticos e fisiológicos do sistema de visão humana. Apesar de riquíssimo e interessante o trabalho não trata especificamente a visão humana toda deixando de lado à parte de processamento visual relacionado ao córtex visual e retina do sistema visual humano. Neste trabalho maior parte da atenção é dada aos aspectos óticos e físicos do sistema visual humano.

O objetivo deste trabalho é construir um arcabouço computacional composto de técnicas matemáticas, físicas e de computação gráfica que permite simular os fenômenos óticos e fisiológicos do olho humano como acomodação e aberração. A proposta é construir modelos esquemáticos do olho humano juntamente com um algoritmo realístico de traçado de raios. Adicionar aos modelos dados in-vivo obtidos de um topógrafo de cónea e então estudar os modelos esquemáticos existende na literatura e calcular características destes modelos como: propriedades gaussianas e aberração. Este trabalho está organizado da seguinte forma:

No Capítulo (2) introduzimos alguns conceitos óticos importantes no desenvolvimento deste trabalho.

No Capítulo (3) apresentamos a anatomia do olho humano bem como os tópicos da fisiologia humana relevante neste trabalho.

O Capítulo (4) é um complemento do Capítulo (3) anterior e descreve os mecanismos internos da visão relacionada à acomodação.

No Capítulo (5) descrevemos os algoritmos e a metodologia adotada.

No Capítulo (6) realizamos algumas simulações que validam os algoritmos e metodologia adotada e depois mostramos resultados interessantes alcançados juntamente com 


\section{Introdução}

a discussão a respeito deles.

Finalmente no Capítulo (7) fazemos uma breve discussão e conclusão dos resultados alcançados e pequena análise de erros nas metodologias.

O Apêndice (A) descreve as convenções adotadas neste trabalho bem como uma lista dos principais símbolos utilizados.

O Apêndice (B) descreve os modelos esquemáticos de olho humano empregados neste trabalho.

Sugerimos que o leitor leia o Apêndice (A) se não estiver familiarizado com alguns termos relacionado às convenções adotadas em ótica fisiológica antes de prosseguir sua leitura na ordem natural dos capítulos. 
Introdução 


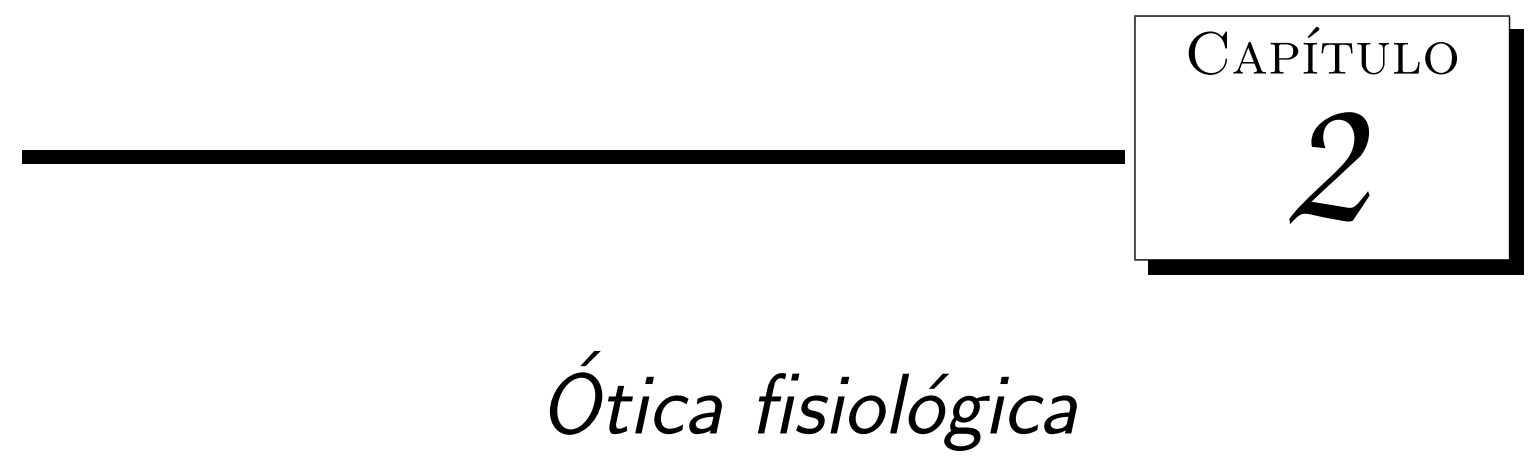

O entendimento da ótica fisiológica do olho humano é em especial, importante para projetistas de dispositivos óticos para diagnósticos oftalmológicos e para sistemas óticos visuais como telescópios.

Neste capítulo introduzimos os conceitos óticos necessários para o compreensão deste trabalho e importantes nos fenômenos fisiológicos do olho humano. Inicialmente é apresentado o comportamento de sistemas óticos do ponto de vista da ótica geométrica e em seguida o comportamento é revisto segunda a ótica ondulatória ou de Fourier.

\section{1 Ótica geométrica}

A ótica geométrica descreve o comportamento da luz quando o comprimento de onda $\lambda$ da luz envolvida é negligenciável em comparação aos componentes relevantes do sistema ótico sendo analisado. Ela é baseada em duas leis verificadas experimentalmente: a lei de reflexão e a lei de Snell enunciadas a seguir. Quando a energia luminosa concentrada em uma direção, chamado raio de luz, atinge uma interface entre dois meios de índices de refrações diferentes. Parte desta luz é refletida e parte é transmitida interface adentro. Destas duas leis são derivadas expressões que descrevem oticamente espelhos e superfícies refratoras. Porém estas duas leis podem ser deduzidas de uma expressão mais geral, 


\section{Ótica fisiológica}

chamada de princípio de Fermat ou princípio do tempo mínimo e foge ao escopo deste trabalho (ver (11)).

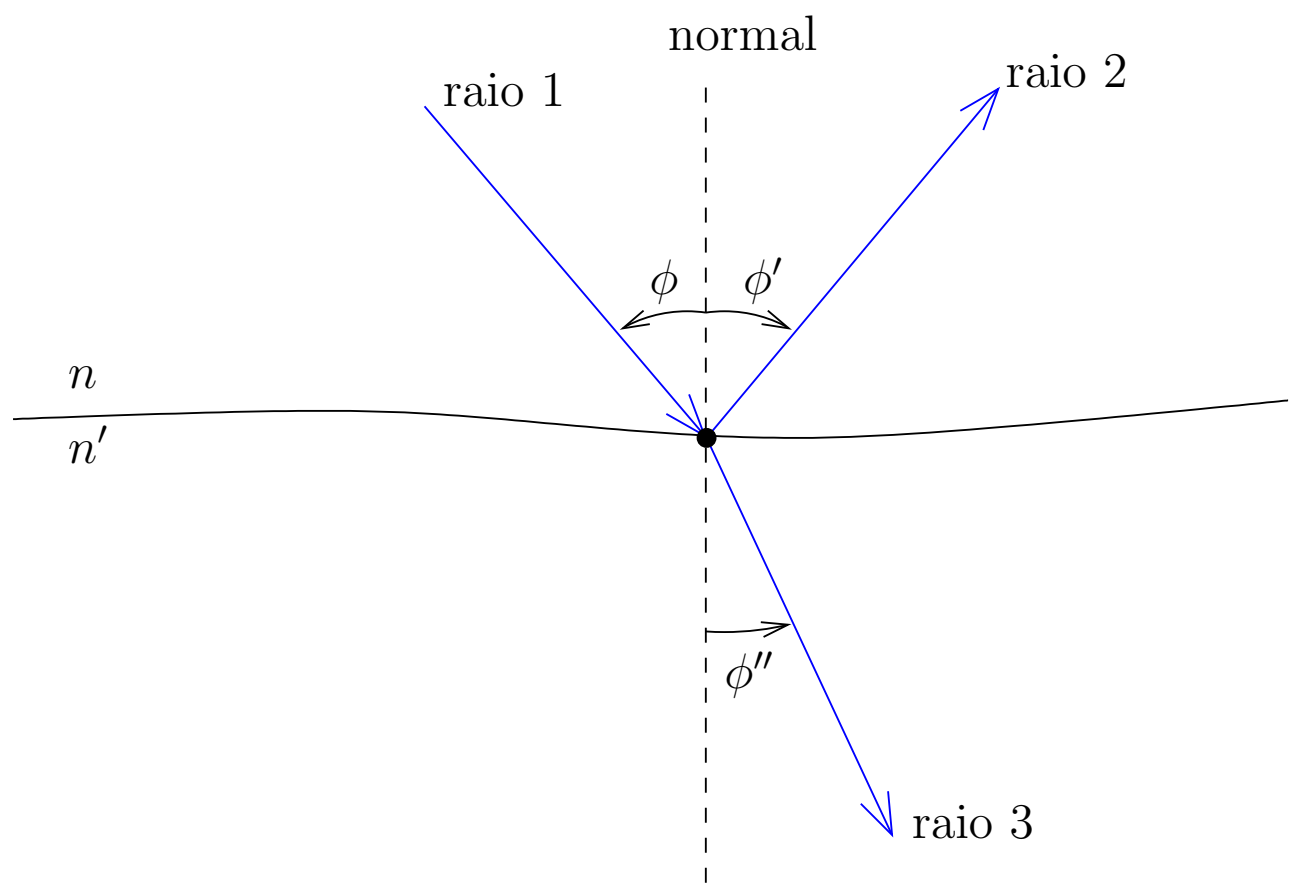

Figura 2.1: Ilustração de uma interface que separa dois meios com índices de refração $n$ e $n^{\prime}$.

Definição 1 (Plano incidência) Plano que contém o raio incidente (raio 1) e a normal à interface no ponto de incidência do raio de luz Figura (2.1).

Lei 1 Lei de Reflexão. Quando um raio de luz é refletido em uma interface que divide dois meios homogêneos e isotrópicos, o raio refletido (raio 2) permanece no plano de incidência, e o ângulo de reflexão $\phi^{\prime}$ é igual ao ângulo de incidência $\phi$ a menos de um sinal, Equação (2.1).

$$
\phi^{\prime}=-\phi
$$

Lei 2 Lei de Refração ou de Snell. Quando um raio de luz é refratado em uma interface que divide dois meios homogêneos isotrópicos com índices $n$ e $n^{\prime}$, o raio transmitido (raio 3) permanece no plano de incidência, e o seno do ângulo de refração $\operatorname{sen}\left(\phi^{\prime \prime}\right)$ é diretamente proporcional ao seno do ângulo de incidência sen( $\phi)$ conforme Equação (2.2). 


$$
n^{\prime} \operatorname{sen}\left(\phi^{\prime \prime}\right)=n \operatorname{sen}(\phi)
$$

Observe que a lei de reflexão Lei (1) é um caso especial da lei de refração Lei (2) com $n^{\prime}=-n$, e assim obtemos a Equação (2.1) novamente.

Na próxima Seção (2.1.1) tratamos a lei de Snell. A lei de reflexão não é mais vista formalmente neste trabalho.

\subsubsection{Lei de Snell}

Os raios de luz ao atravessar uma superfície refratora curvam-se alterando sua direção de propagação inicial. A relação entre a direção de propagação incidente e a direção refratada é dada pela lei de Snell. A Figura (2.2) mostra uma superfície refratora $S$ e um raio de luz propagando de cima para baixo.

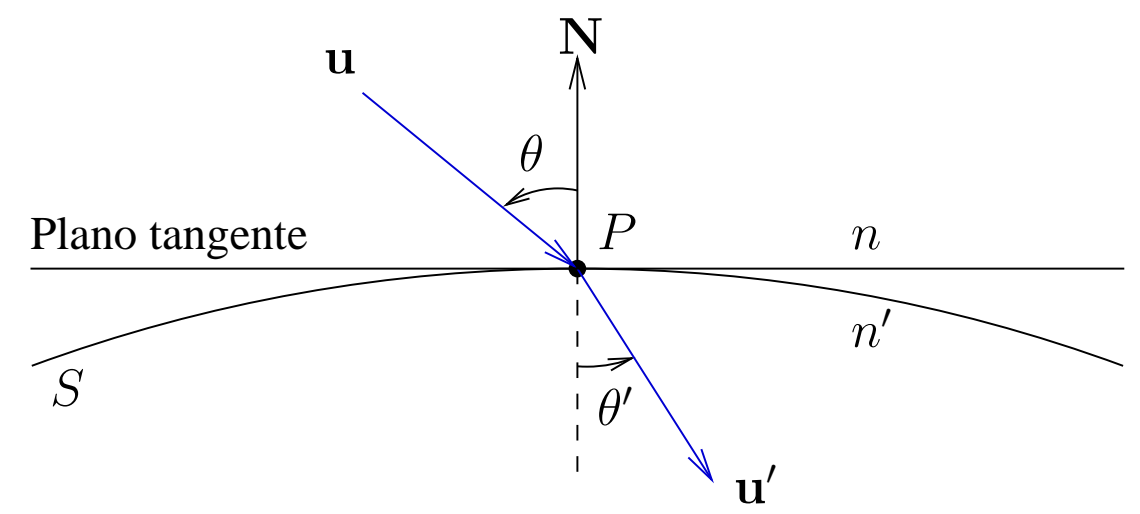

Figura 2.2: Ilustração da lei de Snell. Raio incidente dado pela direção u ,e raio refratado dado pela direção $\mathbf{u}^{\prime}$.

A formulação vetorial da lei de Snell, Equação (2.3), é computacionalmente conveniente para os propósitos deste trabalho e foi utilizado nos algoritmos do Capítulo (5).

$$
\begin{gathered}
\mathbf{u}^{\prime}=n^{\prime \prime} \mathbf{u}+\left(n^{\prime \prime} \cos (\theta)-\cos \left(\theta^{\prime}\right)\right) \mathbf{N} \\
n \operatorname{sen}(\theta)=n^{\prime} \operatorname{sen}\left(\theta^{\prime}\right)
\end{gathered}
$$

Onde $\theta$ e $\theta^{\prime}$ são os ângulos de incidência e o de refração respectivamente, $n$ e $n^{\prime}$ são 


\section{Ótica fisiológica}

os índices de refração dos meios. $P$ é a intersecção entre o raio e a superfície $S, \mathbf{N}$ é a normal em $P$ e $n^{\prime \prime}$ é a razão $\frac{n}{n^{\prime}}$ (ver Figura $(2.2)$ ).

\subsubsection{Propagação em meios inomogêneos}

A propagação da luz em meios inomogêneos, meios em que o índice de refração depende da posição $\mathbf{r}$, ou seja $n=n(\mathbf{r})$, é descrita pela equação diferencial dos raios Equação (2.5) (ver (26)). Exemplos de meios inomogêneos são o cristalino humano e a atmosfera terrestre. A Figura (2.3) ilustra um raio de luz percorrendo o $\operatorname{arco} s$ a partir de $P_{0}$. O vetor $\mathbf{u}$ é tangente à curva $s$ em $\mathbf{r}$ e indica a direção de propagação em $\mathbf{r}$.

$$
\frac{d(n \mathbf{u})}{d s}=\frac{d}{d s}\left[n \frac{d \mathbf{r}}{d s}\right]=\nabla n
$$

Onde $\nabla$ denota o operador gradiente.

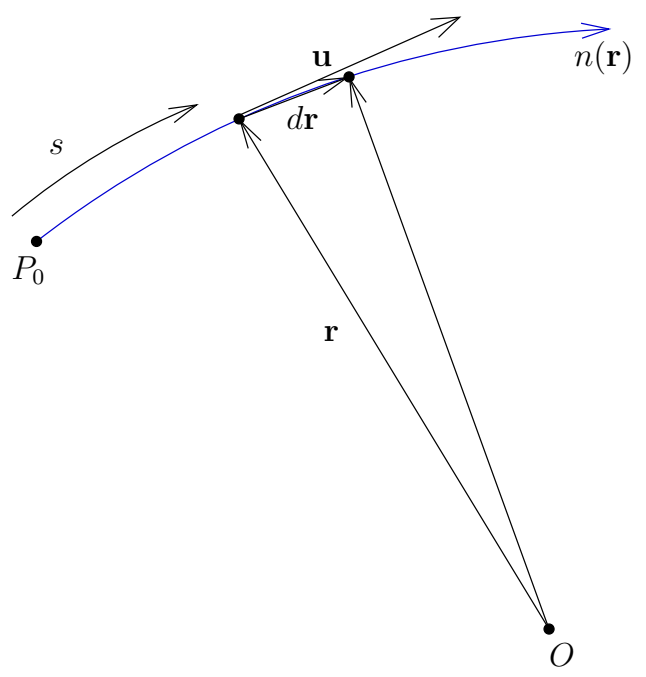

Figura 2.3: Raio de luz propagando do ponto $P_{0}$ em um meio inomogêneo percorrendo o arco $s$. O índice de refração é função da posição $n=n(\mathbf{r})$. $O$ é a origem do sistema de coordenada.

\subsubsection{Sistemas óticos}

Nesta seção discutimos a formação e a qualidade de imagens geradas por sistemas óticos. A seguir introduzimos algumas definições importantes.

Definição 2 (Frente de onda) Frente de onda ou wavefront. A familia de superfícies ortogonais aos raios de luz são chamadas frente de onda. O lugar geométrico onde cada 


\section{Ótica fisiológica}

raio encontra uma frente de onda significa que a luz gastou o mesmo tempo para ser transmitida da fonte até o ponto em questão. Ver Figura (2.4).

Definição 3 (Eixo ótico) Eixo ótico a é o eixo de simetria de um sistema ótico S. Todo o sistema é gerado por revolução em torno do eixo ótico.

Definição 4 (Sistema centrado) Um Sistema centrado é um conjunto de superfícies que têm o mesmo eixo ótico.

Definição 5 (Espaço objeto) Espaço objeto é a região do espaço onde encontra-se os objetos. Os raios nesta região ainda não atingiram nenhuma superfície de reflexão e/ou refratora do sistema ótico em estudo. Nesta região os raios de luz de um ponto objeto (exceto por ponto objeto no infinito cujo raios de luz chegam paralelos) estão divergindo e as frente de ondas estão expandindo. Ver Figura (2.4).

Definição 6 (Espaço imagem) Espaço imagem é a região do espaço que contém os raios de luz que formam a imagem após a última superfície de reflexão e/ou refratora do sistema ótico em estudo. Lugar onde as imagens são formadas. Nesta região os raios de luz provenientes de um ponto objeto que atravessaram o sistema ótico e sua frente de onda estão convergindo (exceto quando a imagem forma no infinito), Figura (2.4).

Definição 7 (Sistemas limitados por difração) Sistemas limitados por difração: Um sistema é dito como limitado por difração se uma frente de onda esférico emanada de um objeto pontual no espaço objeto é convertida em uma frente de onda perfeitamente esférica no espaço imagem e converge para o respectivo ponto imagem ideal (34).

Definição 8 (Pontos conjugados) Dois pontos: $P$ no plano objeto (fonte) e $P^{\prime}$ no plano imagem são ditos pontos conjugados se, e somente se, todos raios que deixam $P$ interceptam-se no ponto $P^{\prime}$ e quando $P$ e $P^{\prime}$ trocam de papel, todos raios que deixam o ponto $P^{\prime}$ interceptam-se no ponto $P$. Dizemos que $P^{\prime}$ é a imagem de P, Figura (2.4).

Definição 9 (Entrada da pupila) É a imagem E formada da abertura (stop) física de $S$ no espaço objeto, ver Figura (2.4). 


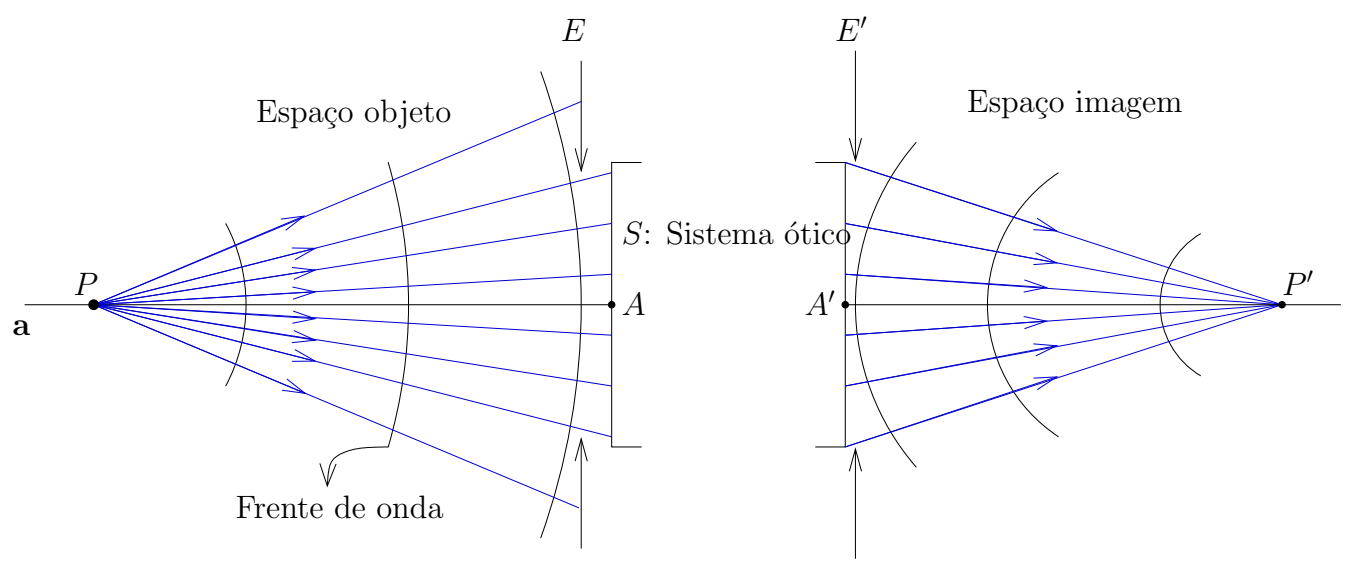

Figura 2.4: Ilustração de sistema ótico. O ponto $P^{\prime}$ é a imagem do ponto $P$.

Definição 10 (Saída da pupila) É a imagem $E^{\prime}$ formada da abertura (stop) física de S no espaço imagem. Figura (2.4).

Definição 11 (Caminho ótico) Caminho ótico: Seja $M$ um meio ótico isotrópico com indice de refração $n(\mathbf{r})$ dependente da posição. Seja $\mathbf{r}$ o vetor posição de um ponto qualquer em $M$. O caminho ótico opl de um raio de luz que propaga ao longo da curva $\Gamma \subset \mathbb{R}^{3}$ do ponto $p_{1}$ ao $p_{2}$ é dado pela integral de linha abaixo:

$$
o p l=\int_{\Gamma} n(\mathbf{r}) d s=\int_{p_{1}}^{p_{2}} n(\mathbf{r}) d s
$$

\subsubsection{Aproximação paraxial}

A maioria dos sistemas óticos centrados são projetados para trabalhar em uma pequena região próxima ao eixo ótico com pequenas aberturas de passagem de luz (stop). Nesta situação as aproximações abaixo, Equação (2.7) são empregadas pelos construtores de instrumentos óticos e são conhecidas como aproximação paraxial ou aproximação gaussiana. Neste trabalho utilizamos ambos os termos paraxial e gaussiana. Normalmente nos referimos à traçado de raios paraxiais e a propriedades gaussianas.

$$
\begin{aligned}
& \operatorname{sen}(\theta)=\theta-\frac{\theta^{3}}{3 !}+\frac{\theta^{5}}{5 !}-\ldots \simeq \theta \\
& \cos (\theta)=1-\frac{\theta^{2}}{2 !}+\frac{\theta^{4}}{4 !}-\ldots \simeq 1 \\
& \tan (\theta)=\theta+\frac{\theta^{3}}{3 !}+\frac{\theta^{5}}{5 !}+\ldots \simeq \theta
\end{aligned}
$$


Ótica fisiológica

Para $\|\theta\| \ll 1$.

Nas próximas seções discutimos o comportamento gaussiano de sistema óticos.

\subsubsection{Pontos cardinais}

Todo sistema ótico centrado que possui dioptria equivalente $D$ possui seis pontos cardinais no eixo ótico:

- Pontos focais $F$ e $F^{\prime}$. A imagem do ponto $F^{\prime}$ no espaço imagem é formada no infinito no espaço objeto. De maneira análoga a imagem do ponto $F$ no espaço objeto é formada no infinito no espaço imagem.

- Pontos principais $H$ e $H^{\prime}$. A imagem de um objeto em $H$ é formada em $H^{\prime}$ ereta e de mesmo tamanho.

- Pontos nodais $N$ e $N^{\prime}$. São pontos conjugados. Raio de luz que formam o ângulo $\alpha$ com o eixo ótico do sistema e que sua prolongação passa por $N$ emerge no espaço imagem com o mesmo ângulo $\alpha$ e seu prolongamento passa por $N^{\prime}$.

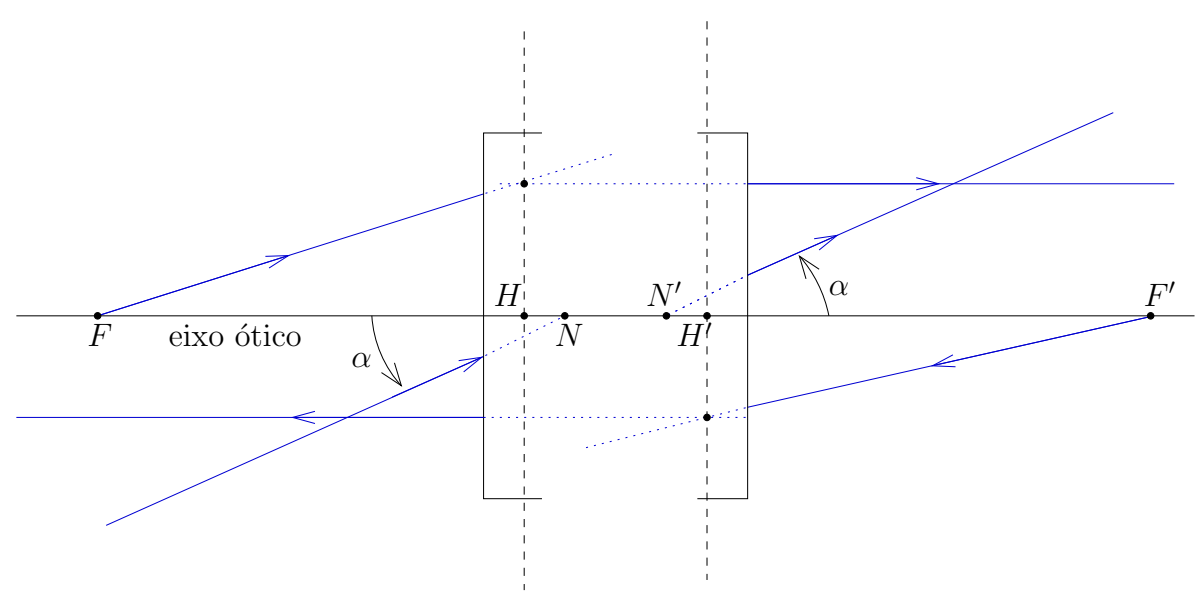

Figura 2.5: Ilustração dos pontos cardinais de um sistema ótico centrado.

\subsubsection{Proximidade e Dioptria}

Nesta seção apresentamos algumas equações que descrevem o comportamento de interface ótica na região paraxial. 


\section{Ótica fisiológica}

Seja a superfície esférica $S$ de raio $r$. Seja o objeto $O$ de tamanho $y$ situado no ponto $P$ à distância $x=V P$ e a imagem $I$ de tamanho $y^{\prime}$ situada no ponto $P^{\prime}$ à distância $x^{\prime}=V P^{\prime}$ ambos no eixo ótico. Onde $V$ é o vértice de $S$. $n$ e $n^{\prime}$ são os índices de refração no espaço objeto e no espaço imagem respectivamente. A Equação (2.8) expressa o fato que $P^{\prime}$ é a imagem de $P$. Todos os raios do cone de luz que deixam o ponto $P$ passam por $P^{\prime}$

$$
\frac{n^{\prime}}{x^{\prime}}=\frac{n}{x}+\frac{n^{\prime}-n}{r}
$$

O aumento lateral é definido como:

$$
M=\frac{y^{\prime}}{y} \equiv \frac{x^{\prime}}{n^{\prime}} \frac{n}{x}
$$

A Equação (6.7) é chamada de fórmula do construtor de lentes.

$$
\frac{n^{\prime}}{f^{\prime}}=-\frac{n}{f} \equiv \frac{n^{\prime}-n}{r}
$$

O conceito proximidade, Equação (2.11), torna as equações (2.8), (2.9) e (6.7) serem escritas mais facilmente.

$$
X=\frac{n}{x} \quad X^{\prime}=\frac{n^{\prime}}{x^{\prime}}
$$

Utilizando a equação Equação (2.11), a dioptria e o aumento lateral de $S$ e a Equação (2.8) tornam-se:

$$
\begin{gathered}
D=\frac{-n}{f}=\frac{n^{\prime}}{f^{\prime}} \equiv \frac{n^{\prime}-n}{r} \\
M=\frac{y^{\prime}}{y} \equiv \frac{X}{X+D} \\
X^{\prime}=X+D
\end{gathered}
$$

Até aqui olhamos para sistemas simples. Mais muitos sistemas óticos são compostos por mais de uma superfície refratora. Ao combinar dois sistemas óticos, $D_{1}$ a dioptria do sistema ótico $S_{1}$ com índices de refração $n$ e $n^{\prime \prime}$, sendo seus pontos principais $H_{1}$ e $H_{1}^{\prime}$; e $D_{2}$ a do sistema ótico $S_{2}$ com índices de refração $n^{\prime \prime}$ e $n^{\prime}$, sendo seus pontos principais $H_{2}$ 


\section{Ótica fisiológica}

e $H_{2}^{\prime}$. A dioptria equivalente $D_{e q}$ do sistema resultante da combinação de $S_{1}$ e $S_{2}$ é dado pela Equação (2.13), ver Figura (2.6):

$$
D_{e q}=D_{1}+D_{2}-\delta D_{1} D_{2}
$$

Onde $\delta$ é a distancia reduzida entre as lentes e é dada por $\delta=\frac{H_{1}^{\prime} H_{2}}{n^{\prime \prime}}$.

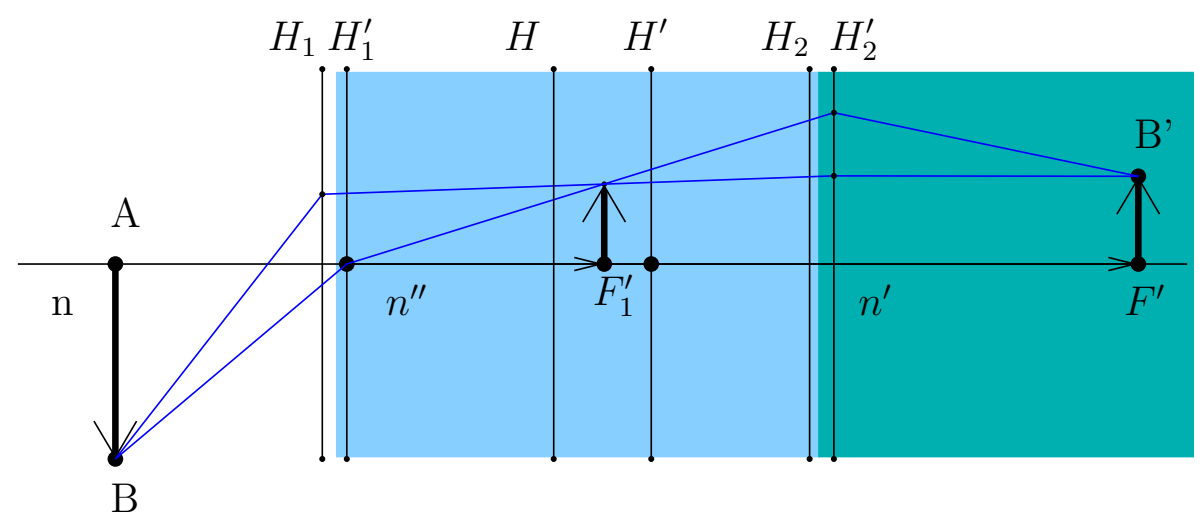

Figura 2.6: Combinação de dois sistemas centrados $S_{1}$ e $S_{2}$. Também são mostrado os pontos principais de $S_{1}, S_{2}$ e do sistema equivalente $S_{e q}$.

Os pontos principais são dados pela Equação (2.14) e as distâncias focais são dadas pela Equação (2.15).

$$
\begin{gathered}
\frac{H_{2}^{\prime} H_{e q}^{\prime}}{n^{\prime \prime}}=\delta \frac{D_{1}}{D_{e q}} \\
\frac{H_{1} H_{e q}}{n^{\prime \prime}}=\delta \frac{D_{2}}{D_{e q}} \\
D_{e q}=\frac{-n}{f} \equiv \frac{n^{\prime}}{f^{\prime}}
\end{gathered}
$$

\subsubsection{Aberrações}

Nesta seção introduzimos a teoria de aberração conhecida como aberração de Seidel de terceira ordem, ver (32). Apesar de utilizarmos uma teoria mais moderna, polinômios de Zernike Seção (2.2.3), a teoria de Seidel ainda é muito utilizada e consiste uma maneira simples e elegante de introduzir assuntos relacionados ao estudo de aberrações. Preferimos por trabalhar com o tratamento dado por Zernike pois esta teoria é capaz de representar termos de mais alta ordens presentes no olho humano. 


\section{Ótica fisiológica}

As equações paraxiais vistas na Seção (2.1.4) são aproximadamente corretas. Na obtenção daquelas equações foi necessário assumir traçados de raios paraxiais, cujo traçado é apropriado para ângulos suficientemente pequenos e para raios próximos ao eixo ótico.Aberrações podem ser entendidas como um desvio de comportamento paraxial do sistema.

A Figura (2.7) ilustra duas frentes de onda emergindo de um sistema ótico. A frente de onda $W_{1}$ é uma frente de onda esférica representando a aproximação paraxial que produz uma imagem na posição $I$. A frente de onda $W_{2}$ é a frente de onda asférica obtida pelo traçado correto dos raios. Os raios de pontos adjacentes $A$ e $B$ perpendiculares as respectivas frentes de onda interceptam o plano imagem paraxial em posições diferentes. Note que os raios traçados que passam no ponto $O$ das duas frentes de onda alcançam o mesmo ponto $I$ no plano da imagem paraxial, sendo raios sem aberração. Os raios com aberração passam pelo ponto fora do eixo ótico apresentam uma diferença de caminho ótico. Podemos definir aberração abaixo como:

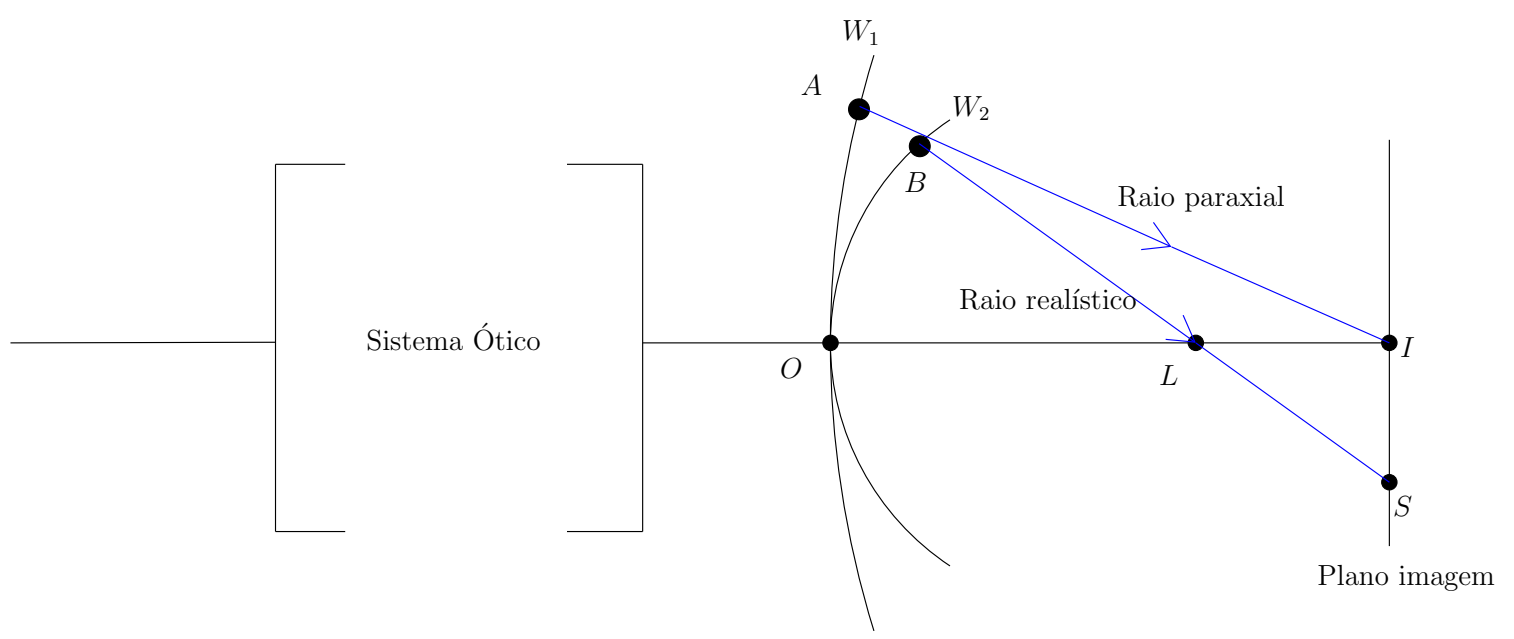

Figura 2.7: Ilustração de duas frente de onda: $W_{1}$ e $W_{2}$. A primeira delas $W_{1}$ representa uma frente de onda esférica formada pelo sistema ótico utilizando a aproximação paraxial. A segunda, $W_{2}$ é a frente de onda gerada pelo traçado exato dos raios de luz que emergem do sistema ótico.

Definição 12 (Raio pupilar) (chief ray ) Raio central do feixe de luz que passa pelo centro da pupila, ver (16).

Definição 13 (Aberração) A aberração dada num ponto $Q$ de um sistema ótico é a diferença de caminho ótico do raio $l=\left[P Q P^{\prime}\right]$ que passa por $Q$ e o caminho ótico do raio principal $l^{\prime}=\left[P B P^{\prime}\right]$, Figura (2.8) . 


\section{Ótica fisiológica}

Seja o traçado da Figura (2.8). A superfície refratora é uma superfície esférica de centro em $C$ e raio $R$. A diferença do caminho ótico entre o raio pupilar e o raio marginal é dada pela Equação (2.16).

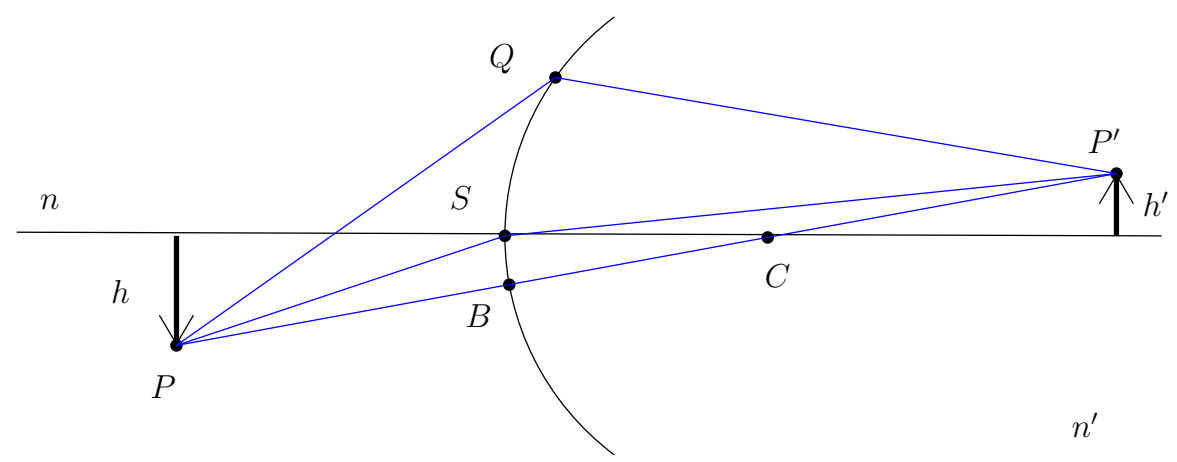

(a)

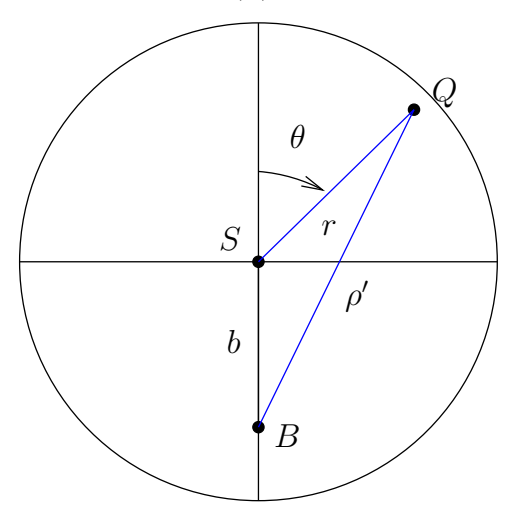

(b)

Figura 2.8: Traçado ótico real em uma superfície esférica que divide dois meios com índices de refração $n$ e $n^{\prime}$. O ponto $P$ está fora do eixo ótico: Em a) vista lateral e em b) vista frontal em detalhe.

$$
a^{\prime}(Q)=\left[P Q P^{\prime}\right]-\left[P B P^{\prime}\right]=c \rho^{\prime 4}
$$

Onde $B Q=\rho^{\prime}$ e $c$ é uma constante de proporcionalidade. Fazendo o mesmo raciocínio anterior, mas agora para o ponto $O$ encontramos:

$$
a^{\prime}(O)=\left[P O P^{\prime}\right]-\left[P B P^{\prime}\right]=c b^{4}
$$

Onde $O B=b$ e $c$ é a mesma constante de proporcionalidade. E escrevemos a aberração no ponto $Q$ como: 


\section{Ótica fisiológica}

$$
a(Q)=a^{\prime}(Q)-a^{\prime}(O)=c \rho^{4}-c b^{4}=c\left(\rho^{4}-b^{4}\right)
$$

Aplicando a lei dos co-senos para a geometria da Figura (2.8(b)), temos.

$$
\rho^{\prime 2}=r^{2}+b^{2}+2 r b \cos (\theta)
$$

Introduzindo a Equação (2.19) na Equação (2.18).

$$
a(Q)=c\left[r^{4}+4 r^{2} b^{2} \cos ^{2}(\theta)+2 r^{2} b^{2}+4 r^{3} b \cos (\theta)+4 r b^{3} \cos (\theta)\right]
$$

Na Figura (2.8(a)), por semelhança de triângulos, vemos que $O B=b$ é proporcional à altura $h^{\prime}$ da imagem paraxial $P^{\prime}$ sobre o eixo ótico. Voltando na equação (2.20):

$$
a(Q)={ }_{0} C_{40} r^{4}+{ }_{1} C_{31} h^{\prime} r^{3} \cos (\theta)+{ }_{2} C_{22} h^{\prime 2} r^{2} \cos ^{2}(\theta)+{ }_{2} C_{20} h^{\prime 2} r^{2}+{ }_{3} C_{11} h^{\prime 3} r \cos (\theta)
$$

Os termos da Equação (2.21) são classificados abaixo e são chamados de aberração de Seidel.

- ${ }_{0} C_{40} r^{4}$ : esférica. A aberração esférica é o único termo na teoria de aberração de terceira ordem que não depende de $h^{\prime}$. Por este motivo ela existe mesmo para objetos pontuais no eixo ótico. A Figura (2.9) ilustrar tal situação.

- ${ }_{1} C_{31} h^{\prime} r^{3} \cos (\theta)$ : coma. Aberração assimétrica presente para objetos à distância $h^{\prime}$ do eixo ótico.

- ${ }_{2} C_{22} h^{\prime 2} r^{2} \cos ^{2}(\theta)$ e ${ }_{2} C_{20} h^{\prime 2} r^{2}$ : astigmatismo e curvatura de campo. As duas aberrações são quase idênticas. O astigmatismo é uma assimetria. Ocorre quando uma superfície apresenta curvaturas desiguais nos seus eixos principais. Então em uma seção a superfície não pode focar um mesmo objeto pontual $P$ em suas seções transversais sagital ao mesmo tempo formando uma elipse difusa no anteparo. Alterando-se a posição do anteparo a elipse difusa muda seus eixos e um 


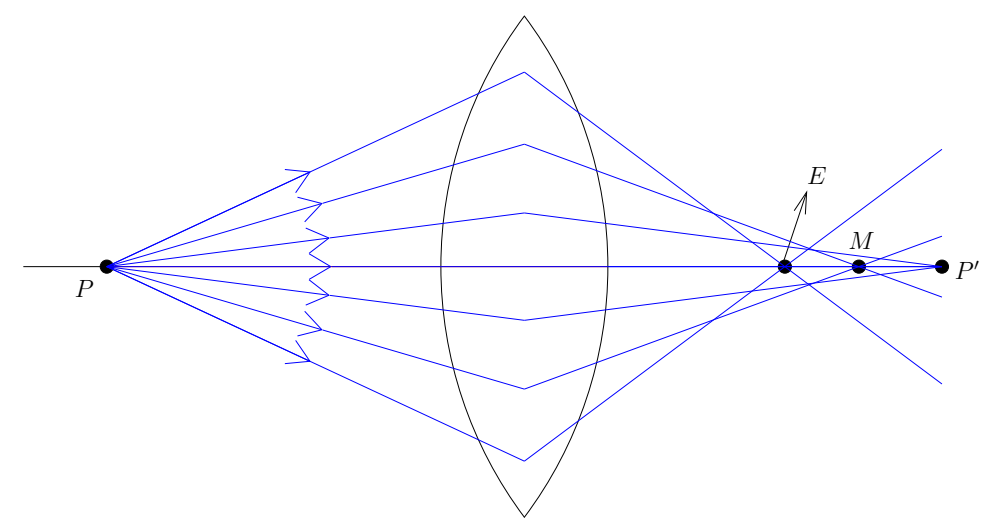

(a)

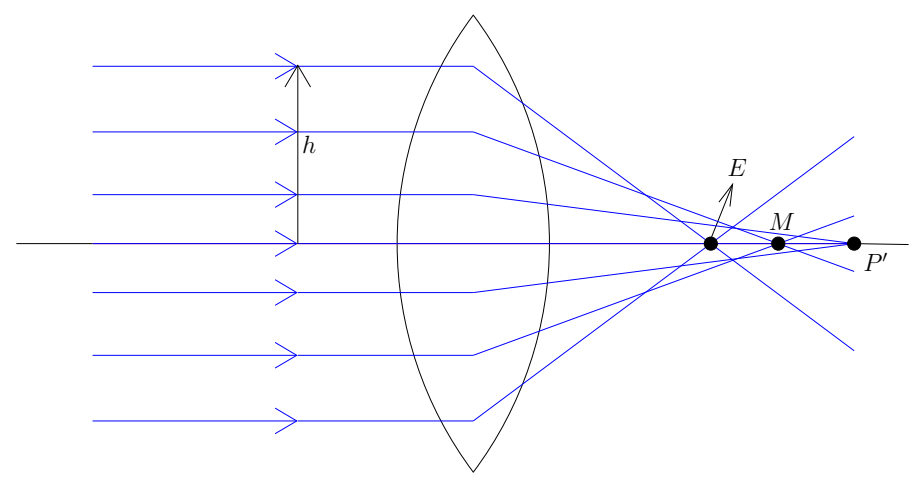

(b)

Figura 2.9: Aberração esférica: a) objeto pontual no eixo ótico produzindo imagens em pontos diferentes: $E, M$ e $P^{\prime}$ b) Objeto pontual no infinito. A imagem resultante depende da abertura $h$ da lente. No ponto $M$ obtemos o menor círculo de difusão e consequentemente a melhor imagem.

círculo difuso aparece no anteparo. Este círculo é conhecido como círculo de menor confusão.

- ${ }_{3} C_{11} h^{\prime 3} r \cos (\theta)$ : distorção. A última das aberrações monocromáticas de Seidel presente mesmo quando todas as outras foram eliminadas. Ocorre que o aumento lateral não permanece constante ao afastar-se do eixo ótico e assim deforma a imagem formada. A Figura (2.10(a)) mostra uma malha quadriculada que serve como objeto. Se o aumento lateral cresce com a distância do eixo ótico o resultado é a imagem da Figura (2.10(b)), caso contrário, a imagem é a Figura (2.10(c)).

A última aberração, mais não menos importante é chamada de aberração cromática. O índice de refração de um material é função do comprimento de onda $\lambda$ da luz incidente. O índice de refração é dado por: $n(\lambda)=\frac{c}{\lambda \nu}$, onde $c$ é a velocidade da luz e $\nu$ é a freqüência 


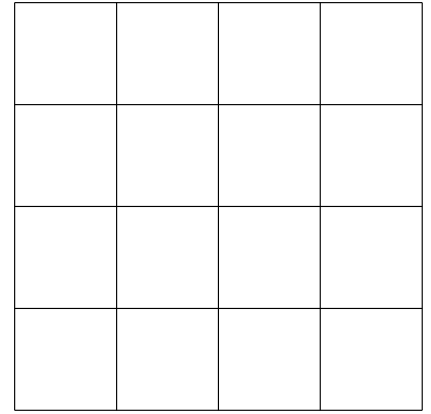

(a)

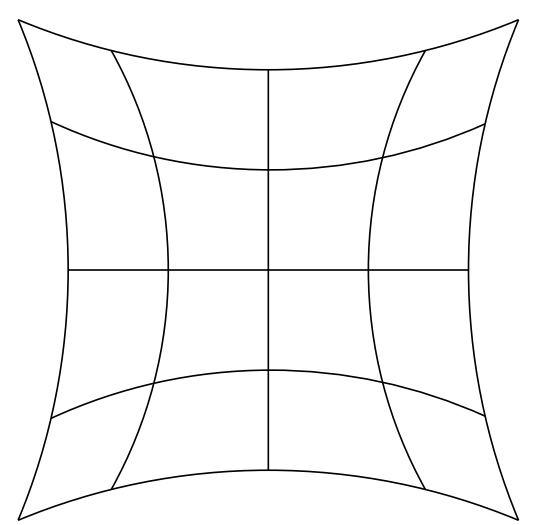

(b)

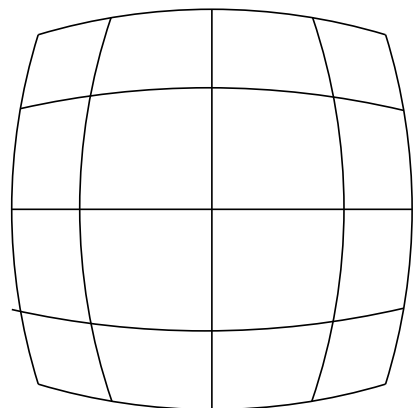

(c)

Figura 2.10: Aberração distorção: a) grade objeto, b) distorção gerada quando o aumento lateral cresce com a distância ao eixo ótico e c) quando diminui.

que a luz propaga no meio. O efeito final, é que cada cor presente em um feixe de luz, por exemplo violeta $(\lambda=380 \mathrm{~nm})$, dobra de maneira diferente na superfície refratora. Motivo pelo qual as cores separam-se ao passar luz branca em um prisma. A situação toda é ilustrada pela Figura (2.11).

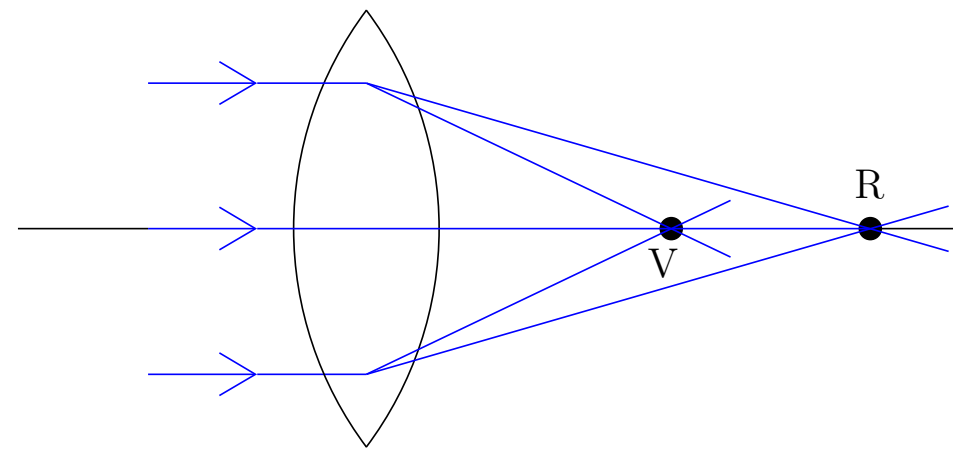

Figura 2.11: Raio de luz incidente formado pelas cores vermelha $R$ e violeta $V$. Devido à diferença de cor o sistema ótico apresenta dois focos diferentes, um para cada cor.

\section{2 Ótica de Fourier}

A ótica de Fourier descreve o comportamento ondulatório de sistemas. Nesta seção introduzimos alguns conceitos importantes do comportamento ondulatório destes sistemas óticos. Aqui consideramos somente a análise de Fourier para luz monocromática e coerente e sistema ditos como isoplanáticos, ver (34).

O comportamento ondulatório da luz é representado matematicamente pela grandeza 
Ótica fisiológica

disturbância $U(x, y)$ ou campo luminoso. A imagem formada pelo sistema ótico na posição $(x, y)$ é dada por:

$$
I(x, y)=U(x, y) U^{*}(x, y)
$$

Onde o símbolo * denota complexo conjugado.

\subsubsection{Sistemas óticos como sistema linear}

Os componentes óticos da visão humana podem ser entendidos como um sistema linear onde o campo luminoso na entrada da pupila e a imagem formada na retina atuam como entrada (input) e saída (output) deste sistema, respectivamente. Em tal sistema podemos utilizar a ótica de Fourier e a teoria de sistemas lineares (34) para descrever o sistema visual humano. O sistema é encarado como uma "caixa preta" que responde linearmente aos estímulos oriundos do espaço objeto. Neste sistemas a função de pupila Equação (2.24), descreve o comportamento ótico do sistema todo. A resposta do sistema ao campo luminoso $U(x, y)$ é dado por:

$$
U^{\prime}\left(x^{\prime}, y^{\prime}\right)=\iint h\left(x^{\prime}, y^{\prime} ; x, y\right) U(x, y) \mathrm{d} x \mathrm{~d} y
$$

Onde $h\left(x^{\prime}, y^{\prime} ; x, y\right)$ é resposta do sistema na posição $\left(x^{\prime}, y^{\prime}\right)$ devido a um objeto pontual na posição $(x, y)$ e é conhecido com resposta impulso do sistema Equação (2.25) e $h\left(x^{\prime}, y^{\prime} ; x, y\right)=h\left(x^{\prime}-x, y^{\prime}-y\right)$.

$$
\begin{gathered}
A(x, y)= \begin{cases}1,0 & \text { se } x^{2}+y^{2} \leq R \\
0,0 & \text { caso contrário }\end{cases} \\
h\left(x^{\prime}, y^{\prime}\right)=\mathfrak{F}\{A(x, y)\}
\end{gathered}
$$

Onde $\mathfrak{F}$ denota transformada de Fourier.

\subsubsection{Teoria ondulatória de aberração}

Na Seção (2.1.5) estudamos os efeitos das aberrações do ponto vista da ótica geométrica. Este tratamento é identificado pelo "borrão" formado no plano imagem pelas intersecções 


\section{Ótica fisiológica}

dos traçados de raios geométricos.

Devido ao efeito de difração sistemas óticos não formam imagens perfeitas e a presença de aberração atua neste padrão prejudicando ainda mais a formação da imagem e limitando o sistema em freqüência (11). A Figura (2.12) mostra uma frente de onda que deixa o sistema ótico $S$ e emerge no espaço objeto deste sistema. Novamente a diferença de caminho ótico $\left[B^{\prime} B^{\prime \prime}\right]$ é utilizada para calcular a função aberração de onda $W(x, y)$.

$$
W(x, y)=\left[B^{\prime}(x, y) B^{\prime \prime}(x, y)\right]
$$

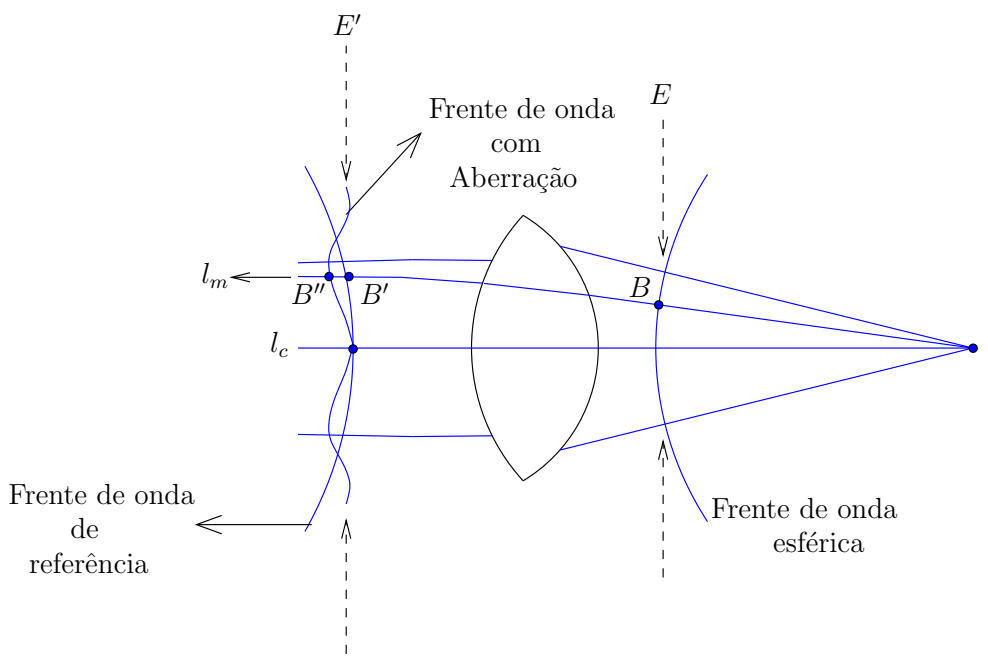

Figura 2.12: Frente de onda: Aberrações são computadas através da diferença de caminho ótico $\left[B^{\prime} B^{\prime \prime}\right]$ entre a frente de onda de referência e frente de onda real. $l_{m}$ é o raio marginal aberrático e $l_{c}$ é o raio pupilar. $E$ e $E^{\prime}$ são a entrada e saída da pupila artificiais respectivamente.

De acordo com a Seção (2.2.1) a imagem do sistema é gerada conhecendo a função de pupila do sistema. A presença de aberração modifica a função de pupila introduzindo uma mudança de fase. A Equação (2.27) mostra este efeito e é denominada função de pupila generalizada.

$$
P(x, y)=A(x, y) \exp \left(-i \frac{2 \pi}{\lambda} W(x, y)\right)
$$

Onde $\lambda$ é o comprimento de onda da luz e $A(x, y)$ é dado pela Equação $(2.24)$. 


\subsubsection{Polinômios de Zernike}

Os polinômios de Zernike (10) são um conjunto de polinômios ortonormais no círculo de raio unitário e provêm uma maneira conveniente de expressar as aberrações de sistemas óticos. Os polinômios são definidos em sua forma polar, onde a coordenada radial $r$ está no intervalo $[0,1]$ e $\theta$ a coordenada azimutal entre $[0,2 \pi]$. Cada polinômio é constituído de um fator de normalização $N_{n}^{m}$, uma função polinomial radial $R_{n}^{|m|}$ e uma componente angular (azimutal), onde o índice $n$ é a maior potência da função polinomial radial e $m$ é a freqüência da componente angular. Os polinômio são definidos abaixo:

$$
\begin{gathered}
Z_{n}^{m}= \begin{cases}N_{n}^{m} R_{n}^{|m|}(r) \cos (m \theta) & m \geq 0 \\
-N_{n}^{m} R_{n}^{|m|}(r) \operatorname{sen}(m \theta) & m<0\end{cases} \\
R_{n}^{|m|}(r)=\sum_{s=0}^{(n-|m|) / 2} \frac{(-1)^{s}(n-s) !}{s ![(n+|m|) / 2-s] ![(n-|m|) / 2] !} r^{n-2 s} \\
N_{n}^{m}=\sqrt{\frac{2(n+1)}{1+\delta_{m 0}}}
\end{gathered}
$$

Onde $\delta_{m 0}$ é uma delta de Kronecker. Evidentemente $n$ é inteiro positivo ou zero e para um $n$ dado temos as relações: $m \neq n$ e $n-|m|=$ par.

Para caracterizar as aberrações indexamos os polinômios de Zernike com uma nomenclatura descrita por somente um índice $j$ dado pela Equação (2.31). Por exemplo, com a indexação utilizada o termo $Z_{12}$ está relacionado com a aberração esférica. Na literatura mais de um esquema de indexação é encontrado. Adotamos o esquema empregado em (13) o qual é encontrado com maior freqüência.

$$
j=\frac{n(n+2)+m}{2}
$$

E a volta temos:

$$
n=\operatorname{roundup}\left(\frac{-3+\sqrt{9+8 j}}{2}\right)
$$


Ótica fisiológica

$$
m=2 j-n(n+2)
$$

Onde roundup é a função de arredondamento superior ${ }^{1}$.

As relações acima: (2.31),(2.32) e (2.33) são muito úteis porque sugerem ordenação lógica não ambígua dos polinômios e permite-nos escrever a relação de ortogonalidade:

$$
\int \mathrm{d}^{2} r \operatorname{circ}(r) Z_{j} Z_{k}=d_{j k}
$$

Onde

$$
\operatorname{circ}(r)= \begin{cases}1 / \pi & r \leq 1 \\ 0 & r>0\end{cases}
$$

Devido às propriedades de ortonormalidade dos polinômios de Zernike, expandimos a frente de onda sobre a abertura da pupila, ver (23), em polinômios de Zernike . Seja $W(r, \theta)$ uma função de aberração de onda de um sistema ótico onde abertura da pupila seja $R$ como a da Figura (2.12), temos:

$$
W(R \rho, \theta)=\sum_{j} c_{j} Z_{j}(\rho, \theta)
$$

Onde $\rho=r / R$ e os termos $c_{j}$ são dados por:

$$
c_{j}=\left(1 / R^{2}\right) \int d^{2} r \operatorname{circ}(r / R) W(r, \theta) Z_{j}(r / R, \theta)
$$

A Tabela (2.1) mostra os 6 primeiros polinômios de Zernike ordenados por $j$ e as respectivas aberrações associadas a eles. Os 3 primeiros termos são descartados pois não têm interesse físico e oftalmológico.

\subsubsection{Função de espalhamento de ponto e função de tranferência de modulação}

A função de espalhamento de ponto, do inglês point-spread-function ( $P S F)$, é a resposta imagem do sistema ótico a um objeto pontual e está relacionada com a resposta

\footnotetext{
${ }^{1} \operatorname{roundup}(2,01)=3$
} 


\section{Ótica fisiológica}

Tabela 2.1: Primeiros 6 polinômios de Zernike e as respectivas aberrações associadas a eles.

\begin{tabular}{ccccc}
\hline$Z_{j}$ & $Z_{n}^{m}$ & polar & cartesiana & descrição \\
\hline$Z_{0}$ & $Z_{0}^{0}$ & 1 & 1 & Pistão \\
$Z_{1}$ & $Z_{1}^{-1}$ & $2 \rho \operatorname{sen} \theta$ & $2 x$ & Inclinação $x$ \\
$Z_{2}$ & $Z_{1}^{1}$ & $2 \rho \cos \theta$ & $2 y$ & Inclinação $y$ \\
$Z_{3}$ & $Z_{2}^{-2}$ & $\sqrt{6} \rho^{2} \operatorname{sen} 2 \theta$ & $2 \sqrt{6} x y$ & Astigmatismo: $45^{\circ}$ \\
$Z_{4}$ & $Z_{2}^{0}$ & $\sqrt{3}\left(\rho^{2}-1\right)$ & $\sqrt{3}\left(-1+2 y^{2}+2 x^{2}\right)$ & Defocus \\
$Z_{5}$ & $Z_{2}^{2}$ & $\sqrt{6} \rho^{2} \cos 2 \theta$ & $\sqrt{6}\left(y^{2}-x^{2}\right)$ & Astigmatismo: $0^{\circ}$ ou $180^{\circ}$ \\
\hline
\end{tabular}

impulso do sistema através da Equação (2.37). Em um sistema limitado por difração, a $P S F$ do sistema é simplesmente o padrão de difração de Fraunhofer (34).

$$
P S F\left(x^{\prime}, y^{\prime}\right)=h\left(x^{\prime}, y^{\prime}\right) h^{*}\left(x^{\prime}, y^{\prime}\right)
$$

Em muitas aplicações é coveniente expressar a $P S F$ em termos dos ângulos visuais $\theta_{x}$ e $z$ thet $a_{y}$. Para ângulos pequenos temos:

$$
\begin{gathered}
P S F\left(\theta_{x}, \theta_{y}\right)=\lambda^{2}\left\|\mathfrak{F}\left\{A(\tilde{x} \lambda, \tilde{y} \lambda) \exp \left[-i \frac{2 \pi}{\lambda} W(\tilde{x}, \tilde{y})\right]\right\}\right\|^{2} \\
\tilde{x}=\frac{x}{\lambda} \quad \tilde{y}=\frac{y}{\lambda}
\end{gathered}
$$

Onde $R$ é o raio da saída da pupila, $x$ e $y$ são coordenadas cartesianas da pupila, $W(\tilde{x}, \tilde{y})$ é a função de aberração de onda dado pela Equação (5.44) e $\lambda$ é o comprimento de onda da luz.

A imagem do sistema ótico é gerada através do teorema da convolução, Equação (2.23) ver (34).

A função transferência ótica (optical transfer function OTF) é computada como sendo a transformada de Fourier da $P S F$ e a função transferência de modulação (modulation transfer function $M T F$ ) seu módulo ao quadrado e correspondem à resposta em freqüência do sistema.

$$
O T F\left(s_{x}, s_{y}\right)=\mathfrak{F}\left\{P S F\left(x^{\prime}, y^{\prime}\right)\right\}
$$


Ótica fisiológica

$$
\operatorname{MTF}\left(s_{x}, s_{y}\right)=\left\|O T F\left(s_{x}, s_{y}\right)\right\|^{2}
$$

Onde $s_{x}$ e $s_{y}$ são as freqüências espaciais nas respectivas direções em ciclos/graus. A seguir apresentamos algumas propriedades geral da $M T F$.

- $\operatorname{MTF}(0,0)=1,0$

- $\operatorname{MTF}\left(-s_{x},-s_{y}\right)=\operatorname{MTF}^{*}\left(s_{x}, s_{y}\right)$

- $\left|\operatorname{MTF}\left(s_{x}, s_{y}\right)\right| \leq|\operatorname{MTF}(0,0)| \equiv 1,0$

\subsection{Formação de imagens em sistemas óticos}

Em um sistema ótico ideal todo o raio de luz proveniente de um ponto no objeto, tem seu respectivo ponto conjugado na imagem. Na prática sistemas assim são difíceis de serem construídos. No entanto um sistema real, não-ideal, não forma uma imagem bem definida, a qualidade da imagem é afetada por diversos fatores apresentados a seguir.

Sejam $P$ um objeto pontual e $P^{\prime}$ sua respectiva imagem paraxial, temos.

- Espalhamento da luz. Alguns raios de luz que deixam $P$ não alcançam o seu respectivo ponto $P^{\prime}$ devido a reflexões nas superfícies refratoras, a reflexão difusa em superfícies de reflexão e o espalhamento causado por meios transparentes inomogêneos ocasiona a perda de raios de luz diminuindo o brilho da imagem.

- Aberrações. Alguns raios de luz que por terem sido espalhados passam pelo ponto $P^{\prime}$ proveniente de outros pontos não-conjugados à $P^{\prime}$. Quando um sistema ótico não consegue produzir uma relação biunívoca entre todo ponto no objeto e seu respectivo ponto na imagem, dizemos que este sistema é um sistema com aberração. As aberrações de um sistema ótico deterioram a imagem formando imagens com perda de nitidez.

- Difração. Uma pequena porção da frente de onda que deixa um ponto no objeto é perdida e a outra segue adentro ao sistema ótico. Devido à perda desta porção da frente de onda, ocorre o fenômeno chamado difração que "borra" a imagem formada. Este efeito não pode ser evitado pois é inerente à natureza ondulatória da luz. 


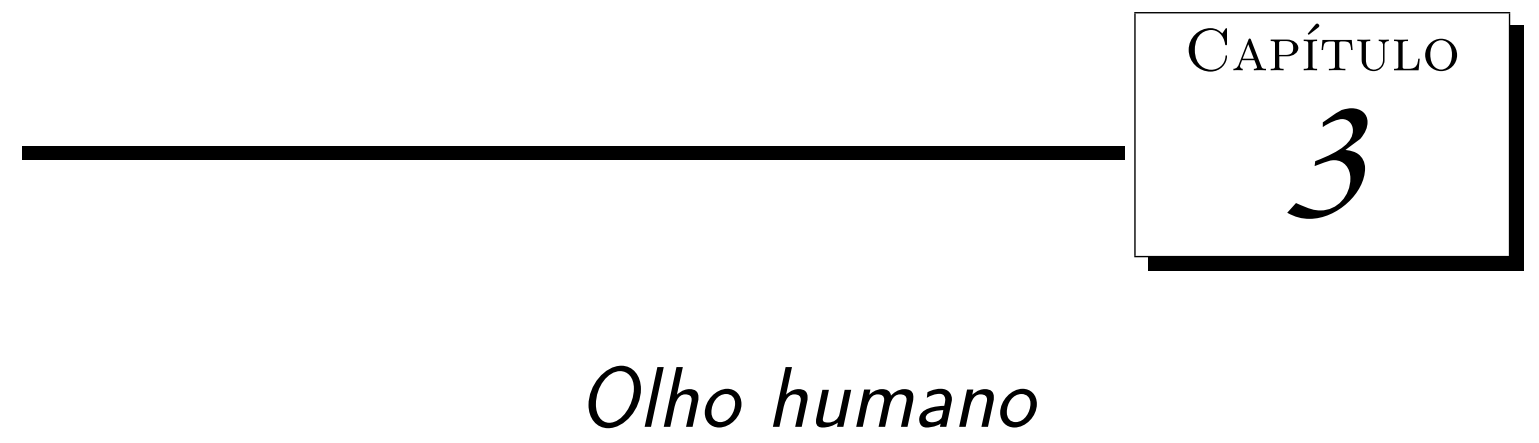

Neste capítulo é apresentada uma breve introdução da anatomia do olho humano e suas funções. O olho em conjunto com o cérebro, constitui um extraordinário sistema bio-ótico. Na próxima seção (3.1) citaremos apenas as partes oticamente relevantes para elaboração deste trabalho.

\subsection{Anatomia}

O olho humano é uma estrutura complexa que pode ser descrita como sendo um globo de forma quase esférica com aproximadamente $23 \mathrm{~mm}$ de diâmetro em média. Em termos óticos, o olho humano é um sistema ótico positivo que refrata a luz incidente em sua porção posterior, chamada retina, para formar uma imagem real invertida (32).

O olho humano Figura (3.1) e suas partes são descritos seguindo o caminho que a luz percorre até a retina. Alguns elementos na Figura (3.1) não são descritos porque não são relevantes neste trabalho.

- Córnea: É um tecido transparente destituído de vasos sanguíneos. Sua estrutura é lente forme e gelatinosa. É a primeira interface que a luz atravessa. O índice de refração da córnea é aproximadamente 1,376. Por isso a interface ar/córnea (índice de refração igual a 1) representa $73 \%$ da dioptria dos olhos. 


\section{Olho humano}

- Humor aquoso: Fluído com índice de refração aproximadamente o da água $(1,336)$ situado na parte anterior do cristalino.

- Íris: Situada no humor aquoso, é responsável pela cor dos olhos. A Íris é um diafragma que controla a quantidade de luz que adentra o olho. Função desempenhada por dois músculos que regulam a abertura no seu centro.

- Pupila: Situada no centro da Íris, abertura que possui a capacidade de mudar seu diâmetro e regular a intensidade incidente na lente cristalino. Entretanto, o diâmetro pupilar sofre uma variação de apenas quatro vezes (corresponde uma variação em área de 16 vezes), enquanto que a variação correspondente ao brilho é superior a 100 mil vezes. Há um mecanismo receptor na retina que se adapta, ele próprio, às grandes diferenças de quantidade de luz.

- Cápsula: Membrana homogênea, elástica que recobre o cristalino (veja próximo item). Sua elasticidade pode ser demonstrada ao imergir o cristalino em água e fazendo um pequeno orifício na cápsula. Quando isto ocorrer, notar-se-á um jato de água. Sua espessura varia de região para região.

- Cristalino: É uma lente complexa constituída por camadas com índice de refração que varia de camada a camada. Possui a capacidade de mudar sua curvatura, possibilitando focar objetos a diferentes distâncias. Fornece o ajuste fino do foco da imagem.

- Humor vítreo: Fluído com índice de refração aproximadamente o da água $(1,336)$ situado na parte posterior do cristalino.

- Retina: Contém milhões de células foto receptoras, os cones e bastonetes. Os bastonetes são extremamente sensíveis a pouca luz, mas são incapazes de distinguirem cores enquanto que os cones são sensíveis a cores (vermelho,verde,azul). A retina tem aproximadamente 100 milhões de bastonetes sendo sua densidade maior na periferia enquanto os cones são em número de 10 milhões e sua concentração é maior em uma região central chamada mácula. 
Olho humano

- Mácula lútea: Também chamada de mancha amarelada, situada na região central da retina, é uma ligeira depressão onde a densidade dos cones é maior.

- Fóvea centralis: Pequena região situada na mácula onde se encontra maior concentração das células foto receptoras, portanto onde a acuidade visual é maior. Quando precisamos de visão em detalhes, posicionamos os olhos de maneira a formar a imagem na fóvea.

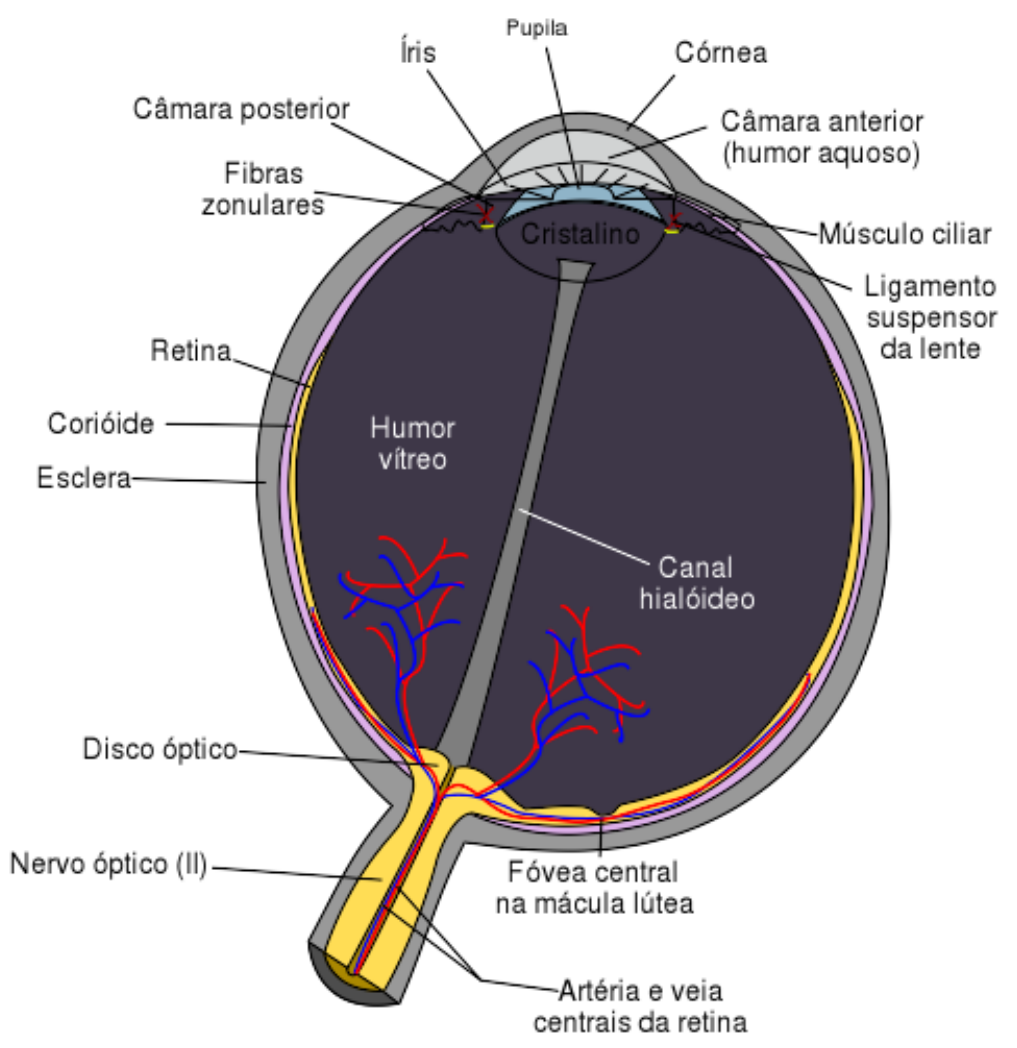

Figura 3.1: Diagrama esquemático do olho humano. Figura extraída de (27)

A visão na fóvea é muito mais nítida do que qualquer outra região na retina. Os músculos que controlam o olho giram o globo ocular até que a imagem do objeto, para o qual a atenção está voltada, seja formada na fóvea.

\subsection{Funções dos olhos}

Para operar eficientemente, os olhos devem formar adequadamente a imagem na retina, seja de objetos próximos ou seja de objetos distantes do olho humano, com pouco ou muita 


\section{Olho humano}

luminosidade. Para conseguir tais resultados, eles realizam uma série de operações que auxiliam o cérebro construir imagens tridimensionais do que está a nossa volta. Abaixo apresentamos algumas delas. A acomodação será vista posteriormente em mais detalhes no Capítulo (4).

- Acomodação: Dependendo das distâncias dos objetos, o cristalino é tencionado ou relaxado pelos músculos ciliares alterando a dioptria da lente fazendo o ajuste fino do foco da imagem.

- Adaptação: Capacidade de responder a sinais luminosos com diferentes intensidades. O fluxo de fótons incidente no olho é regulado pela Íris. As intensidades de luz que conseguimos distinguir são primeiramente controlada pela Íris e posteriormente pelo ganho das células fotorreceptoras.

- Visão estereoscópica ou visão binocular: Hhabilidade de detectar profundidade daquilo que enxergamos devido à interpretação das imagens ligeiramente diferentes obtidas de ambos os olhos.

- Visão periférica: Capacidade de perceber os objetos quando não estamos olhando diretamente para eles.

- Acuidade visual: Habilidade de ver claramente e distinguir detalhes e orientação espacial de objetos.

\subsection{Eixos do olho humano}

A maioria dos sistemas óticos constitui um sistema centrado e por isso são rotacionalmente simétricos em relação ao eixo ótico (ver Definição (4)). No entanto para descrever as propriedades óticas do olho humano é necessário introduzir um certo número de eixos. Alguns destes eixos fazem sentido somente na aproximação paraxial. A seguir definimos os eixos importantes para o entendimento deste trabalho.

Definição 14 (Ponto de fixação) Ponto $M$ de interesse para o qual o olho humano aponta. O ponto $M^{\prime}$ conjugado à $M$ recai no centro da fóvea, ver Figura (3.2). 
Olho humano

Definição 15 (Eixo visual) Não é propriamente um eixo. Traçado de raio que liga o ponto de fixação $M$ ao ponto $M^{\prime}$ no centro da fóvea. Formado por dois segmentos de reta: $M N$ e $N^{\prime} M^{\prime}$, ver Figura (3.2).

Definição 16 (Linha de visada) Linha que liga o ponto de fixação $M$ ao centro da entrada da pupila E, ver Figura (3.2).

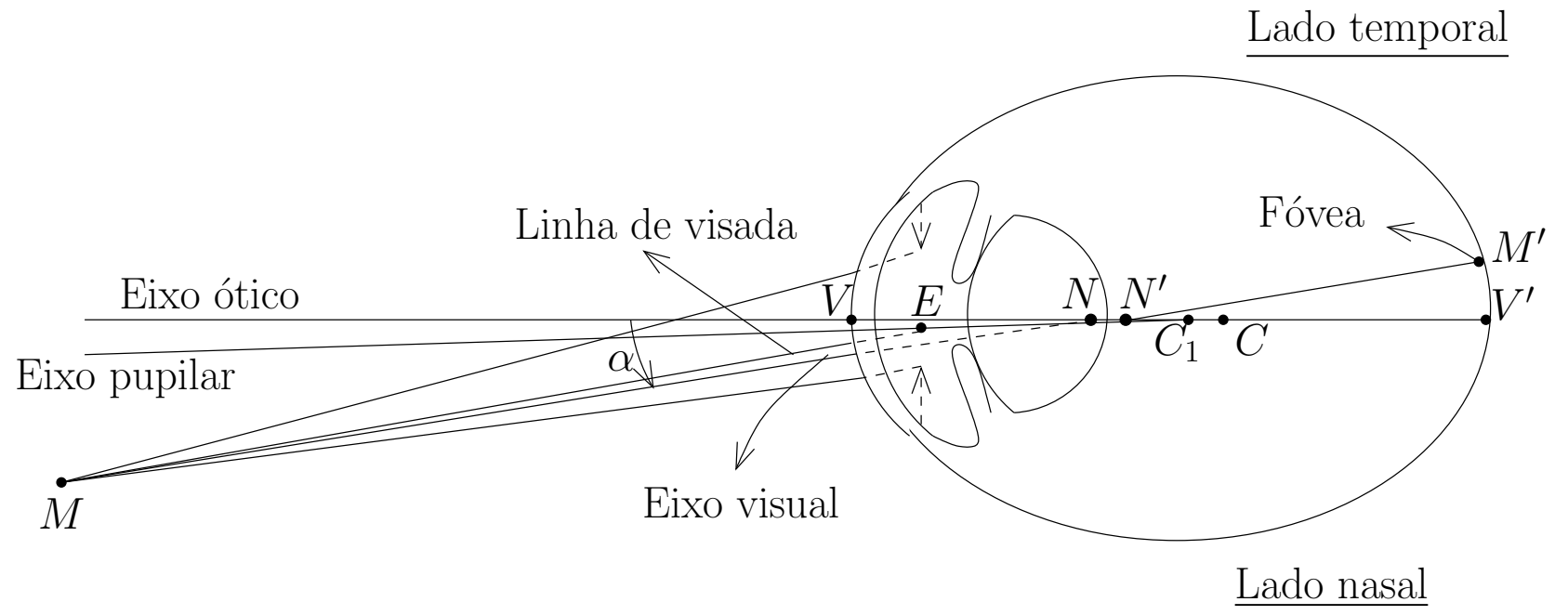

Figura 3.2: Eixos do olho humano. $N$ e $N^{\prime}$ são os pontos nodais do olho humano. $C_{1}$ é o centro de curvatura da superfície anterior da córnea. $C$ é o centro de simetria do olho e $E$ é entrada da pupila. $V$ é o vértice da córnea e $V^{\prime}$ o ponto onde o eixo ótico toca a retina.

Definição 17 (Eixo pupilar) Linha que liga o centro de curvatura $C_{1}$ da superfície anterior da córnea e passa por E, ver Figura (3.2).

Definição 18 (Ângulo $\alpha$ ) Ângulo formado pelo eixo ótico e o eixo visual, ver Figura (3.2).

Alguns métodos para determinar estes eixos dependem da observação de imagens formadas pela reflexão nas primeiras superfícies refratoras do olho. Estas imagens são conhecidas como imagens de Purkinge e são imagens pequenas com baixo contraste, ver (33). As imagens de Purkinge são úteis, e podem ser utilizadas para determinar raios de curvaturas das supefícies das lentes internas do olho. Mas este assunto foge ao escopo deste trabalho. 


\subsection{Modelos óticos}

Modelos esquemáticos do olho humano podem ser construídos utilizando valores médios de parâmetros óticos relevantes. Alguns modelos são muito simples e servem somente para fins educacionais, como o modelo Emsley (ems ). Outros modelos simples, modelam as superfícies da córnea, cristalino e retina como superfícies esféricas. Tais modelos são classificados na literatura como modelos esquemáticos paraxiais e recebem este nome porque estes modelos são precisos em representar o olho humano na região paraxial, ver (16). Estes modelos são muito úteis quando o interesse maior está no calculo das propriedades paraxiais do olho humano. Exemplos destes modelos são: Gullstrand ( gul ) e Le Grand $(\lg r)$. No entanto existem uma categoria de modelos mais sofisticados que os paraxiais que modelam as superfícies como superfícies quádricas, ver Seção (5.1.1), e conseguem modelar adequadamente as aberrações presente no olho humano bem como a qualidade da imagem formada na retina. Este modelos são conhecidos como modelos esquemáticos finitos do olho humano. Exemplos destes modelos são: Lotmar (lot ), Kooijman (koo ), Navarro (nav ) e Liou e Brennan (lbr ). No Apêndice (B) encontra-se os parâmetros necessários para construir os modelos utilizados neste trabalho. As informações encontradas no Apêndice (B) foram extraídas de (16) e (33). 


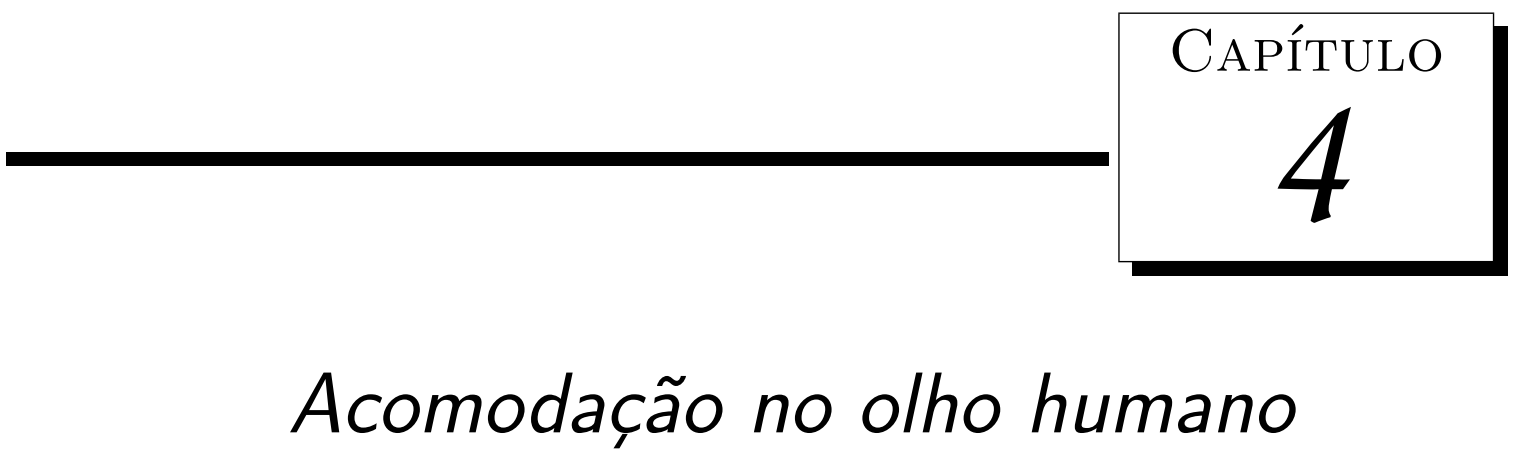

No olho humano a habilidade de alterar o foco envolve o músculo ciliar, as fibras zônulas, a cápsula e a flexibilidade do cristalino. O mecanismo que realiza esta mudança é chamado acomodação visual, definido abaixo. Quando o olho se ajusta para formar corretamente na fóvea a imagem de um objeto de interesse dizemos que o olho está acomodando ebste objeto.

Definição 19 Acomodação visual ou simplesmente acomodação é a habilidade dos olhos de ajustar sua dioptria de modo a propiciar uma imagem nitida ou focar objetos a diferentes distâncias.

A seguir descrevemos o processo de acomodação e alguns fatores que o influenciam.

\subsection{Processo de acomodação}

É sabido que o mecanismo de acomodação é gradual e proporcional à distância do ponto focalizado. Ele é modulado como um sistema realimentado que opera de maneira a aumentar o contraste luminoso da imagem na retina. Não há simplesmente um único estímulo e nem mais importante. Tanto o tamanho do objeto, distância, "borrão" (contraste da imagem), aberração cromática, oscilação da acomodação, movimentos de varre- 


\section{Acomodação no olho humano}

duras dos olhos e como muitos outros fenômenos visuais, inclusive o estado de espírito do indivíduo, são responsáveis pela obtenção da resposta acomodativa apropriada. Durante o mecanismo de acomodação, a principal mudança percebida é na forma do cristalino, principalmente na superfície anterior. Esta mudança provoca uma aumento da espessura do cristalino e da sua dioptria sendo mais acentuada na região central.

Simultâneo ao processo de acomodação ocorre a convergência binocular que consiste em uma rotação em ambos os olhos fazendo-os apontar para o ponto de fixação $M$. A Íris contrai diminuindo o diâmetro da pupila. Além disto é sabido que a aberração esférica diminui com o aumento do nível de acomodação. Todos esses fatos ajudam na obtenção de uma visão nítida de objetos próximos e são conhecidos como resposta próxima. A relação quantitativa entre acomodação e convergência binocular é referida na literatura como a razão $C A / A$ (Convergência Acomodação/Acomodação).

\subsection{Ponto remoto e ponto próximo}

Os raios provenientes de objetos localizados a uma distância maior do que 6 metros, chegam praticamente paralelos ao olho humano. Neste caso, devido, especialmente as propriedades físicas da córnea, não é necessário nenhum ajuste de foco e os raios convergem adequadamente na retina, permitindo uma visão nítida, Figura (4.1). Deste modo, o sistema visual humano, considera os objetos localizados nestas distâncias localizados no infinito. Quando precisamos focalizar objetos mais próximos o cristalino entra em ação funcionando como uma lente de foco variável. O ponto onde o cristalino começa atuar, em média 6 metros, é chamado de ponto remoto do olho humano localizado a uma distância $r$ do vértice da córnea. Para o olho emétrope o ponto remoto encontra-se no infinito e caso contrário o olho é dito amétrope.

O termo ponto remoto não é muito usado na literatura oftalmológica. Ao invés dele é utilizado o termo refração ocular definido abaixo:

Definição 20 Refração ocular ou apenas refração $R$ é a proximidade referente ao ponto remoto. Como normalmente o olho humano encontra-se imerso em ar (índice de refração igual 1,00$)$ temos $R=\frac{1}{r}$.

Neste trabalho $R$ é medido a partir do vértice da córnea (mais usual), porém em alguns 


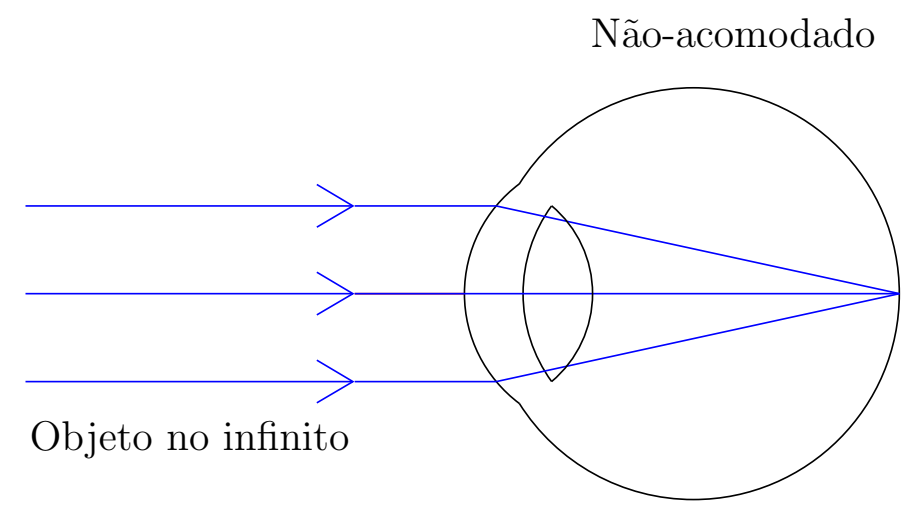

Figura 4.1: Representação esquemática do olho humano focalizando um objeto no infinito, como por exemplo uma estrela.

trabalhos científicos é utilizado a entrada da pupila como origem.

Analogamente ao ponto remoto do olho humano, o ponto mais próximo que conseguimos acomodar objetos situados à uma distância $p$ do vértice da córnea é o ponto próximo do olho humano. Ele está situado a uma distância média de 25 centímetros do vértice da córnea.

A região compreendida entre o ponto remoto e próximo do olho humano é conhecida como zona de acomodação e é a região onde o cristalino e as fibras zônulas trabalham juntos para acomodar os objetos em cena Figura (4.2).

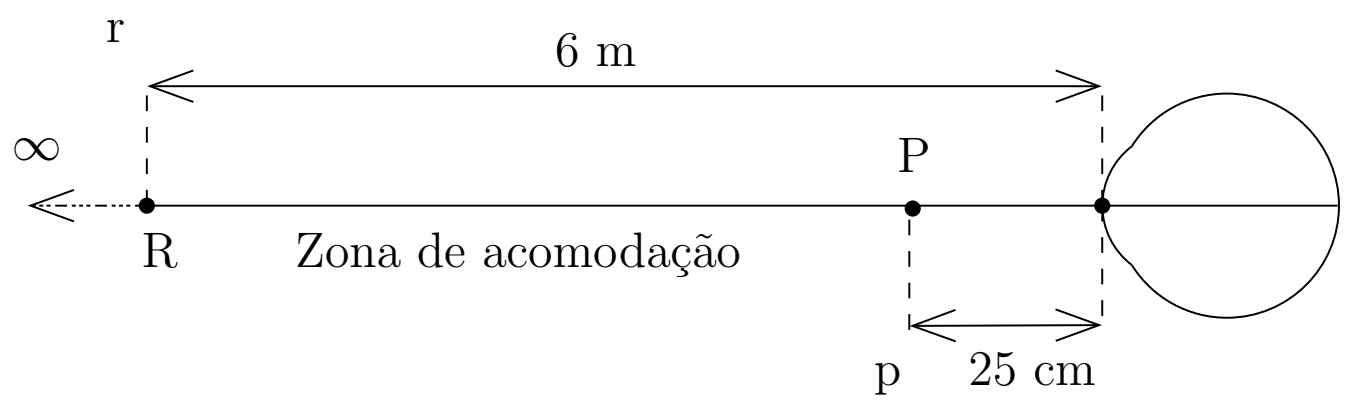

Figura 4.2: Zona de acomodação compreendida entre $R$ e $P$. Nesta região o cristalino funciona com uma lente de foco variável.

\subsection{Convergência binocular}

Simultaneamente ao processo de acomodação ocorre o movimento de convergência binocular. A convergência é um movimento angular aplicado aos dois olhos, alterando o ângulo formado entre os eixos óticos de cada olho. A Figura (4.3) apresenta um diagrama 
sobre a convergência binocular. Quando o ponto de interesse está distante, os eixos óticos de cada olho encontram-se quase paralelos. Entretanto quando o objeto está situado numa posição mais próxima, ocorre a convergência binocular, ou seja, uma torção nos dois olhos, convergem os eixos óticos para o ponto de fixação $M$.

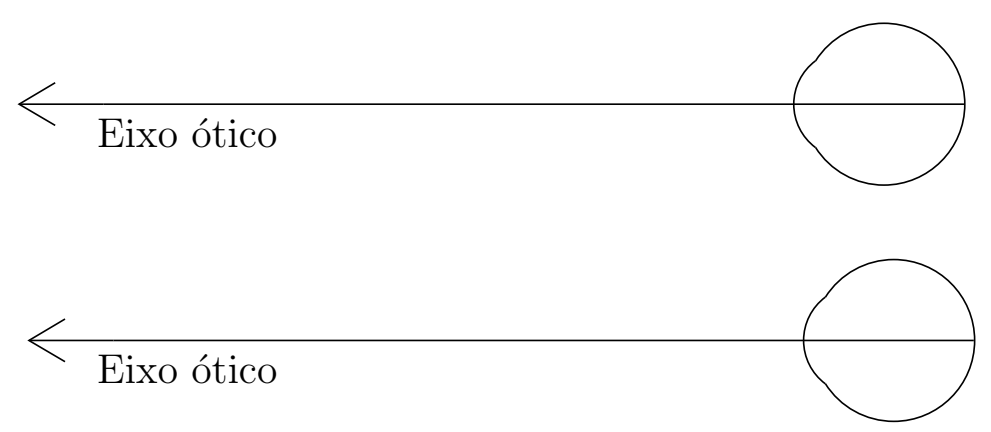

(a)

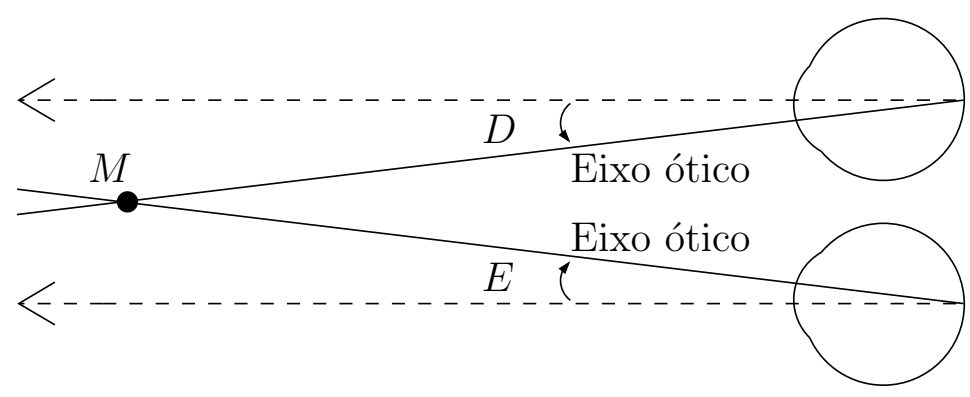

(b)

Figura 4.3: Convergência binocular: (a) Quando o objeto de interesse está distante, o eixo óptico dos olhos estão quase paralelos. (b) Para objetos próximos, ocorre o movimento de convergência binocular, onde cada olho realiza uma torção, formando os ângulos $D$ e $E$ com a posição anterior. Deste modo o eixo ótico de cada olho aponta para $M$.

A convergência binocular auxilia o cérebro na construção das imagens estereoscópica e apresenta-se simultaneamente ao mecanismo de acomodação. Ocorre também uma relação de proporcionalidade entre a convergência binocular e o processo de acomodação.

\subsection{Medidas de acomodação}

O processo de acomodação definido na Definição (19) é medido através da Equação (4.1). A grandeza $A$ é chamada de nível de acomodação ou estado de acomodação.

$$
A=R-X
$$

Onde $R$ é a refração e $X$ é a proximidade referente ao objeto acomodado. Ambos 
medidos a partir do vértice da córnea, no sentido oposto da luz incidente. Devido à convenção adotada nesse trabalho $A \geq 0,0$. A existência do ponto próximo, ver Seção (4.2), a Equação (4.1) alcança um máximo (objetos além deste ponto não são acomodados) denominado amplitude de acomodação $A_{m}$.

$$
A_{m}=R-P
$$

Onde $P$ significa proximidade referente ao ponto. Na prática, não conseguimos manter um objeto acomodado por um longo período de tempo sem evitar a fadiga muscular quando $A=2 / 3 A_{m}$ ou $A=3 / 4 A_{m}$.

Muitos autores aproximam a amplitude de acomodação $A_{m}$ com a diferença de dioptria nos estados não-acomodado $D_{n a}$ e no estado de acomodação máxima $D_{m a}$.

$$
A_{m}=D_{m a}-D_{n a}
$$

O decréscimo progressivo da amplitude de acomodação com o decorrer dos anos é conhecido como presbiopia.

\subsection{Teoria de acomodação}

Ainda hoje o processo de acomodação não é inteiramente compreendido. Grande parte do problema está na dificuldade de obter informações in-vivo do cristalino. A seguir falamos da principal teoria de acomodação e atualmente adotada pelos médicos oftalmologista sobre o mecanismo de acomodação. A teoria de Helmholtz, Seção (4.5.0.1) é a teoria atualmente mais aceita na literatura científica. Na Seção (4.5.0.2) damos uma breve explicação da principal teoria rival de Helmholtz, proposta por Schachar (14) e (4).

\subsubsection{Helmholtz}

A teoria de Helmholtz foi proposta em meados do século 19, e mesmo sendo antiga é a teoria mais difundida e aceita atualmente. Helmholtz propôs que o corpo ciliar é ativo na acomodação observando que os músculos ciliares dos míopes são menores que dos hipermétropes (1).

Segundo Helmholtz os músculos ciliares que circundam o cristalino são ligados ao 


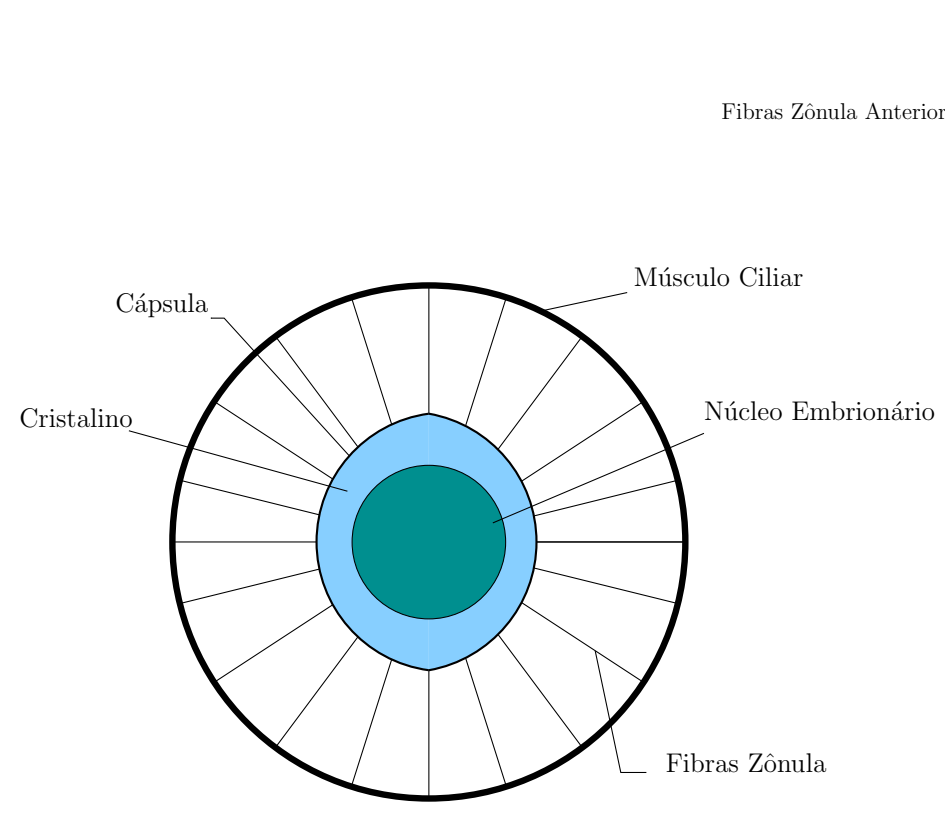

(a)

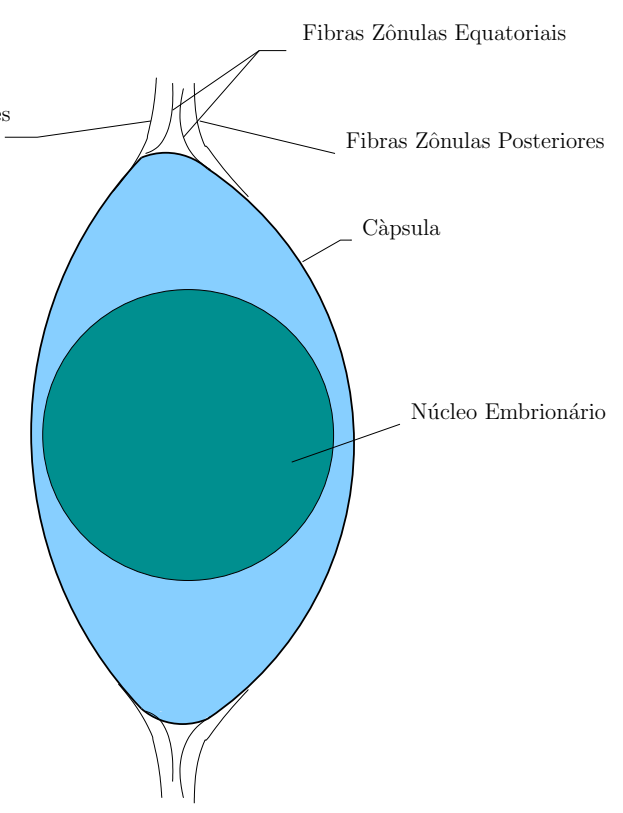

(b)

Figura 4.4: Fibras zônulas exercem força centrífuga no cristalino mantendo-o suspenso. a) Direita, cristalino não-acomodado e b) cristalino acomodado.

equador do cristalino pela fibras zônulas Figura (4.4) que tencionam as fibras zônulas exercendo uma força centrífuga no equador do cristalino, nesta situação o olho encontrase no estado não-acomodado $A=0,0$.

Ao acomodar objetos na zona de acomodação, a contração dos músculos ciliares causa a redução da distância entre o cristalino e o corpo ciliar Figura (4.5). Como resultado, as fibras zônulas relaxam, aliviando a tensão na cápsula que reveste o cristalino, permitindo-o contrair-se alterando a curvatura, assim aumentando sua dioptria.

Ao acomodar um objeto mais distante na zona de acomodação, o músculo ciliar relaxa e as fibras zônulas tornam-se gradativamente tensas novamente tracionando a cápsula ocasionando o movimento contrário, aumentando a distância entre o cristalino e corpo ciliar e assim diminuindo sua dioptria.

A teoria de Helmholtz, apesar de ser a mais aceita, não consegue explicar completamente todo o processo de acomodação. Como exemplo, esta teoria não justifica porque a superfície anterior do cristalino deforma mais do que posterior, ver (33). 


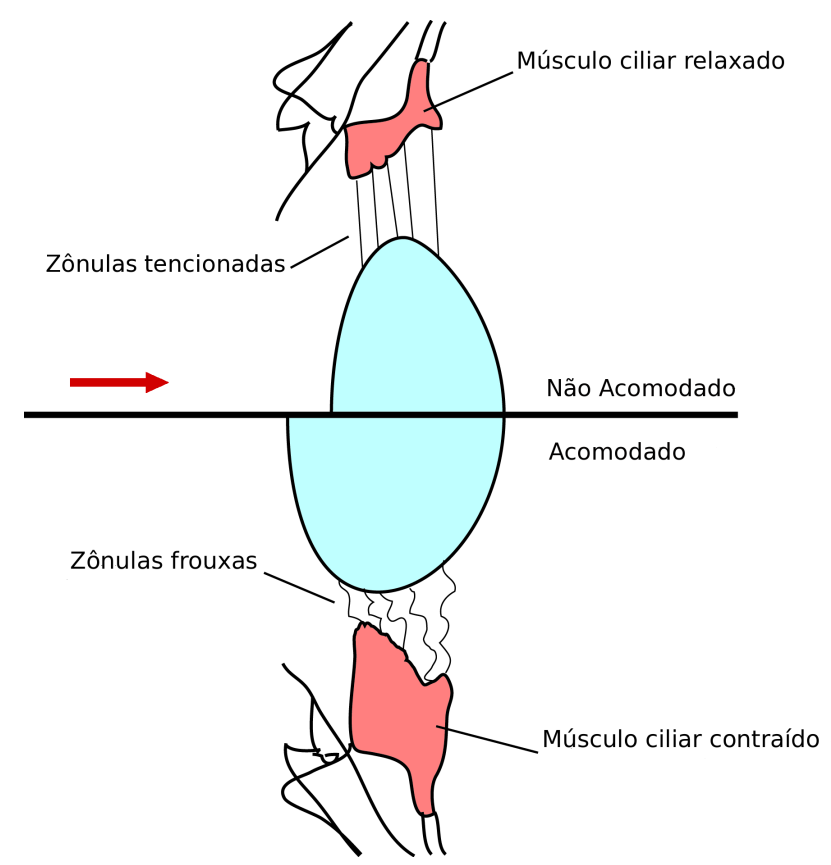

Figura 4.5: Acomodação segundo Helmholtz: topo) olho não-acomodando, músculo ciliares relaxado e zônulas tencionadas, abaixo) olho acomodado, músculo ciliar contraído e zônulas frouxas. A seta vermelha indica o sentido incidente da luz.

\subsubsection{Schachar}

Para Scharchar, as fibras zônulas são divididas em três categorias segundo o local onde elas conectam-se ao cristalino: anterior, posterior e equatorial. As fibras equatoriais são as mais ativas no processo de acomodação. As anteriores e as posteriores servem para estabilizar o cristalino. Durante a acomodação os músculos ciliares trabalham de maneira oposta proposta por Helmholtz. Os músculos ao contrair, aplicam uma tensão extra nas zônulas equatoriais e relaxam as zônulas anteriores e posteriores. Isto faz o centro do cristalino tornar-se mais escarpado. Então a curvatura e dioptria central (pólo do cristalino) aumenta e a superfície periférica do cristalino assemelha-se mais a um plano, ou seja, a curvatura e dioptria periférica diminuem, Figura (4.6). De acordo com Schachar em (14), a espessura central do cristalino aumenta devido ao aumento dos raios de curvaturas centrais das superfícies anteriores e posteriores. Os músculos ciliares ao relaxarem suspendem a tensão nas fibras permitindo ao cristalino retornar à sua forma não-acomodada. 


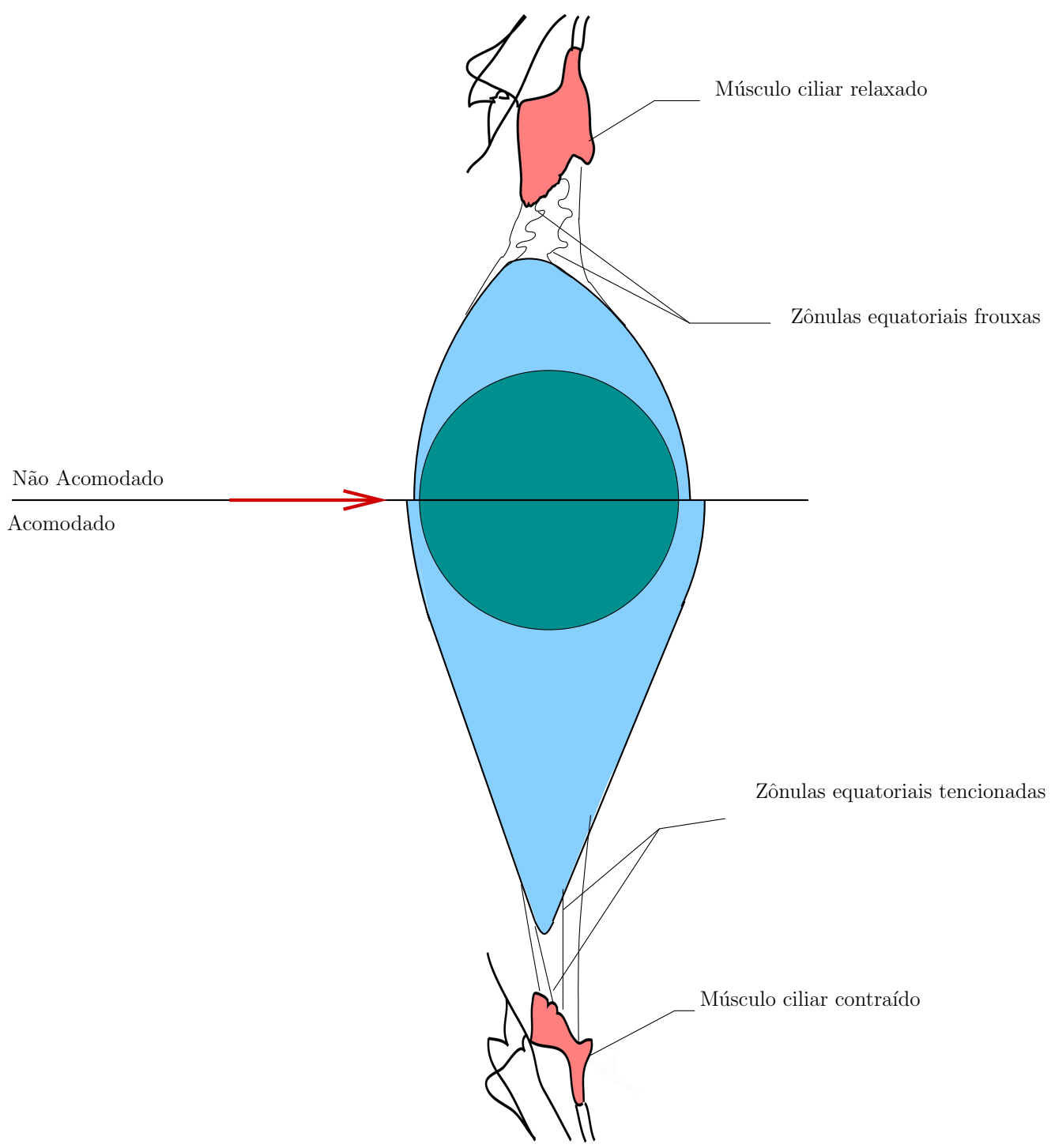

Figura 4.6: Acomodação segundo Schachar: topo) cristalino não-acomodado, músculo ciliar relaxado e zônulas equatoriais frouxas, abaixo) cristalino acomodado, músculo ciliar contraído e zônulas equatoriais tencionadas. A seta vermelha indica o sentido incidente da luz. 


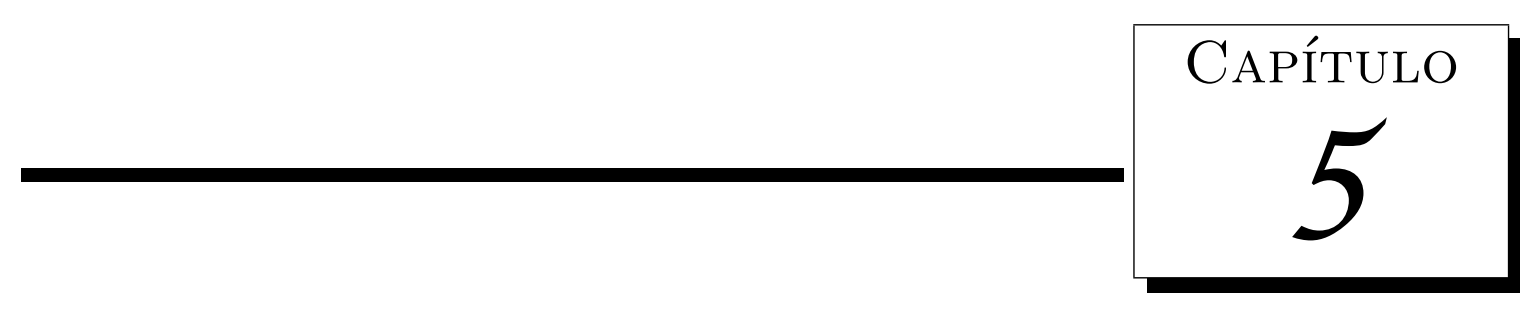

\section{Olho Virtual}

O olho virtual VEye (do inglês Virtual Eye) é um arcabouço computacional desenvolvido com o intuito de modelar/simular o olho humano e conjuntos de lentes. Ele é composto por diversos algoritmos de computação gráfica, matemáticos e físicos. O projeto é capaz de trabalhar com dados in-vivo obtidos de um topógrafo de córnea cedido pelo grupo de ótica oftalmológica da Universidade de São Paulo (USP) campus de São Carlos.

O VEye é dividido em três módulos: modelagem, simulação ou traçado de raios e visualização. O módulo de modelagem as estruturas necessárias: córnea, pupila, cristalino e retina são construídas para formar os modelos esquemáticos do olho humano, ver Apêndice (B).

O módulo de simulação é responsável pela parte ótica do sistema, nele são lançados os raios, computados as intersecções e os raios refratados. A simulação de frente de onda, calculos das propriedades gaussianas entre outras também são realizada neste módulo. E por último o módulo de visualização onde os resultados gerados são visualizados. A seguir descrevemos as funcionalidades de cada módulo. 


\subsection{Modelagem}

Este módulo é responsável por modelar os quatros componentes principais do olho humano: córnea, pupila, cristalino e retina. A seguir apresentamos as estratégias adotadas. A modelagem dos modelos esquemáticos do olho humano Seção (3.4) e Apêndice (B) é discutida na Seção (5.1.1) e a modelagem de dados in-vivo na Seção (5.1.2). A modelagem de dados in-vivo e o módulo visualização do VEye utiliza malhas triangulares superficiais. A manipulação destas malhas é feita com a estrutura de dados topológicos SHE, ver (3) e (31). A Figura (5.1) mostra o sistema de coordenadas do VEye .

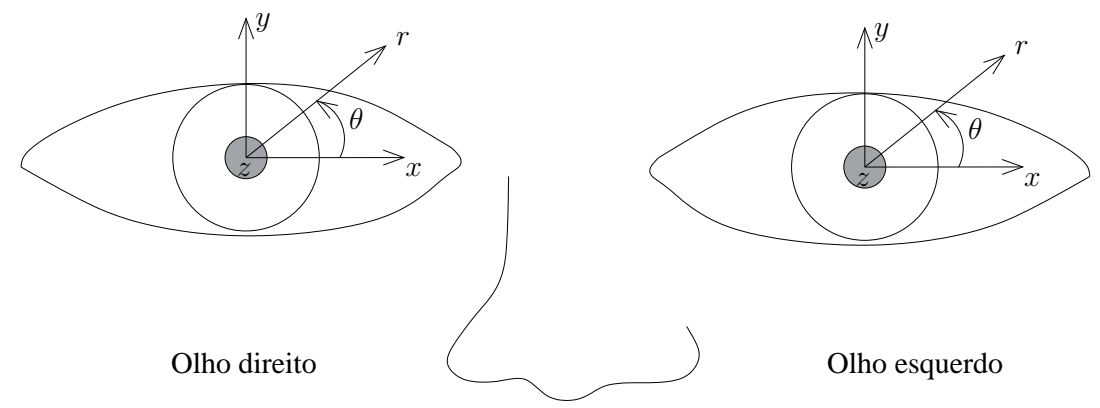

Figura 5.1: Sistema de coordenadas cartesiano e polar. O eixo $z$ está saindo do papel. A origem do sistema de coordenadas é o vértice da córnea.

\subsubsection{Modelagem teórica}

Os modelos esquemáticos empregados são construídos com superfícies quádricas Equação (5.1). Cada superfície que compõe o modelo em questão é construída na origem e depois é transladada para a sua posição correta de maneira que somente a superfície anterior da córnea permaneça na origem.

$$
S(x, y, z)=x^{2}+y^{2}+(1+Q) z^{2}-2 R z \equiv 0
$$

Onde $R$ é o raio de curvatura do vértice (apex) da superfície e $Q$ é asfericidade da superfície:

- $Q<-1$ : A superfície é um hiperbolóide.

- $Q=-1$ : A superfície é um parabolóide. 
Olho Virtual

- $-1<Q<0$ : A superfície é um elipsóide (eixo maior é z).

- $Q=0$ : A superfície é uma esfera.

- $Q>0$ : A superfície é um elipsóide (eixo maior no plano $x y$ ).

\subsubsection{Modelagem dado in-vivo}

Atualmente o VEye modela a superfície anterior da córnea com dados in-vivo. A superfície anterior é aproximada por uma malha triangular superficial $m$ que ajusta-se ao conjunto dos pontos $\Omega \subset \mathbb{R}^{3}$ obtidos de um topógrafo de córnea. O topógrafo mede as elevações relativas ao centro da córnea, ponto $P_{0}$ assumido como elevação nula. Os pontos são amostrados em coordenadas cilíndricas e a origem do sistema de coordenadas é o ponto onde o plano $\pi$ ortogonal ao eixo $z$ tange o vértice da córnea. Cada ponto $P_{k} \subset \Omega$ é representado pela tripla $(r, \theta, h)$ onde $r$ é à distância da origem no plano $\pi, \theta$ é o ângulo medido a partir do eixo $x$ e $h$ é a elevação relativa ao plano $\pi$. Devido à amostragem do topógrafo de córnea gerar o mesmo número de pontos para $\theta=\left\{1^{\circ}, 2^{\circ}, 3^{\circ}, \ldots, 360^{\circ}\right\}$, ordenamos os pontos por $\theta$ e a triangulação destes pontos é construídas por pedaços ilustrados na Figura (5.2).

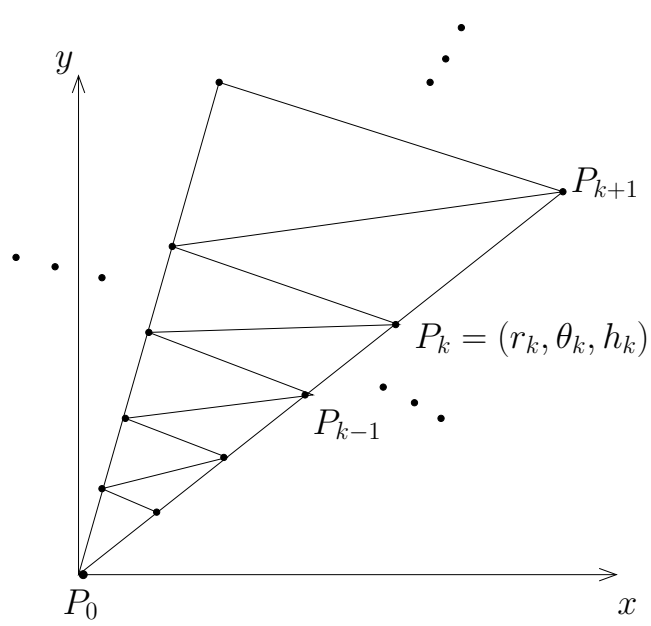

Figura 5.2: Ilustração da triangulação do conjunto de pontos $\Omega \subset \mathbb{R}^{3}$ obtidos do topógrafo de córnea. Os eixos $x$ e $y$ e o ponto $P_{0}$, vértice da córnea, estão no plano $\pi$ (plano do papel). Os demais pontos $P_{k} s$ estão à distância negativa $h_{k}$ de $\pi$. 


\subsubsection{Geração de malhas}

As malhas superficiais são construídas a partir de um modelo em camadas. Refinamentos sucessivos destas camadas são realizados até que alcança-se um nível satisfatório da superfície $S \subset \mathbb{R}^{3}$ dada pela Equação (5.1) que estas malhas representam.

A Figura (5.3) exibe a primeira etapa do processo de construção da malha $m$. Primeiramente é construído o prisma da Figura (5.3), onde o vértice $v_{0}$ é a intersecção entre o eixo ótico $z\left(v_{0} \in z\right)$ e a superfície $S$. Os pontos $v_{1}, v_{2}, v_{3}$ e $v_{4}$ encontram-se no plano $\pi$ e delimitam $m$.

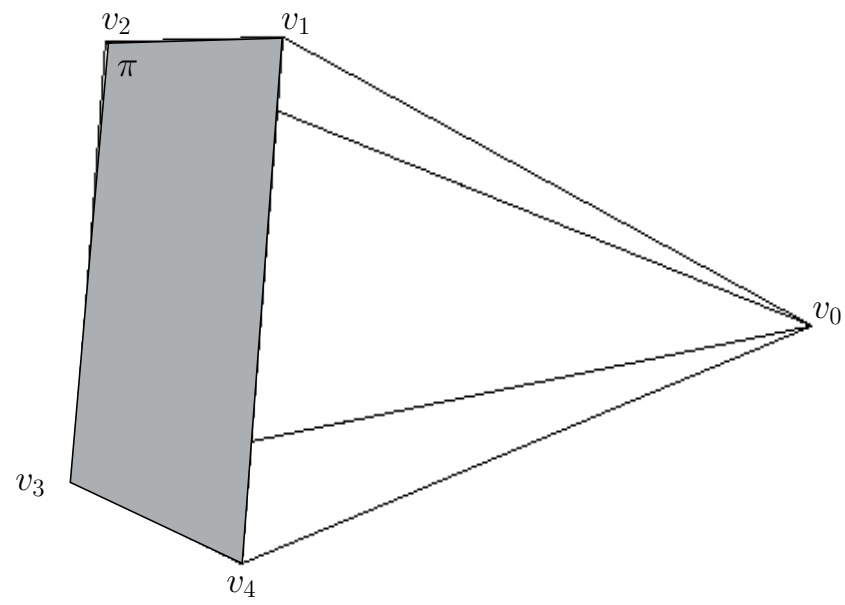

Figura 5.3: Etapa inicial do algoritmo de geração de malha. Prisma que delimita a malha $m$.

No próximo passo camadas são adicionadas entre o plano $\pi$ e $v_{0}$. O plano $\pi^{\prime}$ é criado em $z_{\pi^{\prime}}$ e particiona o prisma da Figura (5.3) ao meio. Quatro novos vértices: $v_{5}, v_{6}, v_{7}$ e $v_{8}$ são criados com a Equação (5.2).

$$
\begin{aligned}
& v_{5}=\left(0, \rho, z_{\pi^{\prime}}\right) \\
& v_{6}=\left(\rho, 0, z_{\pi^{\prime}}\right) \\
& v_{7}=\left(0,-\rho, z_{\pi^{\prime}}\right) \\
& v_{8}=\left(-\rho, 0, z_{\pi^{\prime}}\right)
\end{aligned}
$$

Onde $\rho^{2}=2 R z_{\pi^{\prime}}-(1+Q) z_{\pi^{\prime}}^{2}$. A Figura (5.4) mostra $m$ com duas camadas e ilustra 


\section{Olho Virtual}

este passo.

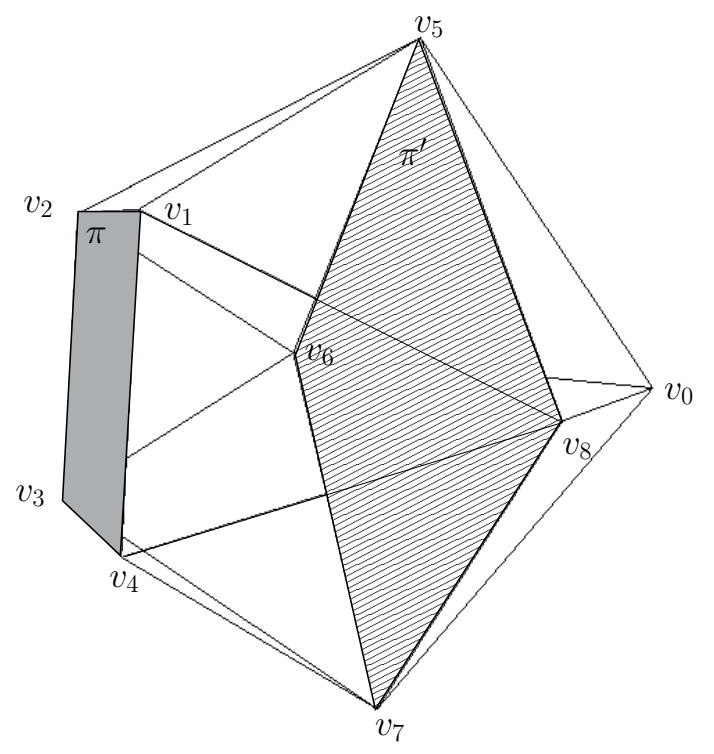

Figura 5.4: Malha $m$ com duas camadas e sem refinamento em construção. O plano $\pi^{\prime}$ delimita as camadas.

Terminado a etapa inicial, começa a etapa de refinamento de camadas. A camada posterior é a mais densa ou refinada. O refinamento é feito da seguinte forma: divide-se as arestas de cada triângulo $t \in m$, por exemplo o triângulo $t=\Delta v_{1} v_{8} v_{4}$, no ponto médio. Depois liga-se os pontos médios formando quatro novos triângulos, ver Figura (5.5). Estes triângulos são adicionados a $m$ e o triangulo original $t$ é removido. Então os três novos vértices: $v_{18}, v_{84}$ e $v_{41}$ são deslocados para a superfície $S$.

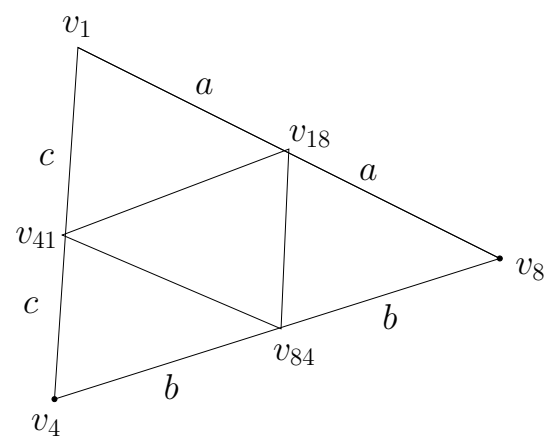

Figura 5.5: Esquema de refinamento da malha triangular $m$. O triângulo $t=\triangle v_{1} v_{8} v_{4}$ da Figura (5.4) é mostrado com um nível de refinamento. Os lados de $t$ são divididos ao meio em segmentos de comprimento $a, b$ e $c$.

Devido à diferença de refinamentos entre camadas de $m$, surgem "buracos" nas frontei- 


\section{Olho Virtual}

ras entre as camadas com diferença de refinamento que são removidas na etapa de ajuste. Nesta etapa o número de vértices em $m$ permanece constante.

Seja $\partial^{-} \subset m$ o conjunto dos triângulos e vértices na camada com menor nível de refinamento e $\partial^{+} \subset m$ o conjunto dos triângulos e vértices na camada com maior nível de refinamento. Seja $\partial=\partial^{-} \cap \partial^{+}$, ou seja o conjunto dos vértices que estão em $\partial^{-}$ e $\partial^{+}$(fronteira). A remoção dos "buracos" é feita no conjunto dos triângulos $\Gamma=$ $\left\{t=\triangle v_{k} v_{i} v_{j}: t \in \partial^{-} \mid v_{k} \in \partial^{-}\right.$e $\left.v_{j}, v_{i} \in \partial\right\}$ cujo vértice $v_{k}$ encontra-se em $\partial^{-}$e os demais vértices em $\partial$. Então $v_{k}$ é ligado ao vértice $v_{l} \in \partial^{+} \mid v_{l}$ é ponto médio da aresta $\overline{v_{i} v_{j}}$ , ver Figura (5.6).

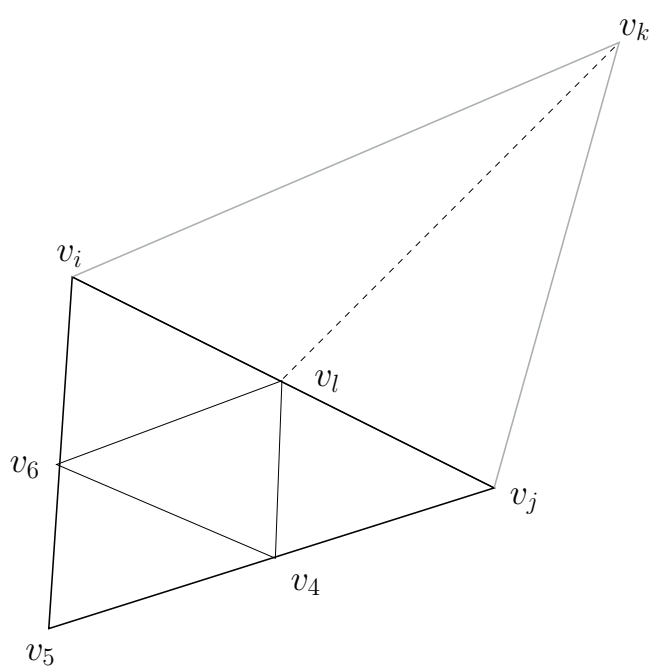

Figura 5.6: Duas camadas representadas em níveis de cinza com diferença de um nível de refinamento. Adicionamos dois triângulos novos a camada com menor número de refinamentos ligando-se o vértice $v_{k}$ a $v_{l}$ (linha pontilhada).

No VEye as camadas são construídas com no máximo dois níveis de refinamento de diferença. A Figura (5.7) mostra $m$ após a etapa de refinamento e ajuste.

\subsection{Simulação: traçado de raios}

O traçado de raios ou ray-tace, é parte mais importante e complicada do projeto VEye - O traçado realístico dos raios Seção (5.2.2.2) segue as leis da física vistas no Capítulo (2). Também implementamos um traçado de raio paraxial Seção (5.2.2.1) útil para inferir as propriedades gaussianas dos modelos.

Este módulo consiste em realizar o traçado ótico de raios através do olho e lentes. 


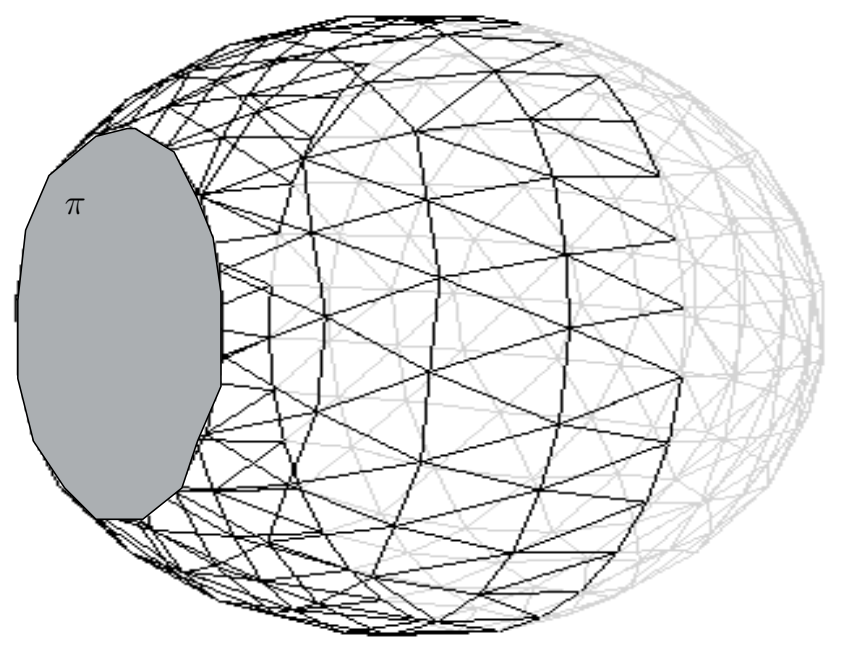

Figura 5.7: Ilustração da malha $m$. Malha construída com duas camadas representadas por níveis de cinza. A primeira camada com 2 níveis de refinamento e a segunda com 3. O plano $\pi^{\prime}$ foi removido para não prejudicar o entendimento da figura.

Primeiramente os raios são lançados contra a primeira superfície refratora, no segundo passo a intersecção entre o raio e a superfície é calculada juntamente com a normal da superfície no ponto. A direção do raio refratado é calculada. O processo é refeito para a próxima superfície até que a última superfície seja alcançada, Algoritmo (5.1).

A seguir detalhamos o processo todo e os procedimentos envolvidos.

\subsubsection{Cálculo de intersecção e normal}

Nesta etapa calculamos a intersecção e a normal da superfície. Implementamos dois algoritmos. O primeiro utilizado quando a superfície é construída a partir da Equação (5.1). E o segundo quando a superfície é baseada em dados in-vivo e malhas tridimensionais superficiais são utilizadas. Estes algoritmos são descritos nas próximas seções.

\subsubsection{Quádrica: intersecção}

O cálculo de intersecção é realizado substituindo a Equação (5.3) na Equação (5.1), resolvendo o sistema de $2^{o}$ grau para $\alpha$ e escolhendo a raiz: $\alpha_{1}$ ou $\alpha_{2}$, apropriada, que resulte no menor valor positivo $\left\{\beta_{1}, \beta_{2}\right\}$ Equação (5.4), ver (7).

$$
\mathbf{R}=\mathbf{R}_{0}+\alpha \mathbf{L}
$$




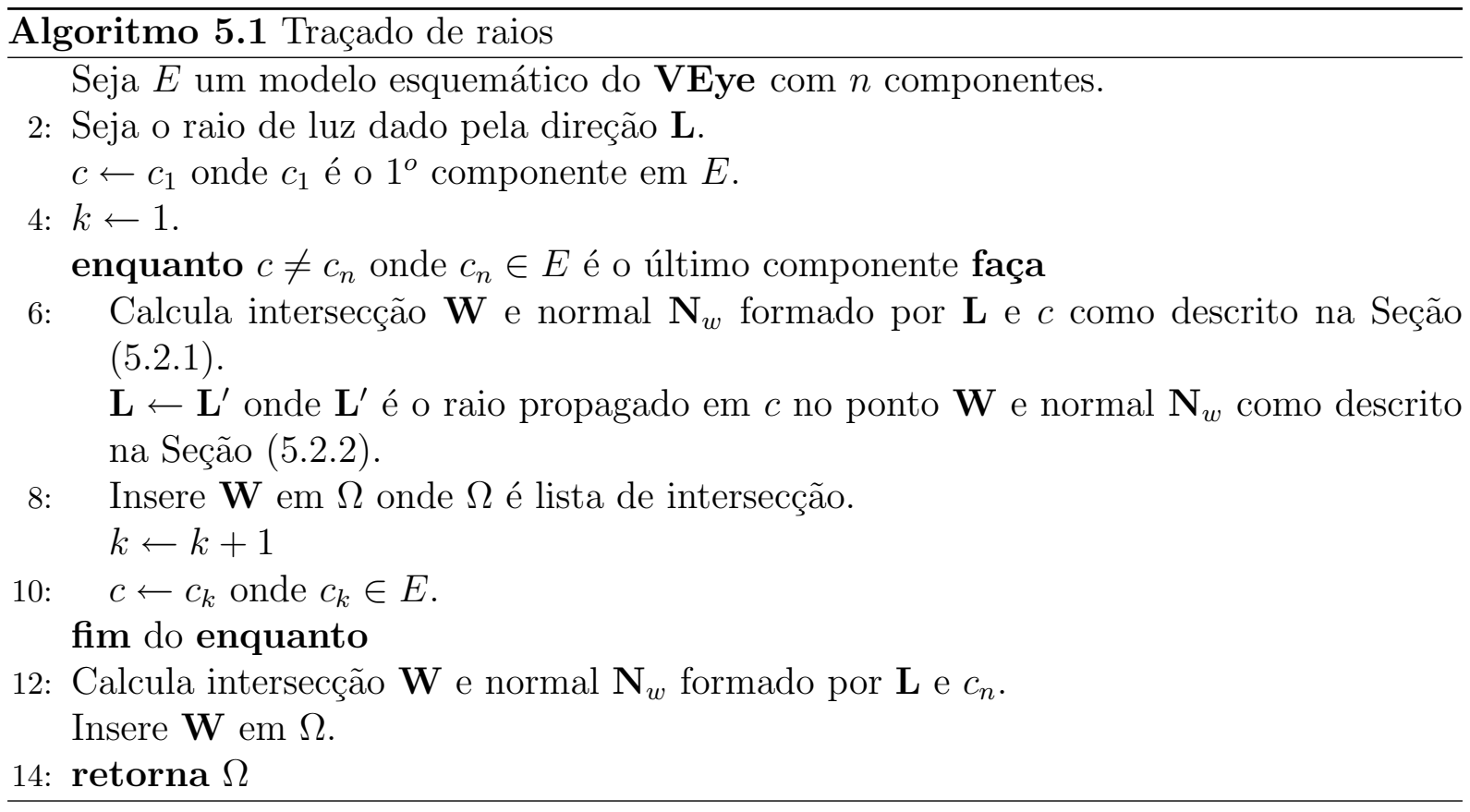

$$
\begin{gathered}
\beta_{i}=\operatorname{acos}\left[\frac{\mathbf{L} *\left(\mathbf{R}_{i}-\mathbf{R}_{0}\right)}{\left\|\mathbf{R}_{i}-\mathbf{R}_{0}\right\|}\right] \\
\mathbf{R}_{i}=\mathbf{R}_{0}+\alpha_{i} \mathbf{L}
\end{gathered}
$$

A intersecção $\mathbf{W}$ é dada por:

$$
\mathbf{W}=\mathbf{R}_{0}+\alpha_{k} \mathbf{L}
$$

Onde $\alpha_{k}$ é a raiz escolhida. A normal em $\mathbf{W}$ é calculado através do operador gradiente.

$$
\mathbf{N}_{w}=\nabla S(\mathbf{W})
$$

Onde:

$$
\nabla S(x, y, z)=\left(\begin{array}{c}
\frac{\partial S}{\partial x} \\
\frac{\partial S}{\partial y} \\
\frac{\partial S}{\partial z}
\end{array}\right)
$$




$$
\begin{aligned}
& \frac{\partial S}{\partial x}=2 x \\
& \frac{\partial S}{\partial y}=2 y \\
& \frac{\partial S}{\partial z}=2[(1+Q) z-R]
\end{aligned}
$$

\subsubsection{Malha: intersecção}

No cálculo de intersecção nas malhas utilizamos o princípio "Door-in Door-out", ver (21). O princípio pode ser enunciado a seguir.

Sejam $\mathbf{V}_{1}, \mathbf{V}_{2}$ e $\mathbf{V}_{3}$ os vetores coordenadas associados aos vértices $v_{1}, v_{2}$ e $v_{3}$ do triângulo $t$ na malha $m$. Suponhamos que o raio $l$ lançado do ponto $\mathbf{R}_{0}$ na direção $\mathbf{L}$, Figura (5.8), intercepte o plano $\pi$ definido pelo triângulo $t$ no ponto $\mathbf{W}$. Então podemos escrever a Equação (5.10):

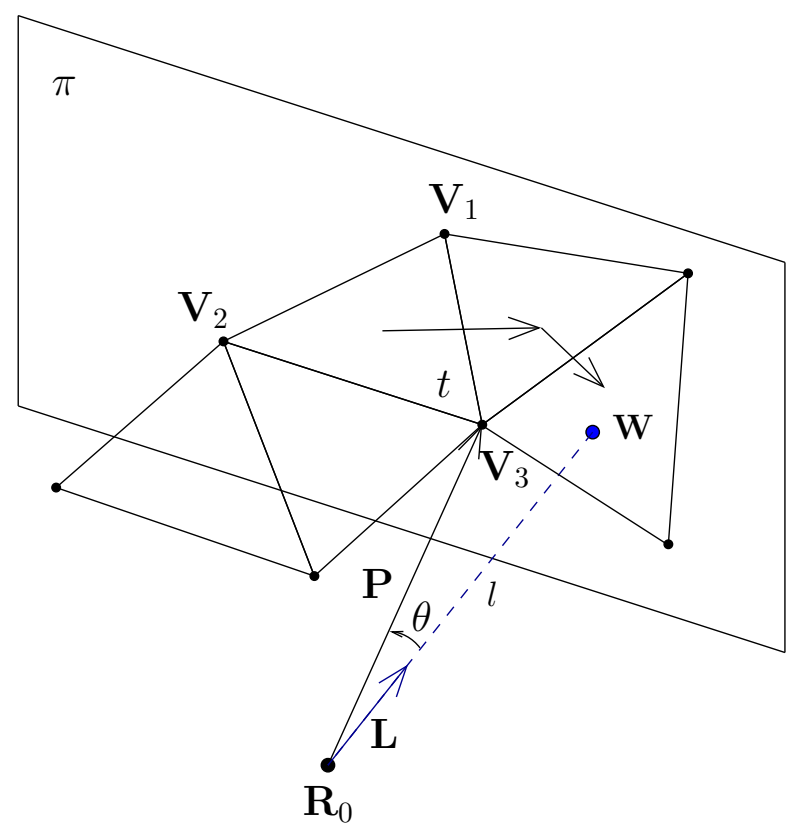

Figura 5.8: Princípio "Door-in Door-out". Raio $l$ lançado da posição $\mathbf{R}_{0}$ na direção de $\mathbf{L}$ intercepta o plano $\pi$ definido pelo triângulo $t=\Delta v_{1} v_{2} v_{3}$ no ponto $\mathbf{W}$.

$$
\mathbf{W}=\mathbf{R}_{0}+a \mathbf{L}
$$

Mas o ponto W também pode ser reescrito como combinação linear dos vetores coordenadas dos vértices de $t$. 


$$
\begin{aligned}
& \mathbf{W}=\lambda_{1} \mathbf{V}_{1}+\lambda_{2} \mathbf{V}_{2}+\lambda_{3} \mathbf{V}_{3} \\
& \lambda_{1}+\lambda_{2}+\lambda_{3}=1
\end{aligned}
$$

O sistema abaixo é derivado da Equação (5.10) e Equação (5.11).

$$
\left(\begin{array}{cccc}
1 & 1 & 1 & 0 \\
\mathbf{V}_{1} & \mathbf{V}_{2} & \mathbf{V}_{3} & -\mathbf{L}
\end{array}\right)\left(\begin{array}{c}
\lambda_{1} \\
\lambda_{2} \\
\lambda_{3} \\
\alpha
\end{array}\right)=\left(\begin{array}{c}
1 \\
\mathbf{R}_{0}
\end{array}\right)
$$

O Sistema (5.12) fornece valores para $\lambda_{1}, \lambda_{2}, \lambda_{3}$ e $\alpha$. Se $\lambda_{i} \geq 0$ para $i=1,2,3$, o raio $l$ intercepta $\pi$ em $\mathbf{W}$ interior a $t$. Caso contrário, pelo menos um $\lambda_{i}<0, \mathbf{W}$ é exterior a $t$ e então $\mathbf{W}$ está na direção oposto ao vértice $\mathbf{V}_{j}$ associado a $\lambda_{j}<0$. Por exemplo, na Figura (5.8), o ponto $\mathbf{W}$ é oposto ao vértice $\mathbf{V}_{2}$ e por isso $\lambda_{2}<0$. Então precisamos pular para o próximo triângulo oposto ao vértice $\mathbf{V}_{2}$, a seta no centro de $t$ indica a direção, assim por diante até que $\mathbf{W}$ seja alcançado.

Os valores de $\lambda_{i}$, para $i=1,2,3$ são usados para interpolar a normal $\mathbf{N}_{w}$ em $\mathbf{W}$. Sejam $\mathbf{N}_{1}, \mathbf{N}_{2}$ e $\mathbf{N}_{3}$ as normais nos vértices respectivamente. $\mathbf{N}_{w}$ é dada por:

$$
\mathbf{N}_{w}=\lambda_{1} \mathbf{N}_{1}+\lambda_{2} \mathrm{~N}_{2}+\lambda_{3} \mathbf{N}_{3}
$$

As normais $\mathbf{N}_{i}$ no vértice $v_{i}$ são calculadas através da média Equação (5.14), onde $\mathbf{N}_{t}$ é a normal do plano definido pelo triângulo $t$ e $T=\left\{t: v_{i} \in t\right\}$ e $n_{t}$ é o número de triângulos no conjunto $T$.

$$
\mathbf{N}_{i}=\frac{1}{n_{t}} \sum_{T} \mathbf{N}_{t}
$$

Desta maneira o algoritmo "Door-in Door-out" pode calcular as intersecções e normais eficientemente. No entanto o algoritmo assumi que a cada triângulo $t$ percorrido a intersecção entre o plano definido por $t$ e o raio $l$ exista. Para garantir esta condição em cada passo do "Door-in Door-out" utilizamos a estratégia AproximaDaIntersecção. Ao lançar o raio de luz definido pela posição da fonte $\mathbf{R}_{0}$ e pela direção deste raio vetor unitário 
L, antes de utilizar o princípio "Door-in Door-out" aproximamos do ponto de intersecção caminhando na direção que minimiza o ângulo $\theta$ formado por $\mathbf{L}$ e $\mathbf{P}$, Equação (5.15) (ver Figura (5.8)).

$$
\mathbf{P}=\mathbf{V}_{k}-\mathbf{R}_{0}
$$

Onde $\mathbf{V}_{k}$ é o vetor coordenada associado aos vértice $v_{k} \in m$. O ângulo formado entre a direção do raio $\mathbf{L}$ e $\mathbf{P}$ é calculado através da Equação (5.16).

$$
\theta=\operatorname{acos}\left(\frac{\mathbf{P} . \mathbf{L}}{\|\mathbf{P}\|}\right), \quad \frac{-\pi}{2}<\theta<\frac{\pi}{2}
$$

A estratégia AproximaDaIntersecção ainda sim pode falhar para malhas onde a curvatura varie bruscamente, mas para as malhas bem comportadas do VEye , ela resolve o problema do princípio "Door-in Door-out" e além do mais aumenta a eficiência do algoritmo de traçado de raios ao diminuir a quantidade de cálculos em triângulos onde obviamente a intersecção não encontra-se.

\subsubsection{Propagação dos raios}

Nesta seção descrevemos os algoritmos de traçados de raios do VEye . Os traçados são divididos em duas categorias: em meios homogêneos onde o índice de refração permanece constante e em meios inomogêneos onde encontramos uma distribuição indicial conhecidos na literatura como GRaded INdex (GRIN) media. Na primeira categoria implementamos traçados de raios realísticos e paraxiais, na segunda delas implementamos traçado realístico e o traçado paraxial é feito lançando-se raios na região paraxial, ver Seção (2.1.4).

\subsubsection{Meio homogêneo: Paraxial}

O traçado de raios paraxial é uma ferramenta importante no estudo do comportamento gaussiano de sistemas óticos. No traçado paraxial, as interseções são calculadas utilizando o algoritmo descrito na Seção (5.2.1), mas a propagação dos raios obedecem a Equação (5.17). 


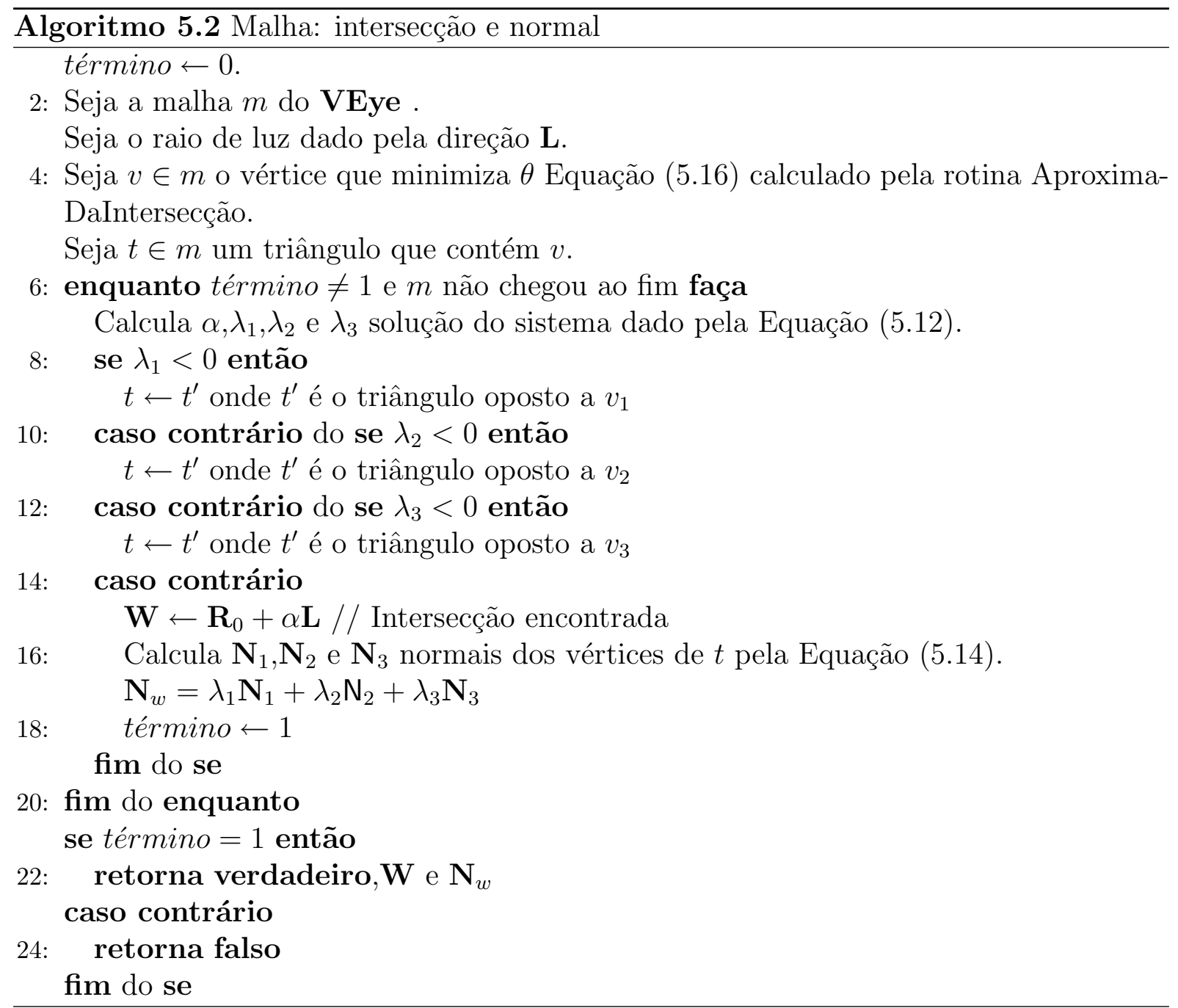




$$
n^{\prime} \phi^{\prime}-n \phi=-h D
$$

Onde $D$ é a dioptria da superfície, $\phi$ e $\phi^{\prime}$ são os ângulos formados entre o raio incidente e o refratado respectivamente com o eixo ótico da superfície. $h$ é a distância do eixo ótico à intersecção $B$ entre o raio $l$ e a superfície $S_{j}$, ver Figura (5.9).

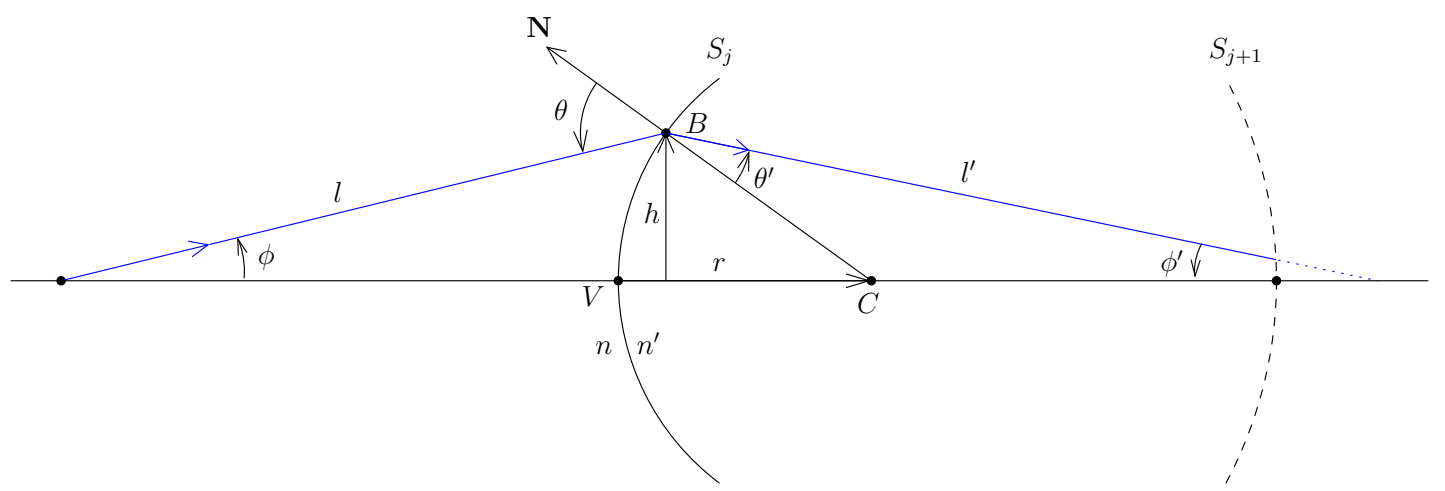

Figura 5.9: Traçado de raio paraxial em uma superfície de refração $S_{j}$. $r$ é o raio de curvatura de $S_{j}$ e $C$ é o centro de curvatura. O raio incidente $l$ intercepta $S_{j}$ em $B$ com normal $\mathbf{N}$. O raio refratado $l^{\prime}$ é propagado até a próxima superfície $S_{j+1} \cdot \theta$ e $\theta^{\prime}$ são os ângulos de incidência e refração respectivamente.

\subsubsection{Meio homogêneo: Realístico}

O traçado de raio realístico é feito com o cálculo da intersecção visto na Seção (5.2.1) e a propagação é utilizado a Equação (2.3) e a Equação (2.4). O caminho ótico opl $=\left[P_{1} P_{2}\right]$ Definição (11) é computado através da Equação (5.18).

$$
o p l=n\left\|P_{2}-P_{1}\right\|
$$

Onde $n$ é o índice de refração do meio.

\subsubsection{Meio inomogêneo}

O traçado realístico em meios inomogêneos é realizado com as equações da Seção (2.1.2). A Equação (2.5) é rearranjada com a mudança de variável.

$$
t=\int \frac{\mathrm{d} s}{n}
$$




\section{Olho Virtual}

Onde $n$ é o índice de refração e ds é o comprimento de arco infinitesimal, ver Figura (2.3).

A Equação (2.5) é reescrita como:

$$
\frac{\mathrm{d}^{2} \mathbf{R}}{\mathrm{d} t^{2}}=\mathbf{D}(\mathbf{R})
$$

Onde:

$$
\begin{gathered}
\mathbf{D}(\mathbf{R})=n(\mathbf{R}) \nabla n(\mathbf{R}) \equiv n\left(\begin{array}{c}
\frac{\partial n}{\partial x} \\
\frac{\partial n}{\partial y} \\
\frac{\partial n}{\partial z}
\end{array}\right) \\
\mathbf{R}=\left(\begin{array}{c}
x \\
y \\
z
\end{array}\right) \quad \mathbf{T}=\frac{\mathrm{d} \mathbf{R}}{d t} \equiv n\left(\begin{array}{c}
\frac{\mathrm{d} x}{\mathrm{~d} s} \\
\frac{\mathrm{d} y}{\mathrm{~d} s} \\
\frac{\mathrm{d} z}{\mathrm{~d} s}
\end{array}\right)
\end{gathered}
$$

A Equação (5.20) é resolvida com as condições iniciais $\mathbf{R}=\mathbf{R}_{0}\left(x_{0}, y_{0}, z_{0}\right)$ e $\mathbf{T}=\mathbf{T}_{0}$ através do método Runge-Kutta , ver (24), elucidado com as equações abaixo:

$$
\begin{gathered}
\mathbf{R}_{k+1}=\mathbf{R}_{k}+\Delta t\left[\mathbf{T}_{k}+\frac{1}{6}(\mathbf{A}+2 \mathbf{B})\right] \\
\mathbf{T}_{k+1}=\mathbf{T}_{k}+\frac{1}{6}(\mathbf{A}+4 \mathbf{B}+\mathbf{C}) \\
\mathbf{A}=\Delta t \mathbf{D}\left(\mathbf{R}_{k}\right) \\
\mathbf{B}=\Delta t \mathbf{D}\left(\mathbf{R}_{k}+\frac{\Delta t}{2} \mathbf{T}_{k}+\frac{1}{8} \Delta t \mathbf{A}\right) \\
\mathbf{C}=\Delta t \mathbf{D}\left(\mathbf{R}_{k}+\Delta t \mathbf{T}_{k}+\frac{1}{2} \Delta t \mathbf{B}\right)
\end{gathered}
$$

Onde $\Delta t$ é o passo de integração. O caminho ótico opl, Definição (11) é dado por:

$$
o p l=\int_{P_{1}}^{P_{2}} n(s) \mathrm{d} s \equiv \int_{t_{1}}^{t_{2}} n^{2}(t) \mathrm{d} t
$$

Seja $o p l_{k}$ o caminho ótico ao longo do raio entre o ponto $P=P_{0}$ em $t_{0}$ e o ponto $P_{k}$ em $t_{k}$, temos. 
Olho Virtual

$$
\begin{aligned}
o p l_{k+1}= & o p l_{k}+\int_{t_{k}}^{t_{k+1}} n^{2}(t) \mathrm{d} t \\
& =o p l_{k}+\int_{0}^{\Delta t} n^{2}(\tilde{t}) \mathrm{d} \tilde{t}
\end{aligned}
$$

Onde fizemos à mudança de variável $\tilde{t}=t-t_{k}$. Como aproximação, consideramos a propagação retilínea no intervalo $\Delta t$ da luz. E opl é dado por:

$$
o p l=\Delta t \sum_{k}\left(p_{k}^{2}+q_{k}^{2}+l_{k}^{2}\right)
$$

Onde:

$$
\begin{aligned}
& n^{2}\left(t_{k}\right)=\mathbf{T}_{k} \mathbf{T}_{k} \\
& \mathbf{T}_{k}=\left(\begin{array}{c}
p_{k} \\
q_{k} \\
l_{k}
\end{array}\right)
\end{aligned}
$$

A tripla $\left(p_{k}, q_{k}, l_{k}\right)$ é conhecida como co-senos das direções óticas (optical direction cosines) (30).

Para lentes GRIN o traçado paraxial é emulado lançando-se raios a altura $h$ e direção u muito próximos ao eixo ótico do sistema e um fator de escala apropriado é utilizado para transformar $h$ e u reais na altura e direção paraxial correspondente, ver (5).

\subsection{Visualização}

O módulo de visualização é formado por um conjunto de ferramentas gráficas desenvolvidas para visualizar o fluxo de dados expelidos pelo VEye . As ferramentas desenvolvidas foram construídas com as bibliotecas GLUT (18) implementação da especificação OpenGL (28) nos sistemas Gnu/Linux. O aplicativo ParaView-3.0.1 também foi utilizado no auxílio da visualização dos resultados.

O VEye utiliza malhas triangulares superficiais Seção (5.1.3) no módulo de visualização. As malhas são visualizadas em wire-frame Figura (5.10) e em shading Figura (5.11) e Figura (5.15). 


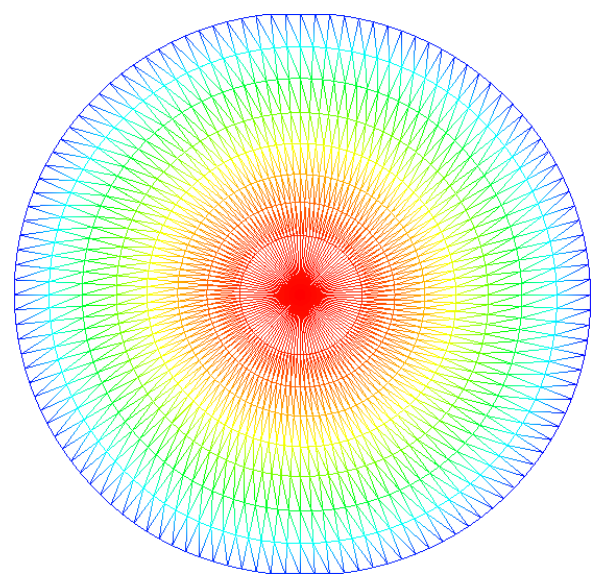

Figura 5.10: Visualização do VEye em wire-frame e mapa de cores representa as elevações. Córnea in-vivo construído com os algoritmos da Seção (5.1.2).

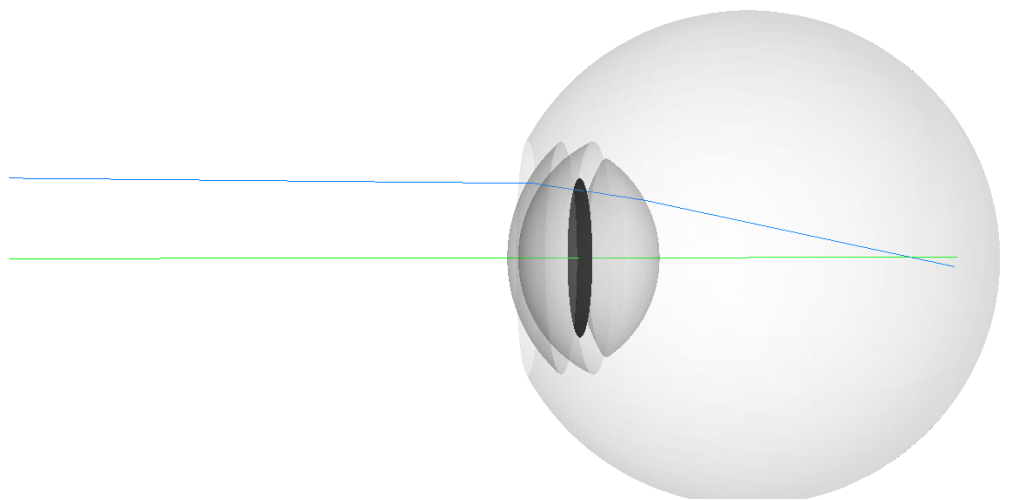

Figura 5.11: Visualização do VEye em shading. Raios de luz em azul e eixo ótico em verde. Modelo de Lotmar.

Nas próximas seções discutimos simulações que utilizam os três módulos descritos anteriormente. Elas extraem informações importantes dos modelos esquemáticos e dos dados in-vivo e auxiliam o entendimento do sistema visual humano como todo.

\subsection{Acomodação no VEye}

O VEye procura seguir fielmente os modelos o máximo possível. Em alguns casos, foi adicionado ao modelo esquemático uma superfície que representa a retina e a pupila já que alguns destes modelos não especificam modelo de retina e pupila.

O processo de acomodação no VEye está presente somente naqueles modelos esquemáticos que implementam acomodação. Os modelos esquemáticos de Le Grand e Gullstrand, ver Apêndice (B), definem dois estados de acomodação: não-acomodado e 


\section{Olho Virtual}

acomodado com $A=6,96 \mathrm{D}$ e $A=10,66 \mathrm{D}$ respectivamente para o modelo de Le Grand e Gullstrand. O modelo proposto por Navarro (22) é o único que propõe um modelo continuo de estados de acomodação no intervalo $A=[0,0 ; 10,0] \mathrm{D}$.

Apesar da teoria de acomodação ainda não estar completamente fechada na literatura científica, os autores dos modelos esquemáticos do olho humano utilizados no VEye não discutem os mecanismo de acomodação abordados na Seção (4.5).

\subsection{Cálculo das propriedades paraxiais}

O cálculo das propriedades paraxiais Seção (2.1.4.1) dos modelos esquemáticos é feita como descrito em (16). A técnica é chamada de traçado finito de raios onde os algoritmos de traçados de raios paraxiais são utilizados no lugar do traçado realístico Seção $(5.2 .2)$.

Os pontos focais $F$ e $F^{\prime}$ são calculados ao lançar um raio de luz paralelo ao eixo ótico $z$ e determina-se a intersecção entre o raio refratado e $z$. Os pontos principais $H$ e $H^{\prime}$ são determinados por $H=F+H F$ e o mesmo para $H^{\prime}=F^{\prime}+H^{\prime} F^{\prime}$. As grandezas $H F=f$ e $H^{\prime} F^{\prime}=f^{\prime}$ são:

$$
f=-\frac{h}{\phi^{\prime}} \quad f=\frac{h}{\phi}
$$

Onde $\phi^{\prime}, \phi$ e $h$ estão indicados na Figura (5.9).

Os pontos nodais $N$ e $N^{\prime}$ são dados por $N=H+H N$ e $N^{\prime}=H^{\prime}+H^{\prime} N^{\prime}$.

$$
H^{\prime} N^{\prime}=H N=\frac{\left(n^{\prime}-n\right)}{D}
$$

Onde $n$ e $n^{\prime}$ são os índices de refração dos meios, ver Figura (5.9) e $D$ é a dioptria da lente. O Algoritmo (5.3) explica o processo todo.

Para determinar a posição da saída e entrada da pupila traçamos o raio paraxial $l_{c}$ do centro da pupila $P$ em direção à córnea (para determinar $E$ ) ou ao cristalino (para $E^{\prime}$ ) e calculamos a intersecção entre $l_{c}$ e $z$. Com base na Equação (5.33) o aumento lateral (magnification) da entrada e da saída da pupila foi obtido. Ver Figura (5.12)

A razão $\eta_{E} / \eta_{P}$ é o aumento lateral $M_{E}$ da entrada da pupila Equação (5.33), onde $\eta_{E}$ é o tamanho da entrada da pupila e $\eta_{P}$ é o tamanho da pupila. 


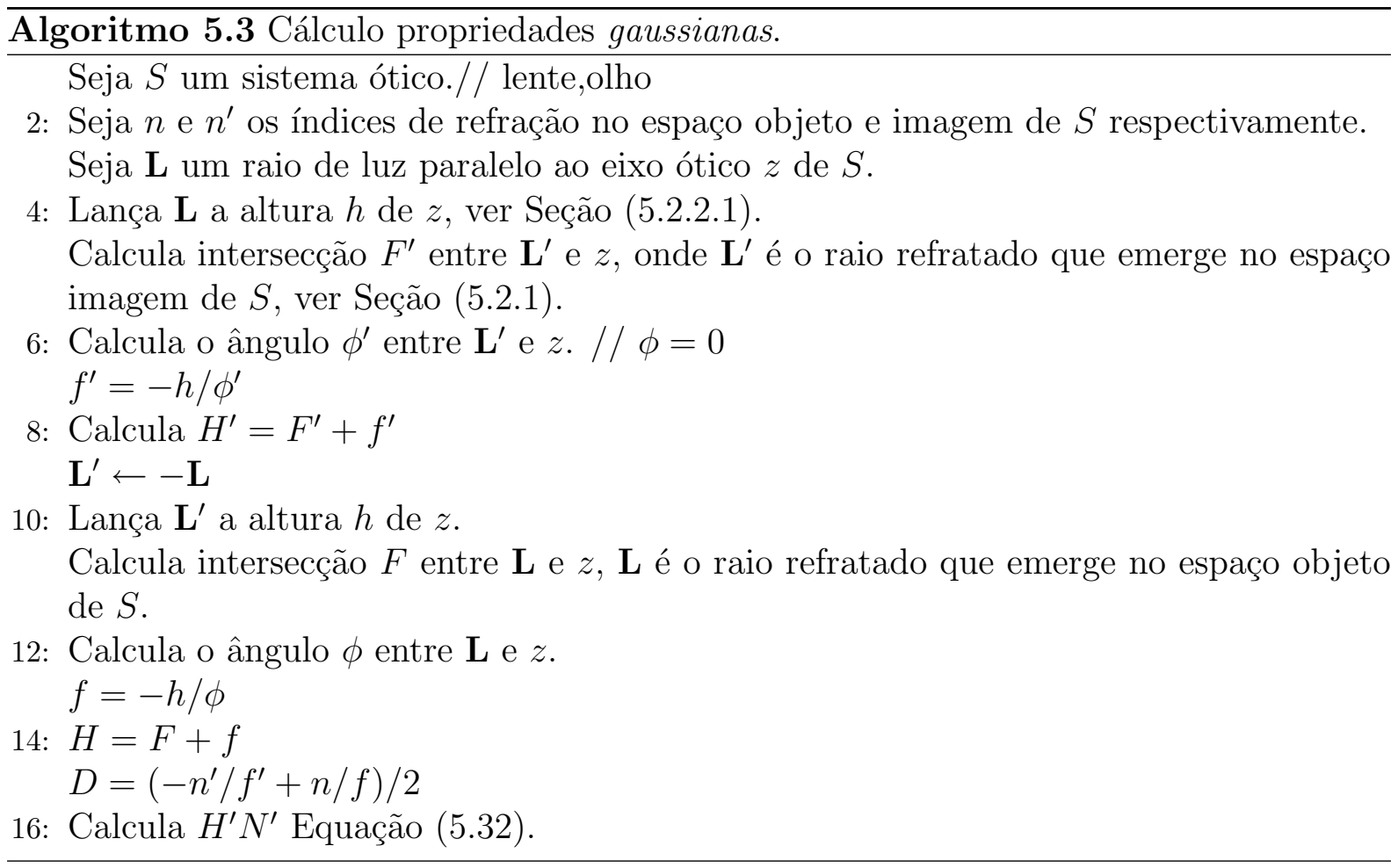

$$
M_{E}=\frac{n l^{\prime}}{n^{\prime} l}
$$

Onde $n$ e $n^{\prime}$ são os índices de refração do ar e do humor aquoso respectivamente e as distâncias $l=H_{1} P$ e $l^{\prime}=H_{1}^{\prime} E, H_{1}$ e $H_{1}^{\prime}$ são os pontos principais da córnea e não estão na Figura (5.12) para facilitar a compreensão. Note que devido a configuração da córnea ${ }^{1}$ temos: $l=V P$ e $l^{\prime}=V E$. A posição da saída da pupila pode ser obtido de maneira análoga, ver Algoritmo (5.4).

A razão $m$ é definida abaixo.

$$
m=\frac{\overline{u^{\prime}}}{\bar{u}}
$$

Onde $\bar{u}$ e $\overline{u^{\prime}}$ os ângulos formado por $l_{c}$ e $z$. A Equação (5.17) é arranjada para obtermos.

$$
\begin{aligned}
& m=[n-(\bar{h} \bar{u})] / n^{\prime} \\
& =[n+\bar{l} D] / n^{\prime}
\end{aligned}
$$

Onde $\bar{h}$ está indicado na Figura (5.12) e $\bar{l}$ é dado por:

\footnotetext{
${ }^{1} \mathrm{~A}$ córnea é representada por uma interface.
} 


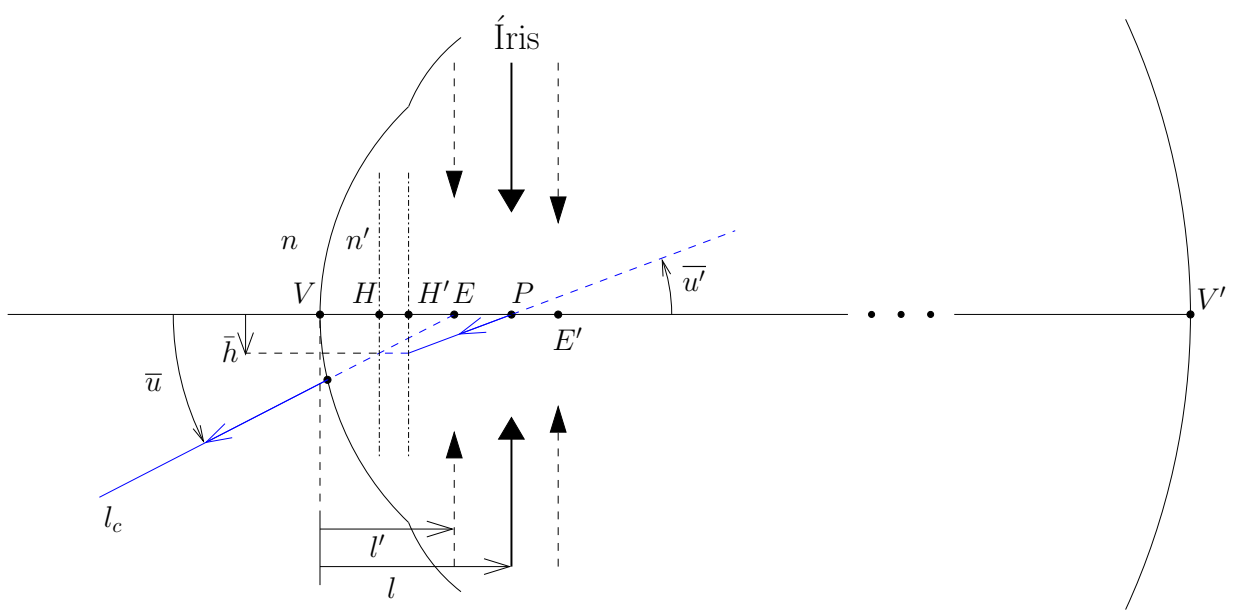

Figura 5.12: Formação da entrada $E$ e saída $E^{\prime}$ da pupila e sua relação com a Íris. A córnea do modelo hipotético é representada com apenas uma superfície para facilidar o entendimento. Também na figura raio pupilar paraxial $l_{c}$ utilizado para determinar a posição da entrada da pupila $E$. $H$ e $H^{\prime}$ são os pontos principais do modelo hipotético, $l$ e $l^{\prime}$ são as distâncias do vértice da córnea $V$ representada por uma única superfície e $n$ e $n^{\prime}$ são os índices de refração do ar e do humor aquoso respectivamente.

$$
\bar{l}=H E \equiv-\bar{h} / \bar{u}
$$

A razão $m$ está relacionada com o tamanho da imagem na retina pela Equação (5.38).

$$
\begin{aligned}
\eta^{\prime} & =\overline{u^{\prime}} d^{\prime} \\
& =\bar{u} m d^{\prime}
\end{aligned}
$$

Substituimos $\bar{u}=-\eta / d$ na Equação (5.37).

$$
\eta^{\prime}=\eta m \frac{d^{\prime}}{d}
$$

Onde $\eta^{\prime}$ é o tamanho da imagem em foco, $d^{\prime}=E^{\prime} V^{\prime}$ onde $V^{\prime}$ é a intersecção entre $z$ e a retina e determina o comprimento axial do modelo esquemático e $d=O E$ onde $O$ é a posição do objeto. Novamente o Algoritmo (5.4) explica o processo todo.

\subsection{Aberração esférica: longitudinal e transversal}

Os efeitos da aberração esférica são ilustrado na Figura (5.11). Os raios de luz

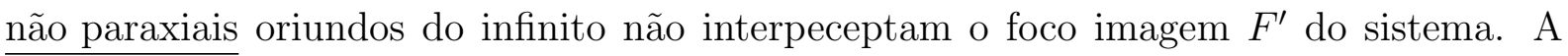




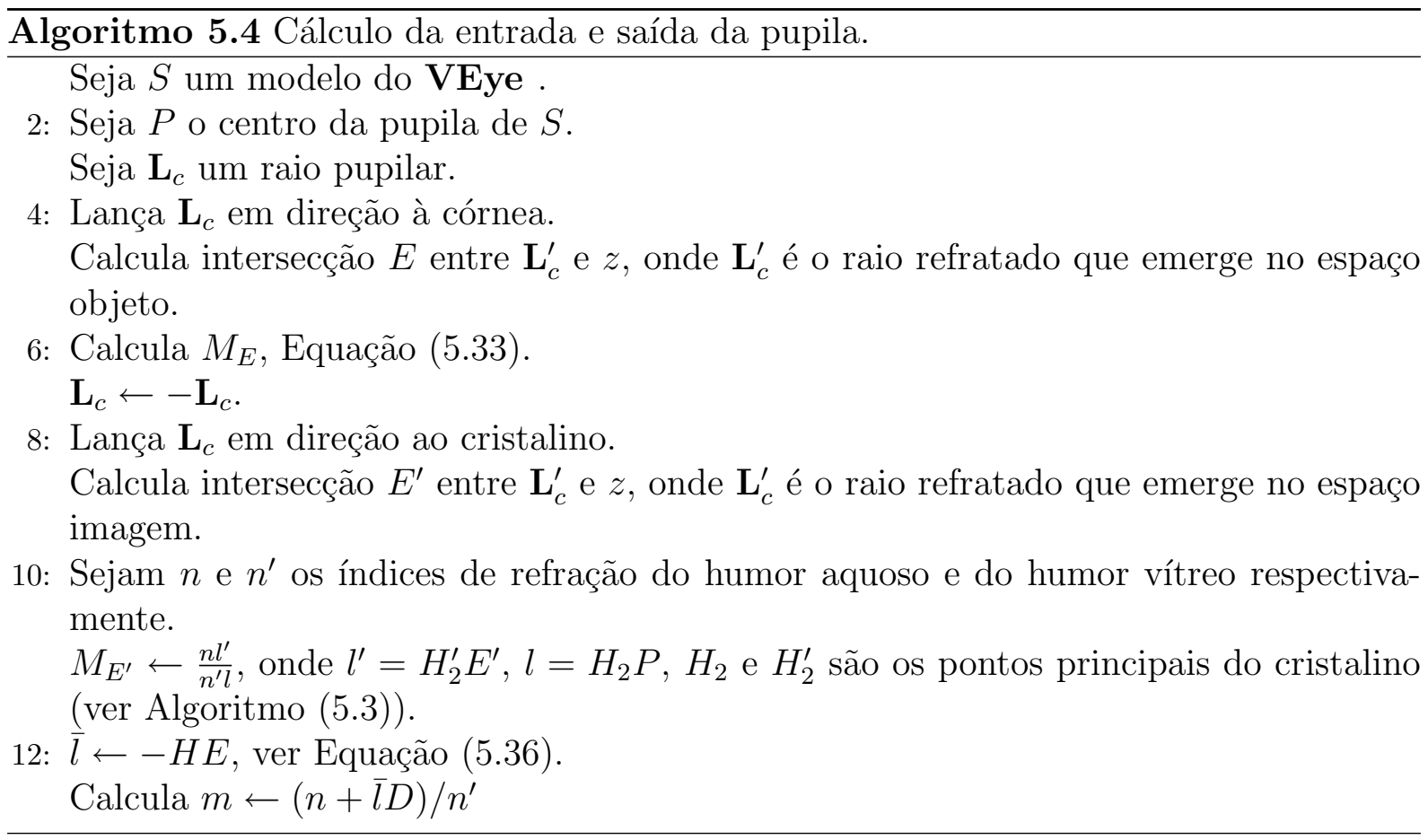

aberração correspondente de cada raio é determinada de duas maneiras diferentes. A primeira delas chamada de aberrção esférica longitudinal $L S A$ (do inglês longitudinal spherical aberration) e a segunda delas de aberração esférica transversal TSA (transverse spherical aberration).

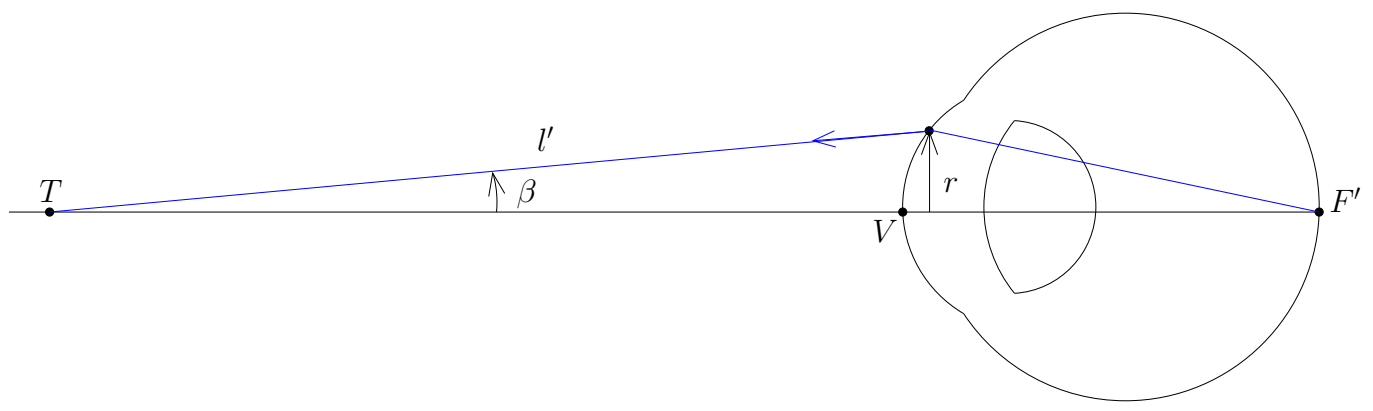

Figura 5.13: Aberração esférica longitudinal e transversal correspondente ao raio $l$.

A $L S A$ é computada com o traçado de raios realísticos. O raios de luz $l$ intercepta a superfície anterior da córnea a altura $r$ do eixo ótico. A intersecção de $l$ com o eixo ótico determina a $L S A$ avaliada em $r$, ver Figura (5.13).

$$
L S A(r)=1 / d(r)
$$


Onde $d(r)$ é a distância $d(r)=V T$. A Equação (5.40) é a expansão da $L S A$ em potências pares de $r$.

$$
L S A(r)=b r^{2}+c r^{4}+d r^{6}+e r^{8}+f r^{10}
$$

O coeficiente $b$ é utilizado para estimar o coeficiente de Seidel ${ }_{0} C_{40}$ da Equação (2.21), ver Seção (2.1.5).

$$
{ }_{0} C_{40}=\frac{b}{4}
$$

A TSA é computada através do ângulo $\beta$ (ver Figura (5.13)) e é dada por.

$$
T S A(r)=\beta(r)
$$

\subsection{Simulação de frente de onda}

A simulação de frente de onda e o estudo de aberração no VEye foi feita no espaço objeto do olho humano como nos aparelhos modernos de frente de onda (scanners wavefront )(13). A Figura (5.14) ilustra a simulação. A frente de onda $W$ emerge do olho carregando as aberrações presentes no modelo do VEye . Com os algoritmos descritos na Seção (5.2.2) de traçado de raios determinamos uma amostragem $\Omega=\left\{P_{1}, P_{2}, \ldots, P_{n}\right\}$ da frente de onda $W$, onde $P_{k}=\left(x_{k}, y_{k}, z_{k}\right)$ são os pontos da amostragem.

Devido à configuração do sistema ${ }^{2}$, a frente de onda $W$ perfaz a função aberração de onda definida na Seção (2.2.2). O Algoritmo (5.5) é mostrado abaixo.

Seja $x$ e $y$ coordenadas cartesianas da saída da pupila. A amostragem $\Omega$ é expandido em polinômios de Zernike expressando $W=W(x, y)$ dado pela Equação (5.44).

$$
W(x, y)=\sum_{j=0}^{n_{z}} c_{j} Z_{j}(x / R, y / R)
$$

Onde $R$ é o raio da saída da pupila e $\left(n_{z}+1\right)$ é o número de polinômios de Zernike utilizado.

\footnotetext{
${ }^{2} \mathrm{O}$ sistema está no estado não-acomodado.
} 


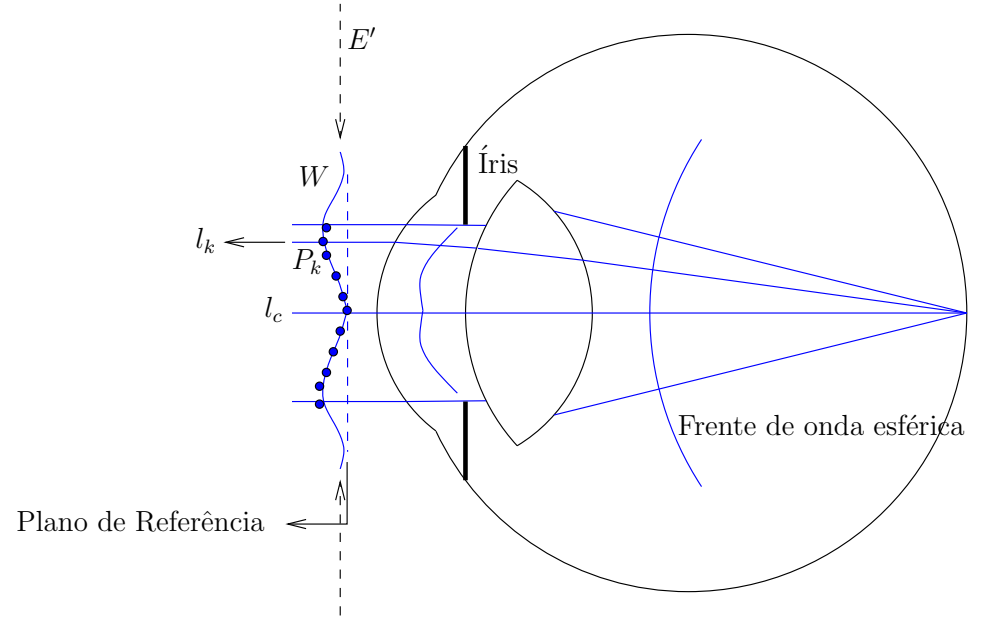

Figura 5.14: Simulação frente de onda: Uma frente de onda perfeitamente esférica deixa a retina dos modelos do VEye e propaga em direção ao ar. $W$ é a frente de onda que emerge no espaço objeto. O raio marginal $l_{k}$ lançado do fundo do olho produz o ponto $P_{k} \in \Omega$ onde $\Omega$ é uma amostragem de $W$. Na figura também o raio pupilar $l_{c}$, plano de referência e saída da pupila $E^{\prime}$ artificial.

Os coeficientes $c_{j} s$ são obtidos através do método dos mínimos quadráticos (9). E são dados pela solução do sistema abaixo.

$$
\mathrm{ZC}=\Omega
$$

Onde $\mathbf{Z}$ é a matriz:

$$
\mathbf{Z}=\left(\begin{array}{ccccc}
Z_{0}\left(\bar{x}_{0}, \bar{y}_{0}\right) & Z_{1}\left(\bar{x}_{0}, \bar{y}_{0}\right) & Z_{2}\left(\bar{x}_{0}, \bar{y}_{0}\right) & \ldots & Z_{n_{z}}\left(\bar{x}_{0}, \bar{y}_{0}\right) \\
Z_{0}\left(\bar{x}_{1}, \bar{y}_{1}\right) & Z_{1}\left(\bar{x}_{1}, \bar{y}_{1}\right) & Z_{2}\left(\bar{x}_{1}, \bar{y}_{1}\right) & \ldots & Z_{n_{z}}\left(\bar{x}_{1}, \bar{y}_{1}\right) \\
Z_{0}\left(\bar{x}_{2}, \bar{y}_{2}\right) & Z_{1}\left(\bar{x}_{2}, \bar{y}_{2}\right) & Z_{2}\left(\bar{x}_{2}, \bar{y}_{2}\right) & \ldots & Z_{n_{z}}\left(\bar{x}_{2}, \bar{y}_{2}\right) \\
\vdots & \vdots & \vdots & & \vdots \\
Z_{0}\left(\bar{x}_{n}, \bar{y}_{n}\right) & Z_{1}\left(\bar{x}_{n}, \bar{y}_{n}\right) & Z_{2}\left(\bar{x}_{n}, \bar{y}_{n}\right) & \ldots & Z_{n_{z}}\left(\bar{x}_{n}, \bar{y}_{n}\right)
\end{array}\right)
$$

$\bar{x}_{k}$ e $\bar{y}_{k}$ são:

$$
\bar{x}_{k}=\frac{x_{k}}{R} \quad \bar{y}_{k}=\frac{y_{k}}{R}
$$

$\mathrm{C}$ e $\Omega$ são: 


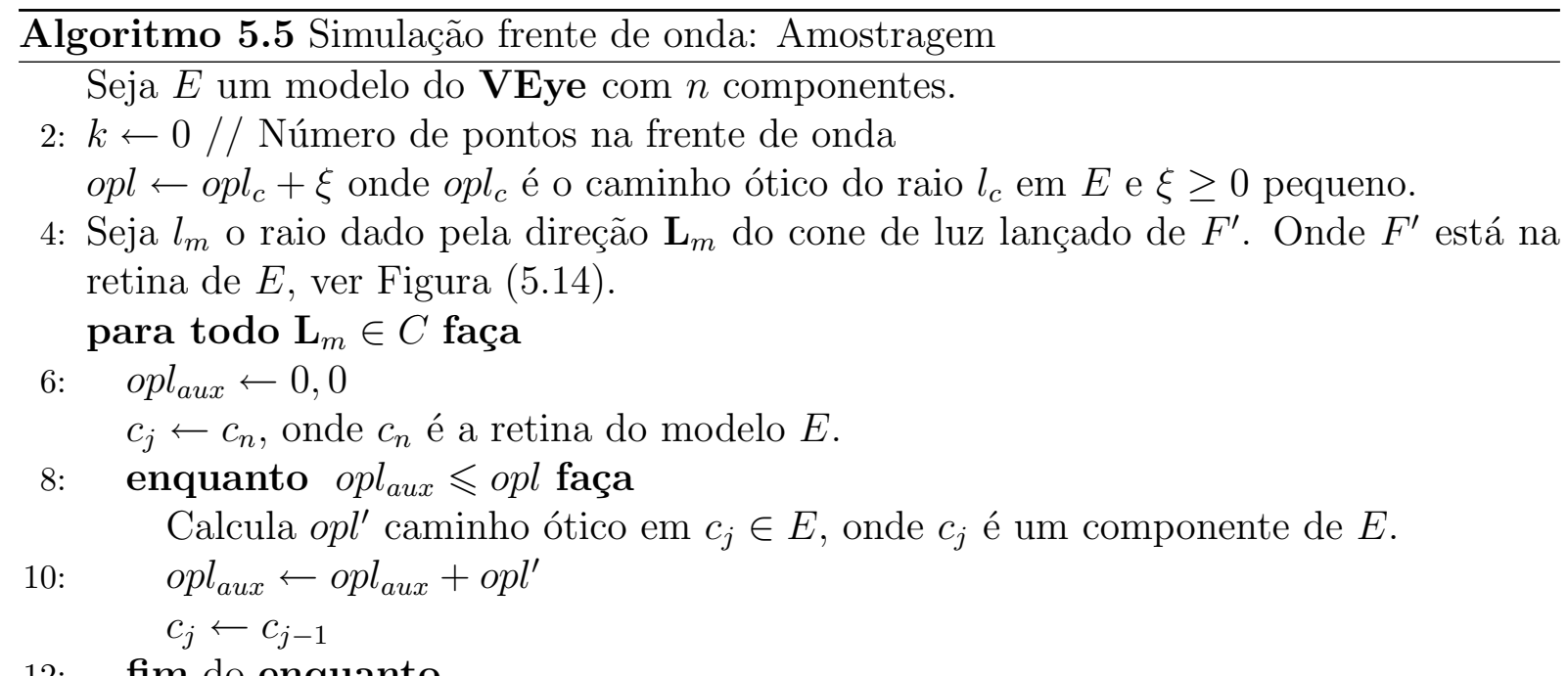

12: $\quad$ fim do enquanto

Adiciona $P_{k}$ em $\Omega$. Onde $P_{k}$ é o ponto que satisfaz a Equação (5.43) e $\Omega$ é a amostragem de $W$.

$$
o p l=\int_{F^{\prime}}^{P_{k}} n(s) \mathrm{d} s
$$

14: $\quad k \leftarrow k+1$

fim do para

16: retorna $\Omega$

$$
\mathbf{C}=\left(\begin{array}{c}
c_{0} \\
c_{1} \\
c_{2} \\
\vdots \\
c_{n_{z}}
\end{array}\right) \quad \Omega=\left(\begin{array}{c}
z_{0} \\
z_{1} \\
z_{2} \\
\vdots \\
z_{n}
\end{array}\right)
$$

$Z_{i}\left(\bar{x}_{k}, \bar{y}_{k}\right)$ é o $i$-ésimo polinômio de Zernike descrito na Seção (2.2.3) e a tripla $\left(x_{k}, y_{k}, z_{k}\right)$ são obtidos de $\Omega$.

\subsection{Projeção de cones}

Com o traçado de raios realísticos da Seção (5.2.2), os modelos empregados no VEye formam imagens em suas retinas. Para tal, utilizamos imagens $I$, como objeto alvo do VEye e projetamos cones de luz de cada pixel da imagem $I$. O resultado é a nuvem de pontos $W^{\prime}$ na superfície $S \subset \mathbb{R}^{3}$ que representa a retina. A simulação é dividida em duas etapas. A primeira etapa constrói-se $W^{\prime}$ e na segunda a imagem final $I^{\prime}$ é formada. 


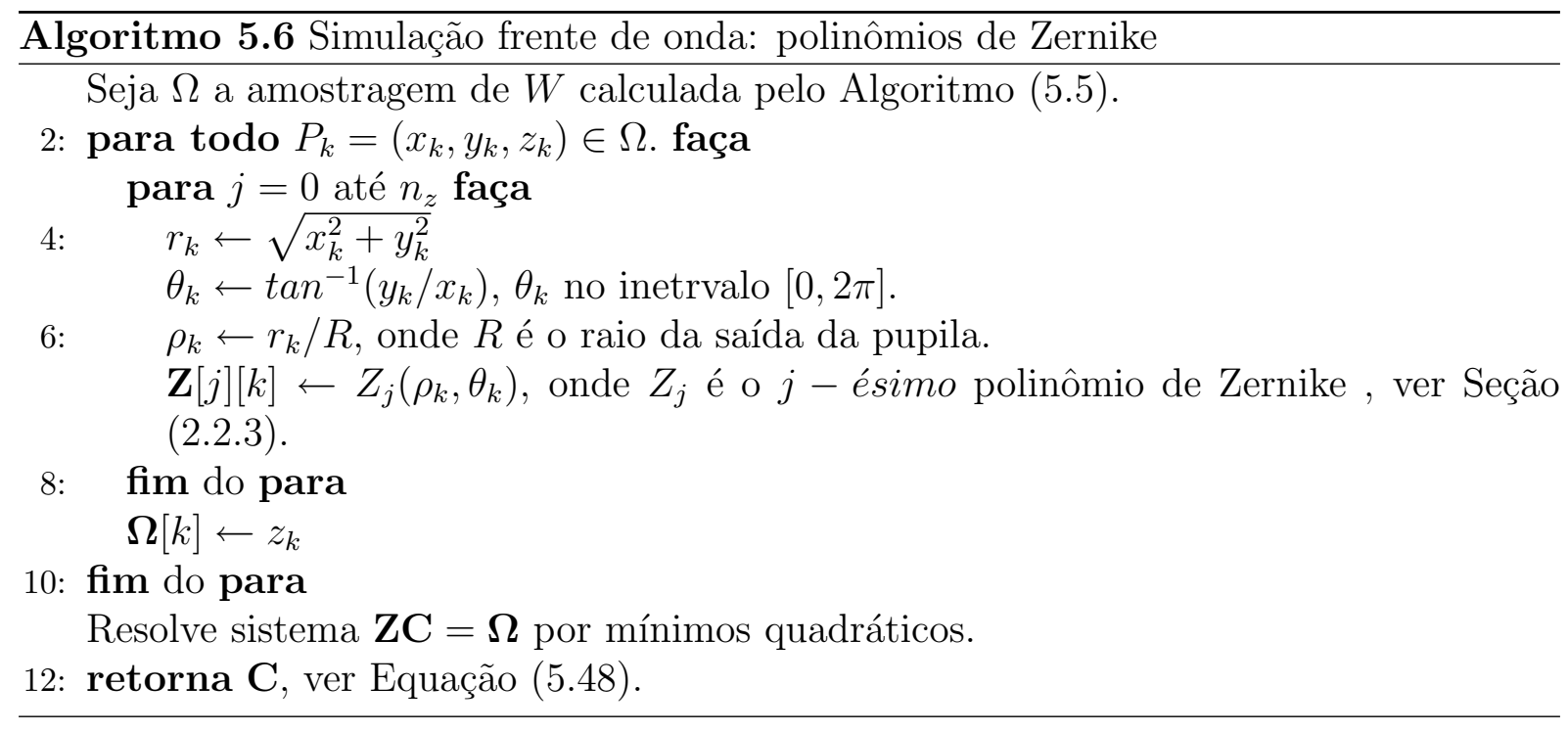

Na primeira etapa os pixels em $I$ são convertidos em coordenadas do mundo através da Equação (5.49) gerando o conjunto $W=\left\{P: P=\left(x, y, z_{0} ;\right.\right.$ cor $\left.)\right\}$.

$$
\begin{aligned}
& x=x_{0}+i \Delta x \\
& y=y_{0}+j \Delta y \\
& \text { cor }=I[i, j]
\end{aligned}
$$

Com $i=0,1,2, \ldots, r_{x}-1$ e $j=0,1,2, \ldots, r_{y}-1$. Onde $z_{0}$ é a posição no eixo ótico do plano objeto, $x_{0}$ e $y_{0}$ são a posição da imagem no plano objeto, $r_{x}$ e $r_{y}$ são as resoluções de $I$ nas respectivas direções e $\Delta x$ e $\Delta y$ são:

$$
\begin{aligned}
& \Delta x=\frac{h}{r_{x}} \\
& \Delta y=\frac{h}{r_{y}}
\end{aligned}
$$

Onde $h$ é a altura e largura que $I$ ocupa no espaço objeto, ver Figura (5.15(a)).

A segunda etapa é um modelo muito simples das células fotorreceptoras na retina ${ }^{3}$. Esta etapa é descrita a seguir.

Seja o conjunto dos pontos $\Omega^{\prime}=\left\{P^{\prime}: P^{\prime}=\left(x^{\prime}, y^{\prime}, z^{\prime} ;\right.\right.$ cor $\left.) \mid\left(x^{\prime}, y^{\prime}, z^{\prime}\right) \in S\right\}$. No primeiro passo cada ponto $P^{\prime}$ é transformado em um sistema de coordenadas inteiras II dado pelo conjunto $\tilde{\Omega}=\left\{\tilde{P}: \tilde{P}=\left(i^{\prime}, j^{\prime} ;\right.\right.$ cor $\left.)\right\}$ onde $\left(i^{\prime}, j^{\prime}\right) \in \mathbb{I}$ são dado pela transformação Equação (5.51).

\footnotetext{
${ }^{3}$ Adicionado aos modelos do VEye pelo autor, pois nenhum modelo esquemático propõe modelo de células fotorrecptoras da retina.
} 


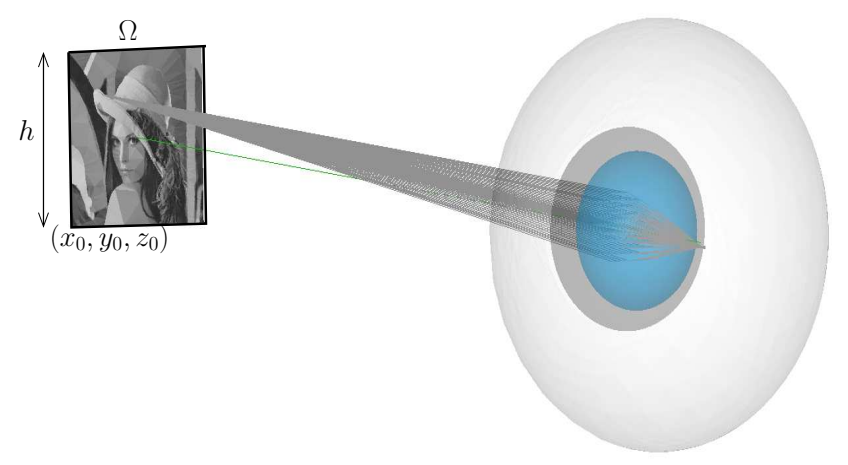

(a)

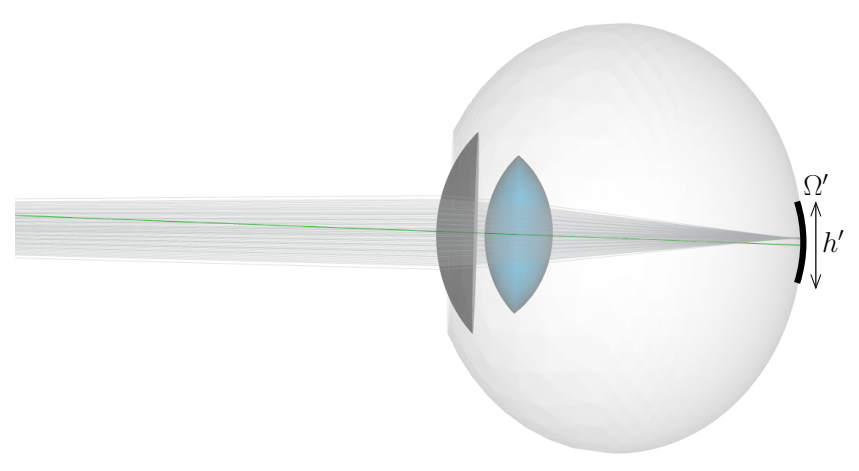

(b)

Figura 5.15: Simulação projeção de cones: Cone de luz $C$ lançado do pixel $I[i, j]$ da imagem $I$ adentra o VEye . a) Vista completa em profundidade e o conjunto $\Omega$ e b) vista lateral exibindo a nuvem de pontos $\Omega^{\prime}$. Eixo ótico em verde.

$$
\begin{aligned}
& i^{\prime}=\text { round }\left[\frac{\left(h^{\prime}-y^{\prime}\right)}{h^{\prime}}\right]\left(r_{y}^{\prime}-1\right) \\
& j^{\prime}=\operatorname{round}\left[\frac{\left(h^{\prime}+x^{\prime}\right)}{h^{\prime}}\right]\left(r_{x}^{\prime}-1\right) \\
& \text { cor }=\text { cor }
\end{aligned}
$$

Onde $h^{\prime}$ é a largura e a altura da imagem em $S$ ajustado apropriadamente para comportar $\Omega^{\prime}, r_{x}^{\prime}$ e $r_{y}^{\prime}$ são as resoluções de $I^{\prime}$ nas respectivas direções e round é a função de arredondamento ${ }^{4}$. Construímos a imagem $I_{\text {aux }}$ onde os elementos de $I_{\text {aux }}$ são $I_{a u x}[l, m]=\delta_{i^{\prime} l} \delta_{j^{\prime} m} \operatorname{cor}, l=0,1, \ldots, r_{x}^{\prime}-1$ e $m=0,1, \ldots, r_{y}^{\prime}-1$ onde $\delta_{i^{\prime} l} \delta_{j^{\prime} m}$ são

\footnotetext{
${ }^{4}$ round $(3,25)=3$
} 


\section{Olho Virtual}

deltas de Kronecker.

No segundo passo convoluimos $I_{a u x}$ com a gaussiana $G_{\sigma}$ Equação (5.53) e acumulamos os valores em $I^{\prime}$.

$$
I^{\prime}=I^{\prime}+I_{a u x} \otimes G_{\sigma}
$$

onde $\otimes$ denota convolução e $G_{\sigma}$ é:

$$
G_{\sigma}\left(i^{\prime}, j^{\prime}\right)=\exp \left[-\frac{1}{2}\left(\frac{i^{\prime 2}+j^{\prime 2}}{\sigma^{2}}\right)\right]
$$

E $\sigma$ é o desvio padrão da gaussiana. O Algoritmo (5.7) descreve o procedimento todo.

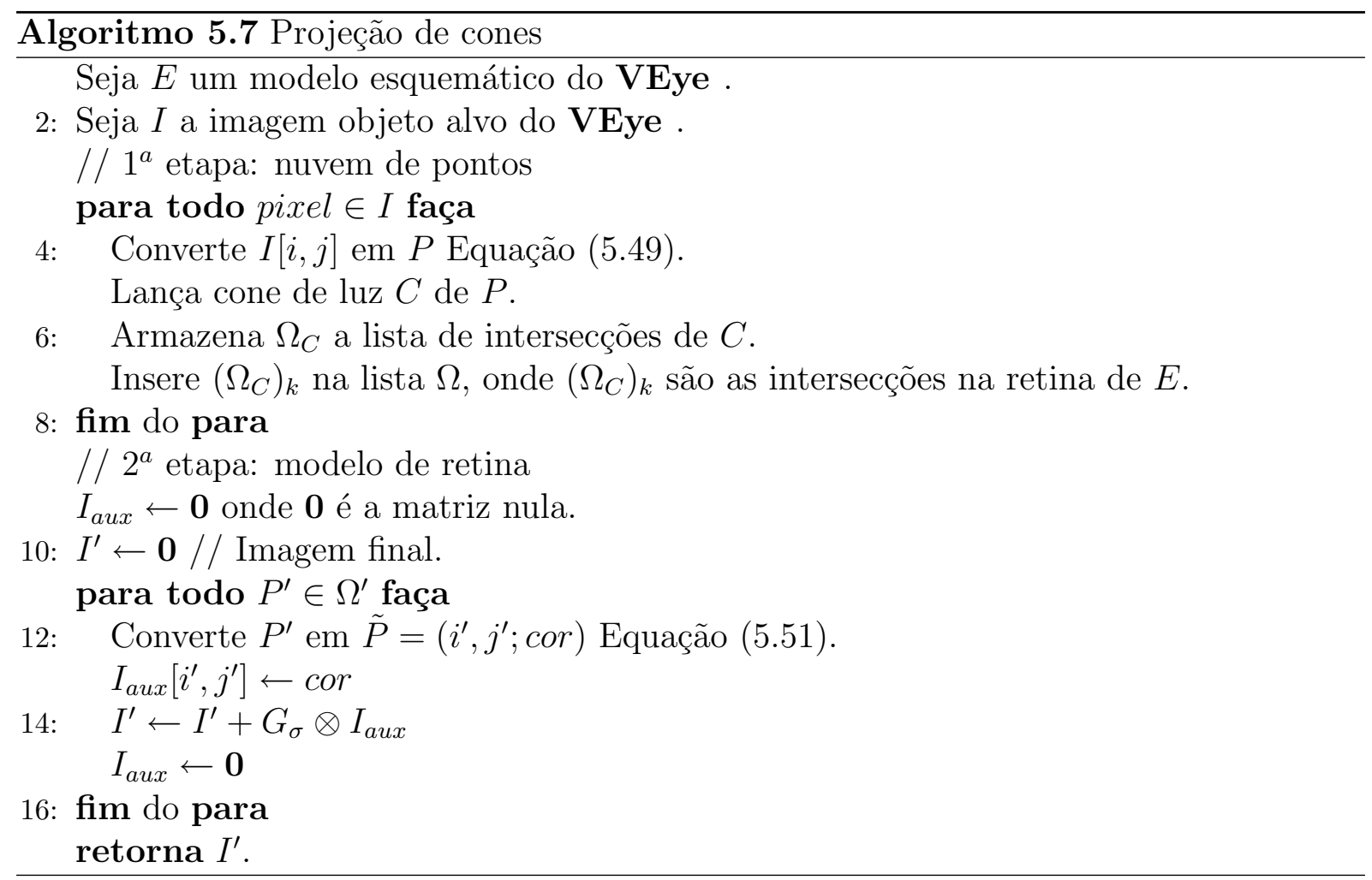




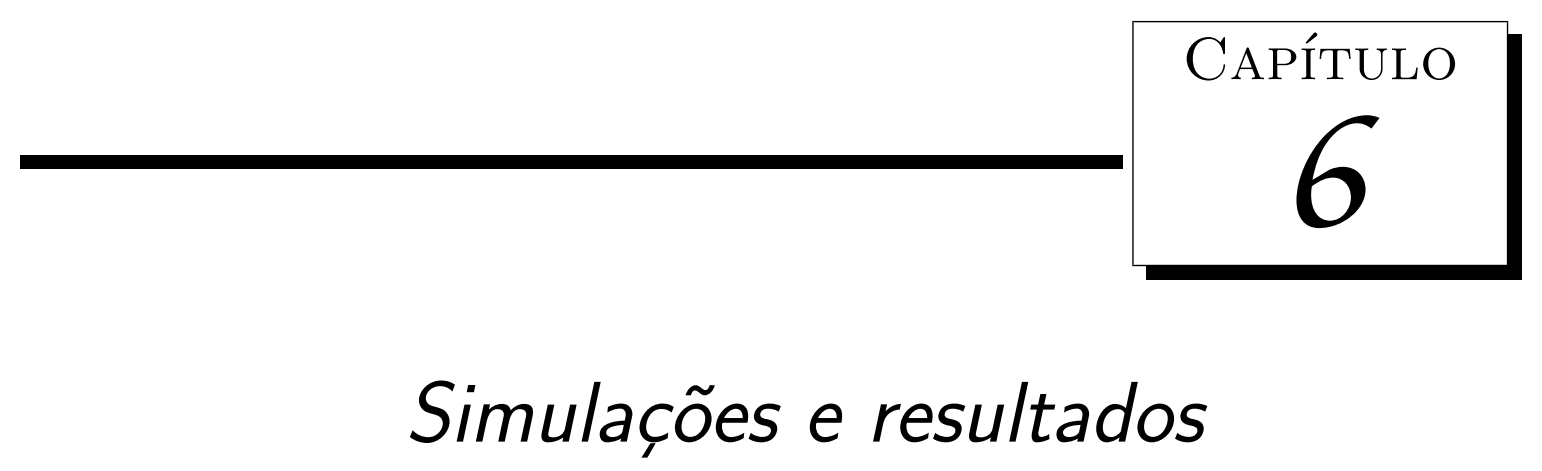

Neste capítulo apresentamos alguns resultados do VEye . O cálculo das propriedades gaussianas dos modelos empregados é um guia útil e ressalta a veracidade do arcabouço VEye ao confrontar seus resultados com os da literatura (16). Na Seção (6.2) mostramos a acomodação feita no VEye pelo modelo proposto por Navarro (22). Na Seção (6.3) calculamos a aberração esférica do ponto de vista da ótica geométrica, novamente estes resultados ajudam-nos a validar o arcabouço ao compará-los com a literatura, ver (16),(2) e (7). Depois, Seção (6.4), fazemos um estudo de aberração segundo a ótica ondulatória inclusive usando dados in-vivo . Na Seção (6.5) mostramos os resultados da simulação projeção de cones da Seção (5.8). Nesta seção os resultados tem um caráter mais qualitativo. Na Seção (6.6) fazemos uma breve introdução sobre diagrama de pontos e sua importância na análise de sistemas óticos em geral. E finalmente na Seção (6.7) fazemos uma análise de erro comparando o traçado de raio utilizando o Algoritmo (5.2.1.2) e utilizando Algoritmo (5.2.1.1).

Não utilizamos o modelo de Emsley pois este modelo é muito simples e não reflete a anatomia do olho humano sendo sua finalidade apenas educacional. Os demais modelos são utilizados, porém optamos por dar maior atenção aos modelos de Le Grand e LiouBrennan. O primeiro por ser uns dos modelos mais populares e o segundo por ser o modelo 


\section{Simulações e resultados}

baseado em dados in-vivo que melhor reflete a aberração esférica do olho humano. Neste modelo de Liou-Brennan o passo $\Delta t$ utilizado no traçado de raio no meio inomogêneo do cristalino de Liou-Brennan é $\Delta t=0,001 \mathrm{~mm}$, ver Seção (5.2.2.3).

Neste capítulo utilizamos um conjunto de siglas para especificar cada modelo, como em $n a v_{5,0}$ significa o modelo proposto por Navarro no estado de acomodação $A=5,0 D$ e $l g r_{u}$ o modelo de Le Grand no estado não-acomodado, ver Tabela (A.2).

\subsection{Propriedades gaussianas}

Para validar e verificar a acuracia dos algoritmos do módulo de modelagem e de traçado paraxial do VEye calculamos as propriedades gaussianas dos modelos: Le Grand (lgr ), Gullstrand-LeGrand (gul ), Lotmar (lot), Kooijman (koo ), Navarro (nav ) e LiouBrennan (lbr ) (16). Os métodos utilizados são descritos na Seção (5.5).

A Tabela $(6.1)^{1}$ exibe as propriedades gaussianas do modelo paraxial de Le Grand $(l g r)$ e de Gullstrand-LeGrand (gul ) nos estados não-acomodado $\left(l_{g} r_{u}\right.$ e $\left.g u l_{u}\right)$ e acomodado $\left(\lg _{a}\right.$ e $\left.g u l_{a}\right)$ respectivamente. Note que a dioptria do modelo $l g r_{u}$ é de $D=59,941 D$, valor levemente inferior ao valor médio mais aceito $\langle D\rangle=60,00 D$ para adultos (ver (2)). A Tabela (A.3) Apêndice (A.4) explica os símbolos utilizados. Nas tabelas dessa seção distâncias estão em $m m$ e dioptria $D$ e acomodação $A$ estão em $D$.

O modelo de gul é uma simplificação do modelo de Gullstrand feita por Le Grand (ver Apêndice (B)) (33). O modelo também apresenta dioptria menor que o valor médio aceito para o olho humano. Olhando a Tabela (6.1) vemos que a amplitude de acomodação $A_{m}$ de $g u l$ é maior do que de $l g r$. O valor de amplitude de acomodação médio $<A_{m}>$ pode ser estimado com base nos valores médios de refração ocular e proximidade do ponto próximo do olho humano (ver (6)). Calculamos $<A_{m}>$ pela Equação (4.2) e encontramos $<A_{m}>=6,67 D$. Valor próximo ao valor do modelo $l g r$.

A Tabela (6.2) mostra as propriedades dos modelos esquemáticos finitos de lot ,koo e $l b r$. Os dois primeiros modelos são baseados no modelo $l g r_{u}$. As superfícies destes modelos são idênticas às superfícies do modelo $l g r_{u}$ exceto pelo parâmetro $Q$ das quádricas, ver Seção (5.1.1). Por isso suas propriedades gaussianas são equivalentes. O último

\footnotetext{
${ }^{1}$ Os valores de acomodação $A$ em $D$ nas tabelas dessa seção (Seção (6.1)) são os valores nominais projetados pelos respectivos autores dos modelos esquemáticos.
} 
Tabela 6.1: Propriedades gaussianas dos modelos:lgr $r_{u}, l g r_{a}, g u l_{u}$ e $g u l_{a}$.

\begin{tabular}{lcccc}
\hline & $\operatorname{lgr}_{u}$ & $\operatorname{lgr}_{a}$ & $g u l_{u}$ & $g u l_{a}$ \\
\hline$A$ & 0,0000 & 6,9600 & 0,0000 & 10,6600 \\
$D$ & 59,9406 & 67,6764 & 58,5894 & 70,5231 \\
$V F$ & $-15,0881$ & $-12,9567$ & $-15,6979$ & $-12,4196$ \\
$V F^{\prime}$ & 24,1968 & 21,9328 & 24,4381 & 21,0690 \\
$V H$ & 1,5950 & 1,8194 & 1,3693 & 1,7592 \\
$V H^{\prime}$ & 1,9081 & 2,1919 & 1,6353 & 2,1248 \\
$V N$ & 7,2006 & 6,7842 & 7,1042 & 6,5236 \\
$V N^{\prime}$ & 7,5136 & 7,1567 & 7,3701 & 6,8892 \\
$H^{\prime} N^{\prime}=H N$ & 5,6055 & 4,9648 & 5,7348 & 4,7644 \\
$f$ & $-16,6832$ & $-14,7762$ & $-17,0672$ & $-14,1789$ \\
$f^{\prime}$ & 22,2887 & 19,7410 & 22,8028 & 18,9441 \\
$V E$ & 3,0330 & 2,6544 & 3,0417 & 2,6607 \\
$V E^{\prime}$ & 3,6826 & 3,2558 & 3,6769 & 3,2665 \\
$M_{E}$ & 1,1309 & 1,1143 & 1,1320 & 1,1147 \\
$M_{E^{\prime}}$ & 1,0408 & 1,0547 & 1,0317 & 1,0495 \\
$\bar{m}$ & 0,81302 & 0,79080 & 0,82184 & 0,79609 \\
\hline
\end{tabular}

modelo é baseado em dados in-vivo coletados da literatura e é um modelo onde o cristalino é constituído de uma lente GRIN descrita na Seção (5.2.2.3). Os cálculos das propriedades gaussianas no modelo $l b r$ são feitos lançando-se raios a uma altura $h=0.01 \mathrm{~mm}$ do eixo ótico $z$, ver Seção (5.5). O modelo apresenta dioptria $D=60,3217 D$ valor acima de $<D>$. Também calculamos o caminho ótico no eixo ótico do cristalino opl $l^{\prime}=\left[V V^{\prime}\right]$ onde $V$ e $V^{\prime}$ são os vértices do cristalino.

O caminho ótico opl $l^{\prime}=\left[V V^{\prime}\right]$ pode ser calculado através da Definição (11), isto é, no eixo ótico do cristalino temos.

$$
\begin{aligned}
& o p l^{\prime}=\int_{0}^{1,59} n_{A}(0, z) \mathrm{d} z+\int_{0}^{2,43} n_{P}(0, z) \mathrm{d} z \\
& =2,2165+3,3874 \\
& =5,6039
\end{aligned}
$$

Onde $n_{A}$ e $n_{P}$ são descritos no Apêndice (B.8). Comparando com o valor da Tabela (6.2), calculado pelo procedimento da Seção (5.2.2.3), encontramos um desvio de $\Delta o p l^{\prime}=$ 0,0040 .

A Tabela (6.3) exibe as propriedades gaussianas do modelo de Navarro em três estados de acomodação: $A=0,0 D\left(\operatorname{nav}_{0,0}\right), A=5,0 D\left(\operatorname{nav}_{5,0}\right)$ e $10,0 D\left(n a v_{10,0}\right)$. 
Tabela 6.2: Propriedades gaussianas dos modelos: lot, koo e $l b r$.

\begin{tabular}{lccc}
\hline & lot & $k o O$ & $l b r$ \\
\hline$A$ & 0,0000 & 0,0000 & 0,0000 \\
$D$ & 59,9431 & 59,9711 & 60,3217 \\
$V F$ & $-15,0870$ & $-15,0898$ & $-15,0352$ \\
$V F^{\prime}$ & 24,1959 & 24,1776 & 23,9665 \\
$V H$ & 1,5949 & 1,5843 & 1,5436 \\
$V H^{\prime}$ & 1,9081 & 1,9001 & 1,8190 \\
$V N$ & 7,2002 & 7,1870 & 7,1136 \\
$V N^{\prime}$ & 7,5134 & 7,5028 & 7,3890 \\
$H^{\prime} N^{\prime}=H N$ & 5,6053 & 5,6027 & 5,5700 \\
$f$ & $-16,6819$ & $-16,6742$ & $-16,5788$ \\
$f^{\prime}$ & 22,2878 & 22,2774 & 0,1475 \\
$V E$ & 3,0317 & 2,9838 & 3,1421 \\
$V E^{\prime}$ & 3,6830 & 3,6331 & 3,7710 \\
$M_{E}$ & 1,1304 & 1,1280 & 1,1355 \\
$M_{E^{\prime}}$ & 1,0407 & 1,0406 & 1,0353 \\
$\bar{m}$ & 0,81296 & 0,81132 & 0,82069 \\
$o p l^{\prime}$ & 5,6800 & 5,6800 & 5,6079 \\
\hline
\end{tabular}

Ao confrontar os resultados do VEye com a literatura (16), não encontramos nenhuma discrepância significativa.

\subsection{Simulação do processo de acomodação}

Nesta seção foi feito uma pequena simulação para demonstrar a acomodação no arcabouço VEye . O modelo proposto por Navarro (nav ) acomoda um objeto situado à distância de 107,0484mm do vértice da córnea. O cone de luz $C$ deixa o ponto $P=107,0484 \mathrm{~mm}$ e percorre as superfícies do modelo até chocar-se com a retina $S \subset \mathbb{R}^{3}$ do modelo. A Figura (6.1(a)) o modelo de Navarro está no estado não-acomodado $(A=0,0 D)$. Na Figura $(6 \cdot 1(\mathrm{c}))$ o modelo acomoda $C$ adequadamente $(A=10,00 D)$. Também foi calculado o círculo de confusão $\rho^{\prime}$, definido abaixo.

Definição 21 (Círculo de confusão) Seja $C$ o conjunto dos raios de luz l no cone de luz lançado do ponto $P$. Seja $\Omega^{\prime} \subset S$ o conjunto de $n$ pontos $P_{k}^{\prime}=\left(x_{k}^{\prime}, y_{k}^{\prime}, z_{k}^{\prime}\right)$ em $S$ gerado pelas intersecções de l com $S$, onde $S \subset \mathbb{R}^{3}$ é a superfície que representa a retina. O círculo de confusão ou raio geométrico $\rho^{\prime}$ é dado por: 
Tabela 6.3: Propriedades gaussianas do modelo de nav : nav $v_{0,0}$, nav ${ }_{5,0}$ e nav $_{10,0}$.

\begin{tabular}{lccc}
\hline & $n a v_{0,0}$ & nav $_{5,0}$ & nav $_{10,0}$ \\
\hline$A$ & 0,0000 & 5,0000 & 10,0000 \\
$D$ & 60,4176 & 65,8907 & 71,5031 \\
$V F$ & $-14,9674$ & $-13,3644$ & $-12,0511$ \\
$V F^{\prime}$ & 24,0035 & 22,4344 & 21,1727 \\
$V H$ & 1,5835 & 1,8118 & 2,0048 \\
$V H^{\prime}$ & 1,8908 & 2,1584 & 2,3935 \\
$V N$ & 7,1448 & 6,9110 & 6,7277 \\
$V N^{\prime}$ & 7,4520 & 7,2577 & 7,1164 \\
$H^{\prime} N^{\prime}=H N$ & 5,5613 & 5,0993 & 4,7229 \\
$f$ & $-16,5509$ & $-15,1762$ & $-14,0559$ \\
$f^{\prime}$ & 22,1128 & 20,2760 & 18,7792 \\
$V E$ & 3,0367 & 2,9506 & 2,9216 \\
$V E^{\prime}$ & 3,6830 & 3,5823 & 3,5526 \\
$M_{E}$ & 1,1320 & 1,1281 & 1,1268 \\
$M_{E^{\prime}}$ & 1,0406 & 1,0493 & 1,0575 \\
$\bar{m}$ & 0,81422 & 0,80467 & 0,79732 \\
\hline & & & \\
\hline
\end{tabular}

$$
\begin{aligned}
& \rho_{k}^{\prime 2}=x_{k}^{\prime 2}+y_{k}^{\prime 2} \\
& \rho^{\prime}=\max \left\{\rho_{k}^{\prime}\right\}
\end{aligned}
$$

Com $k=1,2,3, \ldots, n$. Onde max denota o maior valor.

A Figura (6.1(b)) ilustra o modelo de Navarro com $A=5,0 D$, situação intermediária entre a Figura (6.1(a)) e a Figura (6.1(c)).

Os círculos de confusão são: $\rho^{\prime}=0,0188 \mathrm{~mm}, \rho^{\prime}=0,1570 \mathrm{~mm}$ e $\rho^{\prime}=0,3067 \mathrm{~mm}$ para $A=0,0 D, A=5,0 D$ e $A=10,0 S$ em dioptrias respectivamente. Observamos uma diminuição gradual dos círculos de confusão $\rho^{\prime}$. Entretanto $\rho^{\prime}$ não se anula em $A=10,0 D$ devido à presença de aberração no modelo, ver as seções (6.3) e (6.4). A Figura (6.2) exibe o gráfico do círculo de confusão $\rho^{\prime}$ em função do estado de acomodação $A$ em $D$ do modelo nav . O raio da pupila utilizado é $R=2,0 \mathrm{~mm}$.

\subsection{Aberração esférica}

O procedimento descrito na Seção (5.6) foi utilizado para calcular as aberrações esféricas (aberração geométrica) dos modelos do VEye : longitudinal $L S A$ e transversal $T S A$. Na Figura (6.3) encontramos $L S A$ para os modelos do VEye . 


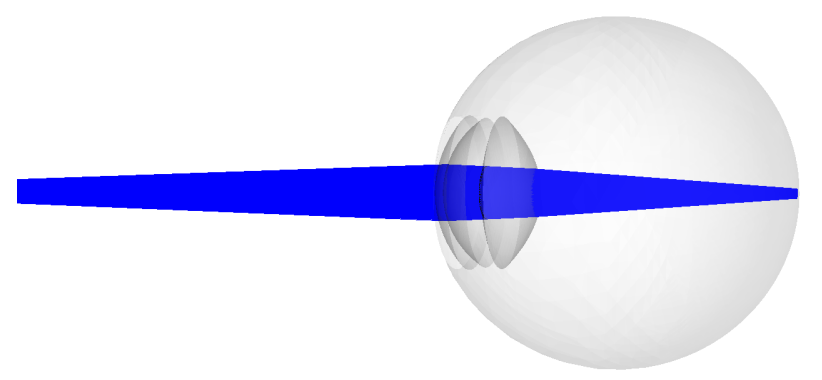

(a)

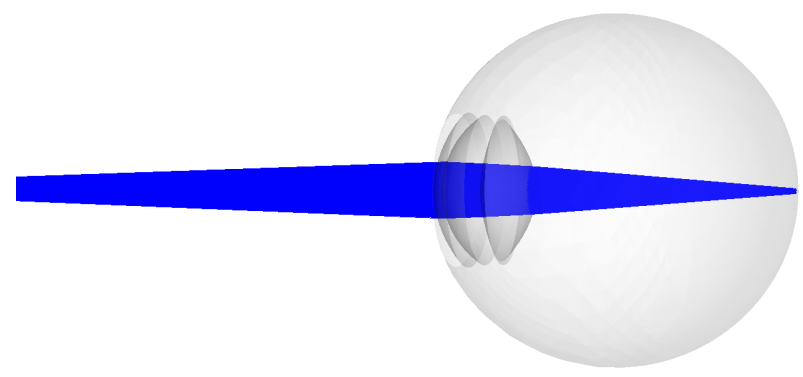

(b)

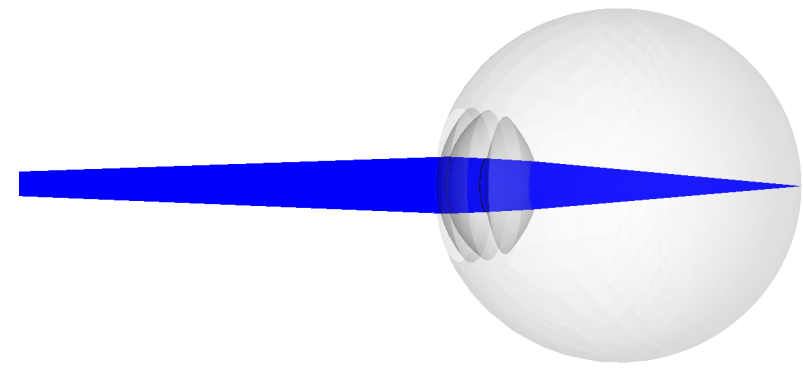

(c)

Figura 6.1: Cone de luz lançado do ponto $P=107,0484 \mathrm{~mm}$ no modelo de Navarro. a) $A=0,0 D$ e $\rho^{\prime}=0,3067 \mathrm{~mm}$ b) $A=5,0 D$ e $\rho^{\prime}=0,1569 \mathrm{~mm}$ c) $A=10,0 D$ e $\rho^{\prime}=0,0188 \mathrm{~mm}$.

A Tabela (6.4) mostra os termos da Equação (5.40) estimados por mínimos quadrados para os modelos: $l g r_{u}$, lot e $k o o$. E a Tabela (6.5) dos modelos de $n a v_{0,0}$ e $l b r$. Os termos estão em: $\mathrm{mm}^{-3}, \mathrm{~mm}^{-5}, \mathrm{~mm}^{-6}, \mathrm{~mm}^{-7}, \mathrm{~mm}^{-9} \mathrm{~mm}^{-11}$ para $b, c, d, e$ e $f$ respectivamente. Através do valor de $b$ calculamos o termo ${ }_{0} C_{40} \mathrm{em} \mathrm{mm}^{-3}$ de aberração de Seidel, ver Seção (2.1.5). Na Tabela (6.4) e Tabela (6.5) percebemos que $b$ é uma ordem de grandeza maior do que os termos restantes.

Smith (17) levantou na literatura científica os valores experimentais do coeficiente $b$ da Equação (5.40) em metodologias diferentes e construiu a Equação (6.3) que sintetiza os valores médios da $L S A(<b\rangle=0,0760 \mathrm{~mm}^{-3}$ e os outros termos são nulos). Na Figura (6.3) mostramos o gráfico da Equação (6.3) juntamente com os dados obtidos da 


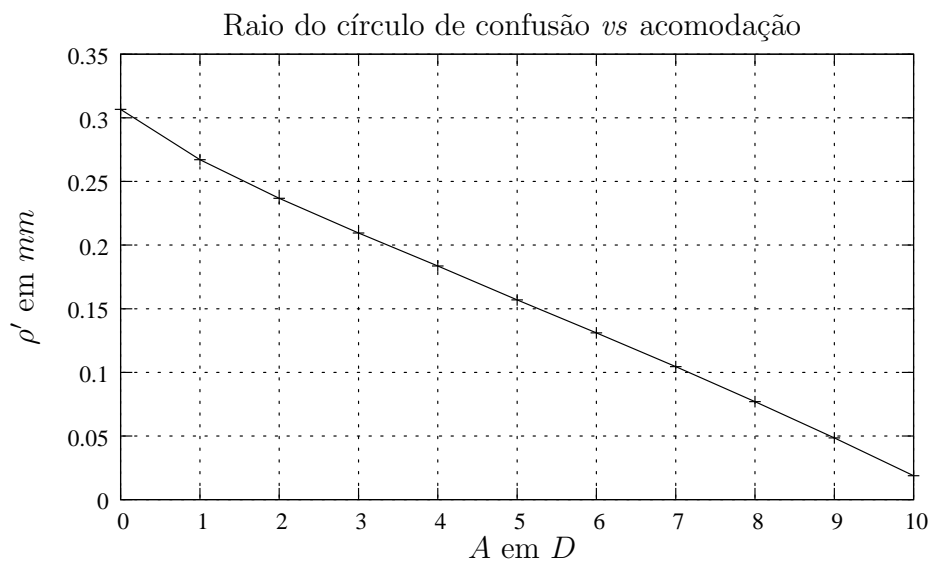

Figura 6.2: Gráfico do raio $\rho^{\prime}$ do círculo de confusão en função da acomodação $A$ no modelo nav .

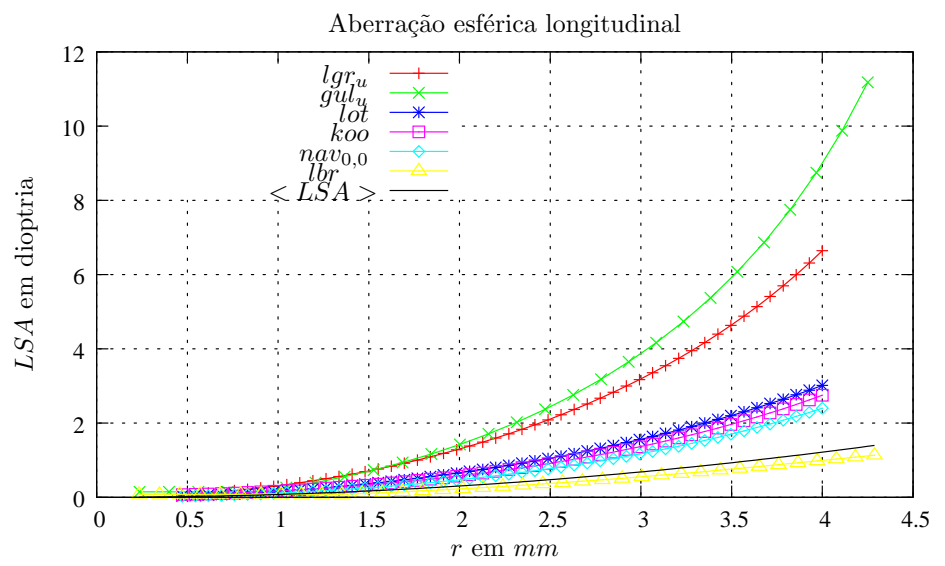

Figura 6.3: Aberração esférica longitudinal $L S A .<L S A>$ é dado pela Equação (6.3).

simulação do VEye .

$$
<L S A>(r)=0,076 r^{2}
$$

A Figura (6.4) temos a TSA para os mesmos modelos.

Observando os gráficos da Figura (6.3) e Figura (6.4), vemos que os modelos de $l g r_{u}$ e $g u l_{u}$ apesar de apresentarem propriedades gaussianas equivalentes aos modelos de lot , $k o o$ e $n a v_{0,0}$, não apresentam níveis de aberração esférica combatível com as aberrações esféricas do olho humano encontradas na literatura científicas, exceto na região gaussiana. Isto refleti ao proósito ao qual estes modelos foram projetados. O melhor modelo para estudo de aberração esférica do olho humano é o modelo lbr proposto por Liou-Brennan. 
Tabela 6.4: $L S A$ termos da Equação (5.40) para os modelos $l g r_{u}$ e lot .

\begin{tabular}{lccc}
\hline Modelo & $\operatorname{lgr}_{u}$ & lot & Kooijman \\
\hline$b$ & $3,7634 e-04$ & $2,0446 e-04$ & $2,1230 e-04$ \\
$c$ & $2,72793 e-07$ & $-4,86013 e-06$ & $-1,87934 e-05$ \\
$d$ & $1,48502 e-06$ & $1,18747 e-06$ & $3,05654 e-06$ \\
$e$ & $-8,43266 e-08$ & $-6,89383 e-08$ & $-1,73335 e-07$ \\
$f$ & $2,55445 e-09$ & $1,49352 e-09$ & $3,63149 e-09$ \\
${ }_{0} C_{40}$ & $9,40861 e-05$ & $5,1116 e-05$ & $5,30761 e-05$ \\
\hline
\end{tabular}

Tabela 6.5: $L S A$ termos da Equação (5.40) para os modelos nav $v_{0,0}$ e $l b r$.

\begin{tabular}{lcc}
\hline Modelo & nav $_{0,0}$ & $l b r$ \\
\hline$b$ & $1,4630 e-04$ & $6,95624 e-05$ \\
$c$ & $-4,85985 e-06$ & $-6,77334 e-06$ \\
$d$ & $1,26821 e-06$ & $1,23049 e-06$ \\
$e$ & $-7,43118 e-08$ & $-8,10689 e-08$ \\
$f$ & $1,60733 e-09$ & $1,79347 e-09$ \\
${ }_{0} C_{40}$ & $3,65748 e-05$ & $1,73906 e-05$ \\
\hline
\end{tabular}

\subsection{Simulação frente de onda}

Nesta seção realizamos uma análise dos modelos do VEye do ponto de vista da ótica de Fourier Seção (2.2). Na Seção (6.4.1) realizamos um experimento para validar os algoritmos da Seção (5.7). Na Seção (6.4.2) calculamos algumas frentes de onda dos modelos do VEye . Na Seção (6.4.3) mostramos os coeficientes de Zernike utilizados na Seção (6.4.2) para gerar as frentes de ondas dos modelos do VEye . Na Seção (6.4.4) computamos a função de espalhamento de ponto e função de transferência de modulação

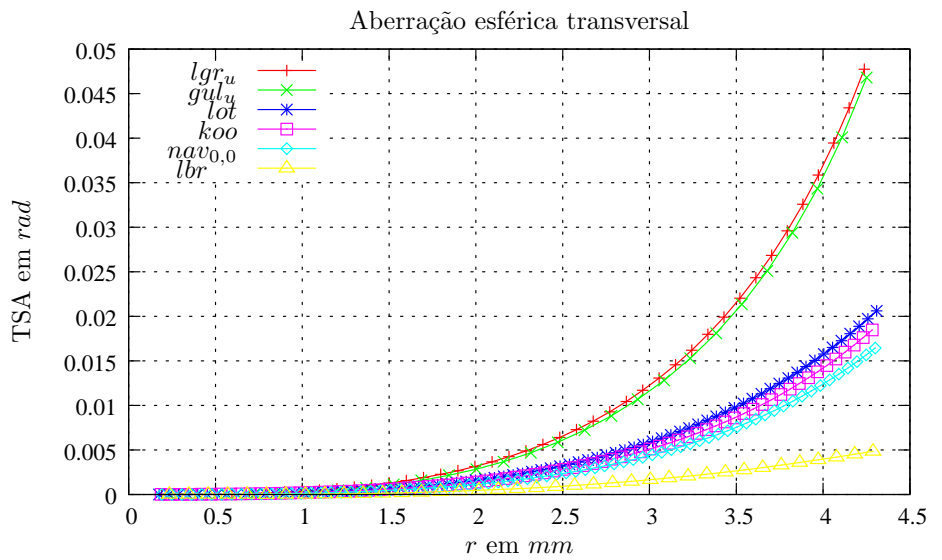

Figura 6.4: Aberração esférica transversal TSA. 


\section{Simulações e resultados}

das respectivas frentes de onda da Seção (6.4.2).

A Figura (6.5) mostra os coeficientes de Zernike do voluntário $S_{1}$ (olho direito do autor deste trabalho) extraídos de um parelho comercial de frente de onda (Wave-Scan). A Figura (5.10) é a representação em malha da córnea deste mesmo indivíduo composta a partir dos procedimento da Seção (5.1.2). Utilizamos estes dados nas simulações com dados in-vivo . O raio da pupila retornado pelo aparelho durante a medição foi $R=$ $2.85 \mathrm{~mm}$.

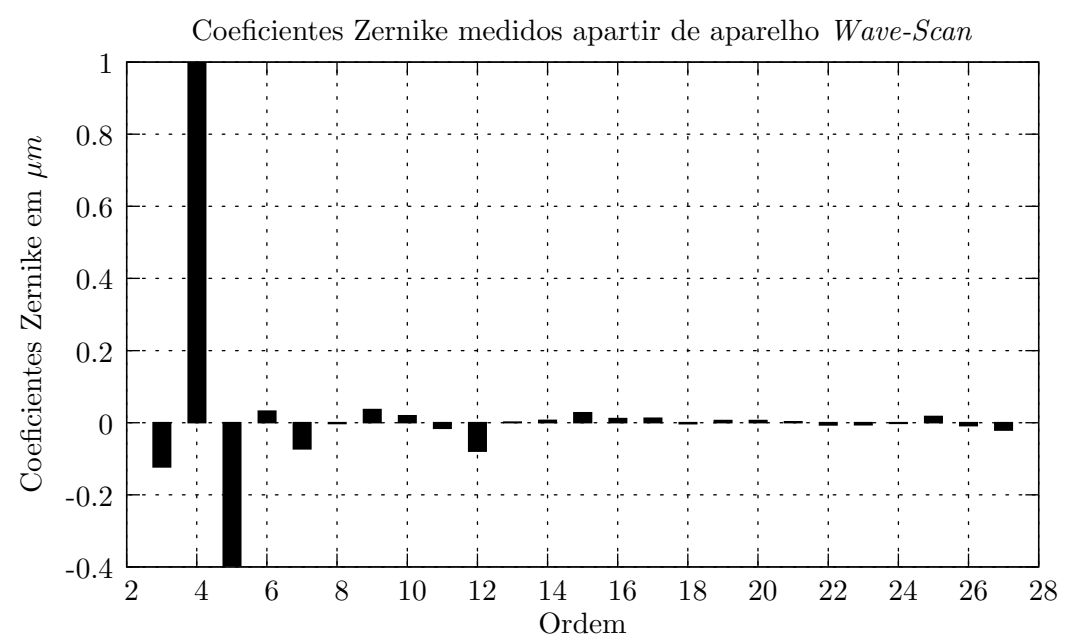

Figura 6.5: Coeficientes de Zernike extraídos de aparelho comercial de frente de onda Wave-Scan.

\subsubsection{Validação}

Com o intuito de verificar a veracidade do Algoritmo (5.5) e do Algoritmo (5.6) da simulação de frente de onda. Nós utilizamos estes algoritmos em cálculos de dioptria de lentes simples. A lente $L_{1}$, na verdade o cristalino de $l b r$, foi utilizado em nossos cômputos. Ajustamos manualmente o ponto $F^{\prime}$ que minimiza o coeficiente $c_{4}$ de Zernike (defocus) no espaço objeto da frente de onda oriunda de $F^{\prime}$ que atravessa $L_{1}$ e emerge em seu espaço objeto quase plana. Então adicionamos uma quantidade de astigmatismo conhecida ao introduzir uma lente cilíndrica $C_{\alpha}$ no plano da saída da pupila, ver Figura (6.6). Os eixos de astigmatismo são controlados rotacionando $C_{\alpha}$ em torno do eixo ótico $z$ das lentes. O ângulo $\alpha$ é o ângulo formado entre o eixo $x$ e o eixo de maior curvatura principal de $C_{\alpha}(12)$, eixo de astigmatismo. 


$$
\alpha=\frac{1}{2} \tan ^{-1}\left(-\frac{c_{3}}{c_{5}}\right)
$$

Onde $c_{3}$ e $c_{5}$ são os coeficientes de Zernike explicados na Seção (2.2.3).

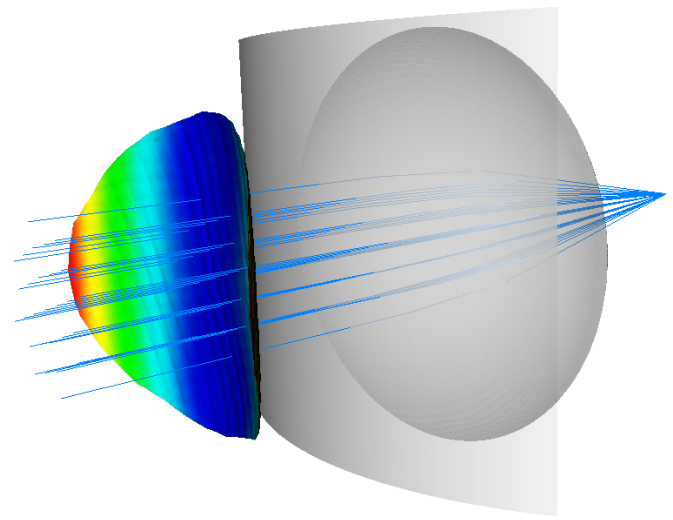

Figura 6.6: Ao fundo lente $L_{1}$, depois lente cilíndrica $C_{\alpha}$ e mais à frente a frente de onda com astigmatismo. O raio da pupila utilizado é $R=1,7 \mathrm{~mm}$ e a posição do foco de $L_{1}$ é $F^{\prime}=12,2397 \mathrm{~mm}$. A frente de onda sofreu operação de escala para propiciar melhor visualização.

A Tabela (6.6) mostra os resultados encontrados.

Tabela 6.6: Eixo astigmatismo. Em todos os casos a medida de astigmatismo foi $\phi_{A}=$ $15,5507 D$.

\begin{tabular}{lllll}
\hline anglo (graus) & $c_{3}$ & $c_{5}$ & $\alpha$ (graus) & Desv \\
\hline $0^{\circ}$ & $-0,0021$ & 4,4519 & 0,0134 & 0,0134 \\
$15^{\circ}$ & $-2,2343$ & 3,8679 & 15,0062 & 0,0062 \\
$30^{\circ}$ & $-3,8483$ & 2,2206 & 30,0067 & 0,0067 \\
$45^{\circ}$ & $-4,4274$ & $-0,0020$ & 45,0130 & 0,0130 \\
\hline
\end{tabular}

Repetimos o procedimento anterior, porém substituímos $C_{\alpha}$ pela lente $S_{D}$ e o cristalino de $l b r$ por um de $l g r_{u}$. A lente $S_{D}$ tem raio de curvatura $r_{1}=10,00 m m$ e $r_{2}=-6,00 m m$ e sua dioptria é ajustável alterando o índice de refração $n_{D}$ em seu interior. Nestas condições a dioptria esfero-cilíndrica $\phi_{D}$ de $S_{D}$ é dada pela Equação (6.5):

$$
\phi_{D}=4 \sqrt{3} \frac{c_{4}}{R^{2}}-\phi_{A}
$$




$$
\phi_{A}=4 \sqrt{6} \frac{\sqrt{\left(c_{3}^{2}+c_{5}^{2}\right)}}{R^{2}}
$$

Onde $R$ é o raio da saída da pupila. Mas a dioptria de $S_{D}$ também pode ser calculada pela Equação (6.7).

$$
D=\left(n_{D}-1\right)\left(\frac{1}{r_{1}}-\frac{1}{r_{2}}\right)-\frac{\left(n_{D}-1\right)^{2}}{n_{D}} \frac{e}{r_{1} r_{2}}
$$

Onde $e$ é a espessura da lente. Neste trabalho optamos por $e=0,4 \mathrm{~mm}$ e pelo raio da saída pupila de $R=1,70 \mathrm{~mm}$. A Tabela (6.7) exibe os resultados.

Tabela 6.7: Cálculos de dioptria. Raio da pupila $R=1.70 \mathrm{~mm}$.

\begin{tabular}{llll}
\hline$D$ & $c_{4}$ & $\phi_{D}$ & Desv \\
\hline$-2,50$ & $-1,0507$ & $-2,5197$ & 0,0197 \\
$-2,00$ & $-0,8395$ & $-2,0133$ & 0,0133 \\
$-1,50$ & $-0,6292$ & $-1,5091$ & 0,0091 \\
1,50 & 0,6193 & 1,4848 & 0,0152 \\
2,00 & 0,8268 & 1,9823 & 0,0177 \\
2,50 & 1,0344 & 2,4801 & 0,0199 \\
\hline
\end{tabular}

A discrepância Desv aumenta com o módulo da dioptria de $S_{D}$. Este mesmo comportamento foi encontrado em (29). O número de raios lançados por cone de luz bem como o número de termos de polinômios Zernike são limitantes da precisão dos resultados. Além do mais, as lentes $S_{D}$ são geradas variando-se os índices de refração em seu interior. Consequentemente os erros numéricos encontrados são amplificados pelo fator $n_{D}$.

\subsubsection{Frente de Onda}

O Algoritmo (5.5) e o Algoritmo (5.6) foram usados para construir a frente de onda que emerge dos modelo do VEye . A Figura (6.7) é a frente de onda do modelo $\operatorname{lgr}_{u}$ e a Figura (6.8) a do modelo $l b r$.

O VEye é robusto o suficiente para trabalhar com dados in-vivo . Então removemos a córnea teórica do modelo lbr e em seu lugar adicionamos a córnea construída a partir de dados in-vivo da Figura (5.10). O resultado é o modelo hibrido $l b r_{h}$. A Figura (6.9) exibe a frente de onda que emerge deste modelo onde mantivemos o ponto focal imagem 
Frente de onda

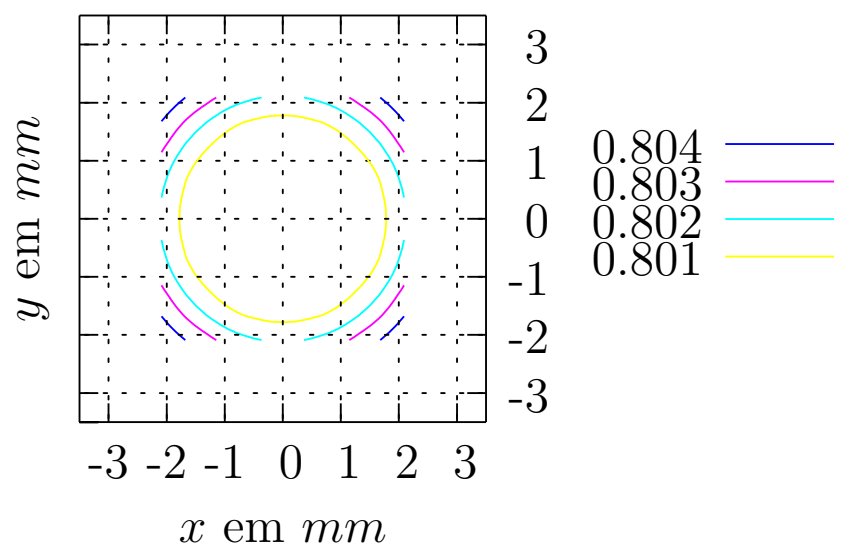

Figura 6.7: Curvas de níveis (em $\mathrm{mm}$ )da frente de onda que emerge do modelo $l g r_{u}$.

Frente de onda

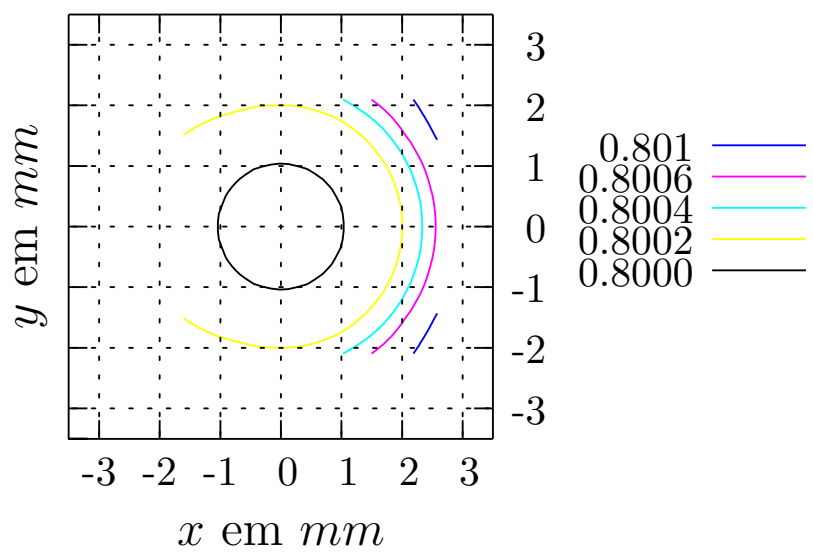

Figura 6.8: Curvas de níveis (em $m m$ )da frente de onda que emerge do modelo lbr .

de $l b r\left(V F^{\prime}=23,9665 \mathrm{~mm}\right)$. Analisando as curvas de níveis da Figura (6.9) percebemos a presença de astigmatismo em $l b r_{h}$.

\subsubsection{Coeficientes de Zernike}

Nesta seção calculamos os coeficientes de Zernike descrito na Seção (2.2.3) das frente de ondas calculadas na Seção (6.4.2) com o auxilio do Algoritmo (5.6). O valor $R M S_{\text {erro }}$ definido pela Equação (6.8) foi calculado, juntamente com o raio da saída da pupila artificial $R_{E^{\prime}}$, ver Figura (5.14).

$$
R M S_{\text {erro }}=\sqrt{\sum_{i=3}^{n_{z}} c_{i}^{2}}
$$


Frente de onda

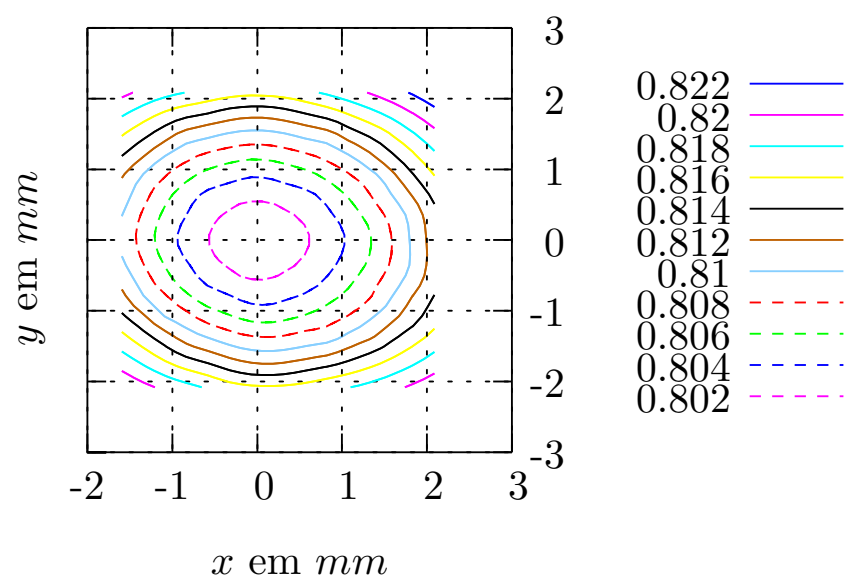

Figura 6.9: Curvas de níveis (em $\mathrm{mm}$ ) da frente de onda que emerge do modelo hibrido $l b r_{h}$.

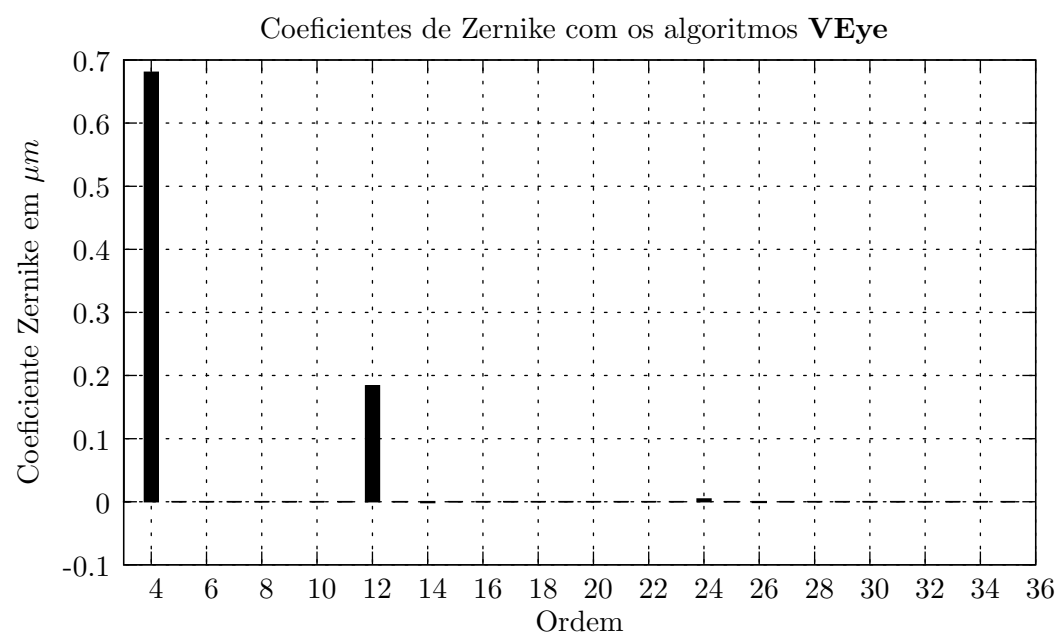

Figura 6.10: Coeficientes de Zernike da frente de onda da Figura (6.7), modelo de $l g r_{u}$. O valor $R M S_{\text {erro }}=0,7047 \mu \mathrm{m}$ e o raio da saída da pupila artificial é $R_{E^{\prime}}=2,2210 \mathrm{~mm}$.

Para o modelo $l g r_{u}$ encontramos: $R M S_{\text {erro }}=0,7047 \mu \mathrm{m}$ e $R_{E^{\prime}}=2,2210 \mathrm{~mm}$. E para $l b r: R M S_{\text {erro }}=0,2353 \mu \mathrm{m}$ e $R_{E^{\prime}}=2,7150 \mathrm{~mm}$.

A Figura (6.12) mostra os coeficientes de Zernike obtido a partir da frente de onda da Figura (6.9). O coeficiente de defocus $c_{4}=4,4813 \mu \mathrm{m}$ corresponde à $\phi_{D} \approx 6,72 D$ e foi removido da Figura (6.12) para facilitar a visualização. O valor $R M S_{\text {erro }}$ é $R M S_{\text {erro }}=$ $0,6294 \mu \mathrm{m}$ e $R_{E^{\prime}}=2,1490 \mathrm{~mm}$, onde anulamos $c_{4}$ no computo do valor $R M S_{\text {erro }}$.

Ao comparar os coeficientes de Zernike obtido do aparelho frente de onda, Figura (6.5), com os dados obtidos do VEye ,Figura (6.12), vemos que o segundo tem uma quantidade maior de defocus $c_{4}$. Os motivos pelo qual isto ocorreu são justificados pelas diferenças 


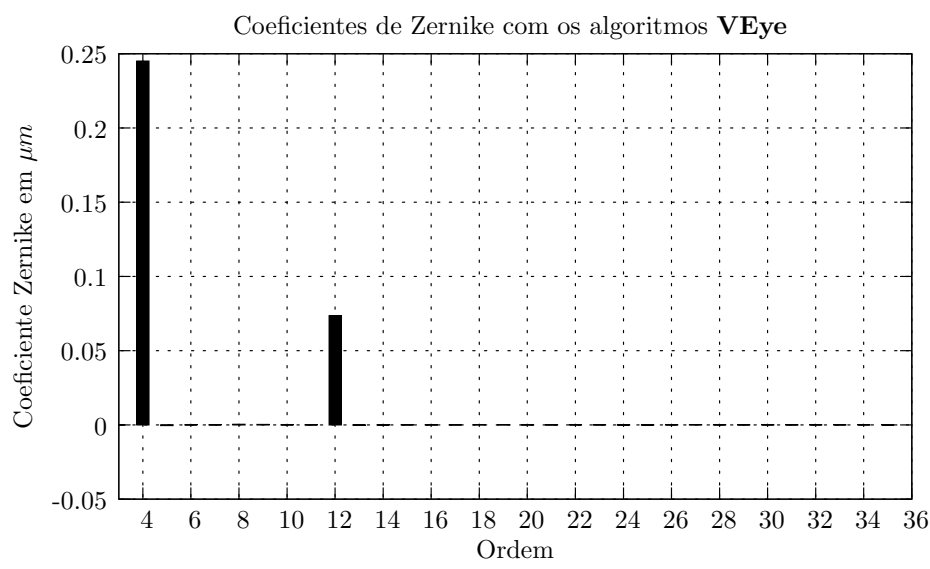

Figura 6.11: Coeficientes de Zernike da frente de onda da Figura (6.8), modelo lbr . O valor $R M S_{\text {erro }}=0,2353 \mu \mathrm{me}$ o raio da saída da pupila artificial $R_{E^{\prime}}=2,7150 \mathrm{~mm}$.

dos componentes óticos do modelo $l b r$ : cristalino, superfície posterior da córnea e o comprimento axial do modelo com os respectivos componentes óticos do olho do indivíduo $S_{1}$. Particularmente o termo de aberração esférica $c_{12}$ : $-0,07474 \mu m$ e $-0,0792 \mu m$ respectivamente calculado pelo VEye e pelo aparelho de frente de onda tiveram uma boa concordância.

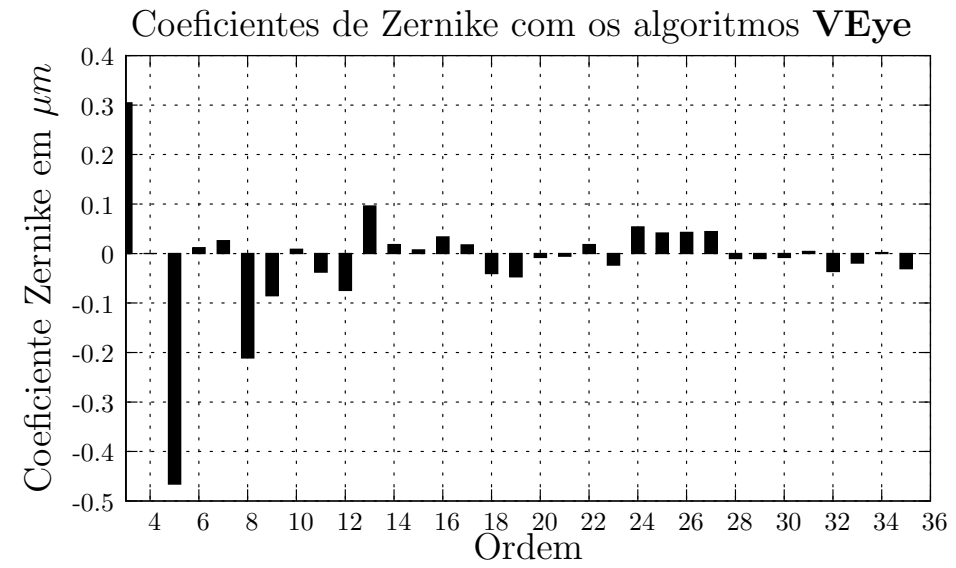

Figura 6.12: Coeficientes de Zernike da frente de onda da Figura (6.9), modelo $l b r_{h}$. O coeficiente $c_{4}=4,4813 \mu \mathrm{m}$ e removido da figura para facilitar a visualização. O valor $R M S_{\text {erro }}=0,6294 \mu \mathrm{m}$. Onde foi feito $c_{4}=0 \mu \mathrm{m}$ e o raio da saída da pupila artificial $R_{E^{\prime}}=2,1490 \mathrm{~mm}$

É sabido na literatura (2) que aberração esférica $c_{12}$ do olho humano tende a compensar a aberração esférica da córnea. O modelo $l b r$ proposto por Liou-Brennan foi construído de maneira a refletir esta propriedade do cristalino humano. O gráfico da Figura (6.13) mostra os coeficientes de Zernike do cristalino e do olho todo do modelo $l b r$. A aberração 


\section{Simulações e resultados}

do cristalino foi calculada como na Seção (5.7) mas a frente de onda foi propagada somente até a região entre o cristalino e a córnea (segmento anterior). Novamente o coeficiente $c_{4}$ foi anulado para proporcionar melhor visualização.

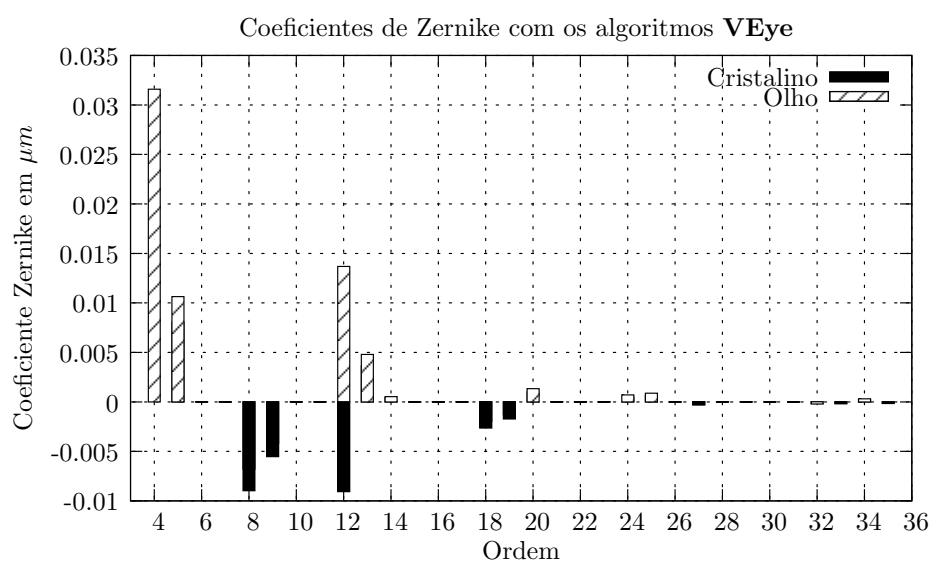

Figura 6.13: Coeficientes de Zernike do modelo $l b r$ e cristalino de $l b r$. O raio da pupila foi $R=1,0 \mathrm{~mm}$. O coeficiente $c_{4}$ foi eliminado da figura novamente para melhorar a visualização.

Analogamente à Seção (6.3) alteramos os valores do raio da pupila do modelo e construímos o gráfico da Figura (6.14).

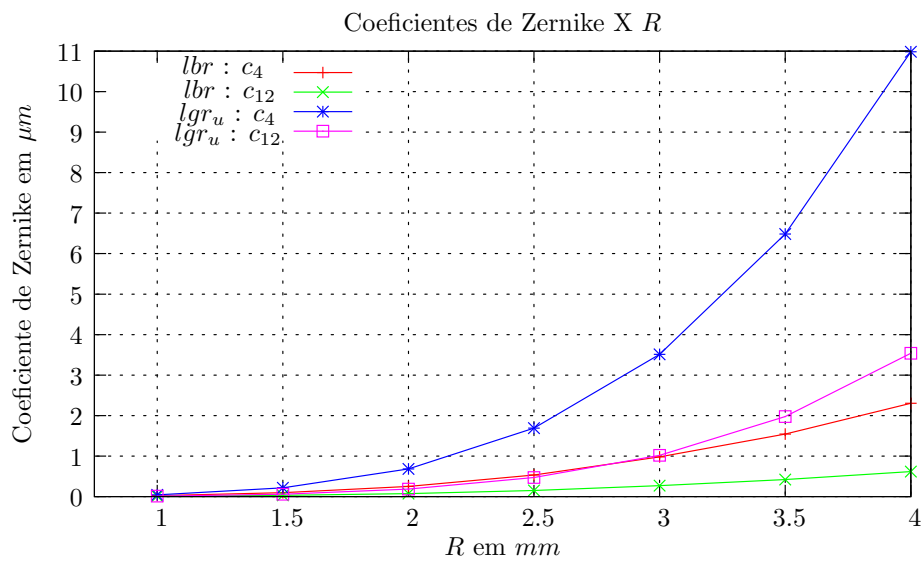

Figura 6.14: Coeficientes defocus $c_{4}$ e esférico $c_{12}$ em função do raio da pupila $R$ dos modelos: $l g r_{u}$ e $l b r$.

Novamente percebemos o mesmo comportamento. As aberrações crescem com o raio da pupila $R$. Note que o crescimento no modelo $l g r_{u}$ é maior do que no modelo $l b r$. 


\subsubsection{Função de espalhamento de pontos e função de trasferência de modulação}

A eficiência com que as células fotorrecptoras na fóvea respondem aos estímulos luminosos oriundo da saída da pupila depende da posição entrante. Este fenômeno importante é conhecido como efeito Stiles-Crawford Equação (6.9) e tem origem nas redes neurais da retina do olho humano, mas é incluído nos modelos esquemáticos através de uma modificação da função generalizada de pupila, ver (16) e (2).

$$
A(r)=\exp \left(-\beta r^{2}\right)
$$

Nós introduzimos o efeito Stiles-Crawford no modelo $l b r$ através da modificação da função generalizada de pupila com $\beta=0,0576$.

$$
P(x, y)=\exp \left(-\beta\left(x^{2}+y^{2}\right)\right) \exp \left(-i \frac{2 \pi}{\lambda} W(x, y)\right)
$$

As função de espalhamento de ponto $P S F$ Equação (2.38) e a função de transferência de modulação MTF Equação (2.41) são calculadas a partir da frente de onda do modelo $l b r$ da Seção (6.4.2). Nesta seção fixamos o raio da pupila em $R=2,00 \mathrm{~mm}$. A Figura (6.15(a)) mostra as curvas de níveis da $P S F$ de $l b r$.

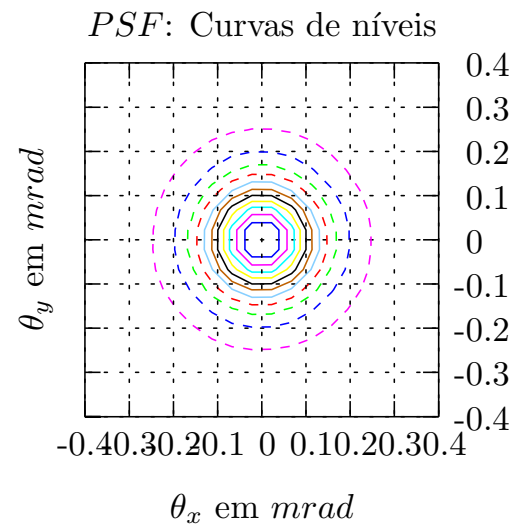

(a)

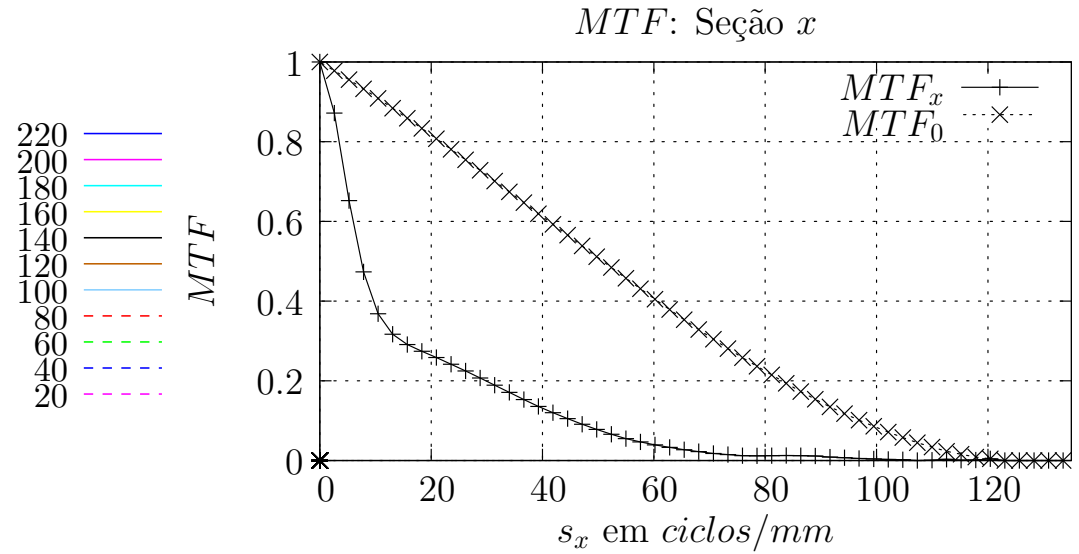

(b)

Figura 6.15: Modelo $l b r$ : a) Curvas de níveis (em $m m$ ) da $P S F$ e b) $M T F_{x}$ seção $x$ da função de tranferência de modulação e $M T F_{0}$ é a respectiva seção para a função de tranferência de modulação livre de aberração. O raio da pupila é $R=2,0 \mathrm{~mm}$. 


\section{Simulações e resultados}

A razão de Strehl $S_{r}$, ver (15), é uma métrica importante e é amplamente encontrada na literatura científica, ver Definição (22).

Definição 22 (Razão de Strehl) Definido como a razão dada pela Equação (6.11).

$$
S_{r}=\frac{\max \{P S F\}}{\max \left\{P S F_{0}\right\}}
$$

Onde max representa maior valor e $P S F_{0}$ é a função de espalhamento de ponto livre de aberração (diffraction-limited) onde a função de aberração de onda é $W(\tilde{x}, \tilde{y}) \equiv 0$ na Equação (2.38).

Valores de $S_{r}$ próximo da unidade indicam um sistema ótico com níveis baixo de aberração.

Ao analisar função de transferência de modulação estamos interessado em saber as freqüências espaciais que o modelo esquemático consegue capitar em sua retina. Neste trabalho utilizamos o termo freqüência de corte $f_{c}$ como a freqüência onde a $M T F$ se anula em uma dada direção. Outros autores definem o termo de maneira diferente, ver(15) para uma discussão mais detalhada.

A Figura (6.15(b)) mostra a função de transferência de modulação do sistema livre de aberração $M T F_{0}$ e a $M T F_{x}$, onde $M T F_{x}$ é a seção $x$ da função de transferência de modulação de $l b r$. No gráfico podemos confirmar o efeito da aberração em alterar o contraste e diminuir a freqüência de corte em comparação ao sistema livre de aberração. A razão de Strehl para a $P S F$ do modelo $l b r$ é $S_{r}=0,192$.

A Figura (6.16(a)) e a Figura (6.16(b)) são as respectivas funções de espalhamento de ponto e de transferência de modulação para o modelo híbrido $l b r_{h}$. Analisando a Figura (6.16(a)) percebemos as assimetrias provocadas pelas aberrações de mais alta ordem. Na Figura (6.16(b)) também mostramos $M T F_{y}$, onde $M T F_{y}$ é a seção $y$ da função de transferência de modulação. Nela notamos que $f_{c}$ não é o mesmo nas direções $x$ e $y$ e que ambas são menores que a freqüência de corte do sistema livre de aberração.

A razão de Strehl é $S_{r}=0,020$ para o modelo $l b r_{h}$ valor uma ordem de grandeza menor do que $S_{r}$ do modelo $l b r$. 


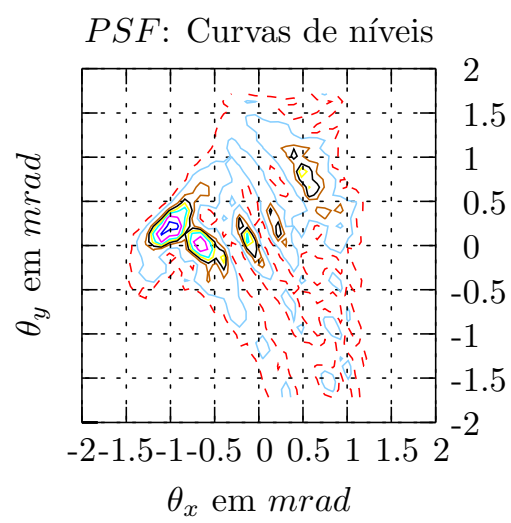

(a)

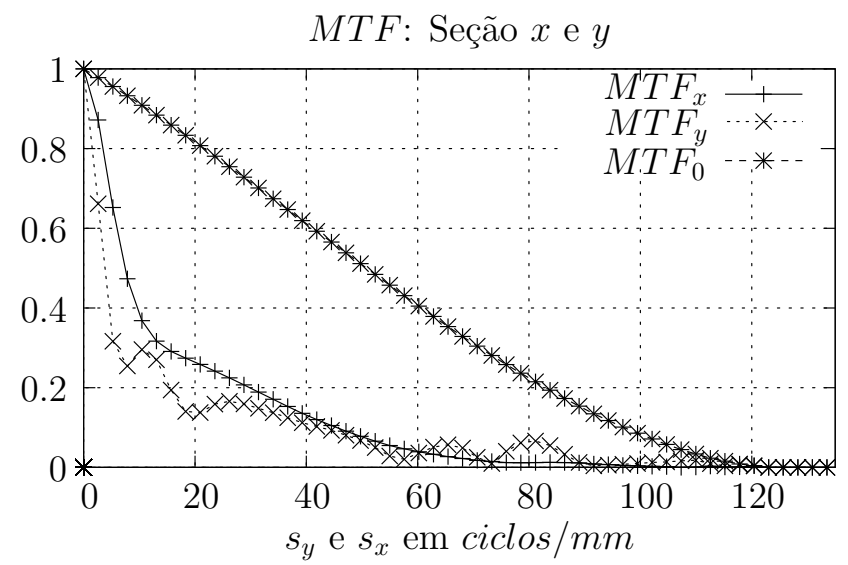

(b)

Figura 6.16: Modelo híbrido $l b r_{h}$ : a) Curvas de níveis (em $m m$ ) da $P S F$ e b) $M T F_{x}$ e $M T F_{y}$ são as seções $x$ e $y$ da função de tranferência de modulação e $M T F_{0}$ é a respectiva seção para a função de tranferência de modulação livre de aberração. O raio da pupila é $R=2,0 \mathrm{~mm}$.

\subsection{Formação de imagens}

Nesta seção realizamos a simulação de projeção de cones da Seção (5.8). Os resultados encontrados aqui tem um aspecto qualitativo mas enriquecem o entendimento do comportamento físico/ótico dos modelos esquemáticos.

A Figura (6.17(a)) é utilizada como entrada $I$ do Algoritmo (5.7). A imagem $I$ com dimensão $h=11,6 \mathrm{~mm}$ é colocada no plano $z=141,787 \mathrm{~mm}$ no espaço objeto do modelo $l g r_{a}$. Nesta situação, também calculamos o raio do círculo de confusão $\rho^{\prime}$, ver Definição (21) do cone de luz no eixo ótico de $l g r_{a}$ lançado de $z$.

Variamos o raio $R$ da pupila de $l g r_{a}$ para estudar o efeito tamanho da pupila na formação de imagens $I^{\prime}$. Antes de apresentar os resultados, convoluímos I Figura (6.17(a)) com uma distribuição gaussiana $G_{\sigma}$ para $\sigma=\{1,0 ; 2,5\}$ para mostrar o efeito na imagem $I^{\prime}$ da convolução realizada na $2^{a}$ etapa do Algoritmo (5.7).

A Figura (6.17(b)) e Figura (6.17(c)) mostram a imagem da Figura (6.17(a)) original convoluida com $\sigma=1,0$ e $\sigma=2,5$ na Equação (5.53).

Observando a Figura $(6.17(\mathrm{~b}))$ e a Figura $(6.17(\mathrm{c}))$ vemos que a convolução com $G_{\sigma}$ não altera significativamente $I$ para $\sigma=1,0$. Então utilizamos $G_{1,0}$ no Algoritmo (5.7) para formar a imagem $I^{\prime}$ na retina de $l g r_{a}$. Projetamos cones de luz dos pixels de $I$. Os 


\section{Simulações e resultados}

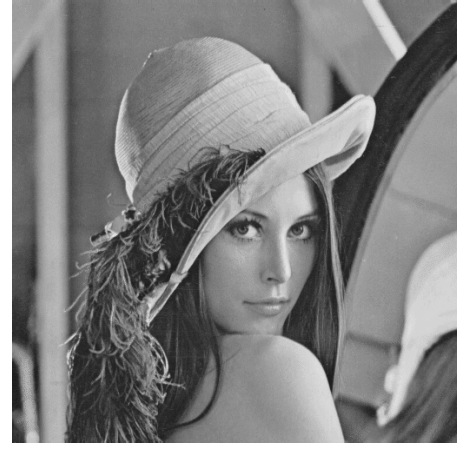

(a)

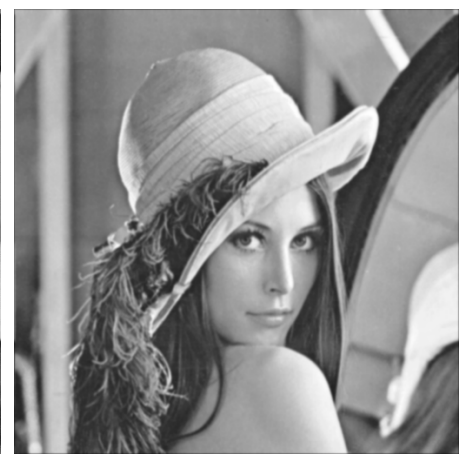

(b)

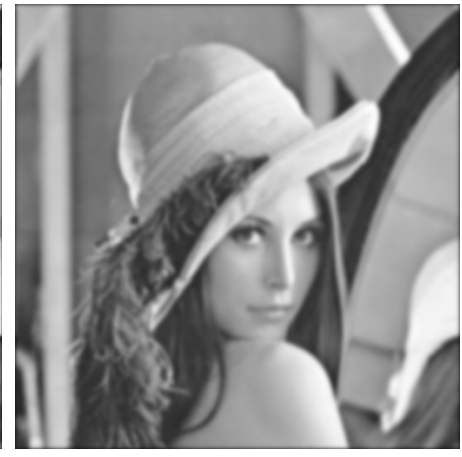

(c)

Figura 6.17: Experimento de convolução com $G_{\sigma}$ : a) imagem original b) $\sigma=1,0$ e c) $\sigma=2,5$.

raios das pupilas utilizadas são: $R=1,0 \mathrm{~mm}, R=2,5 \mathrm{~mm}$ e $R=4,0 \mathrm{~mm}$. Os resultados juntamente com os respectivos histogramas da imagem $I^{\prime}$ estão nas figuras (6.18), (6.19) e (6.20). Como esperavamos , a imagem $I^{\prime}$ é real e invertida com a presença de "borrão" a partir do raio da pupila $R=2,5 \mathrm{~mm}$.

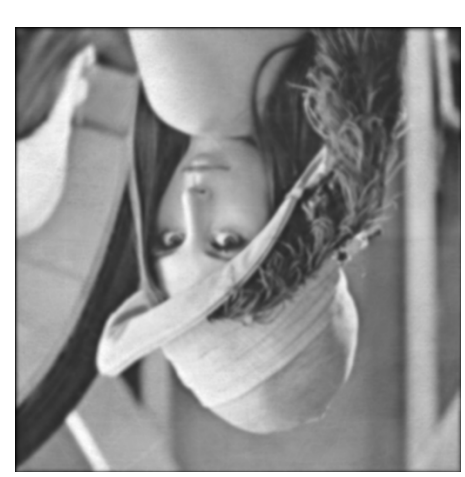

(a)

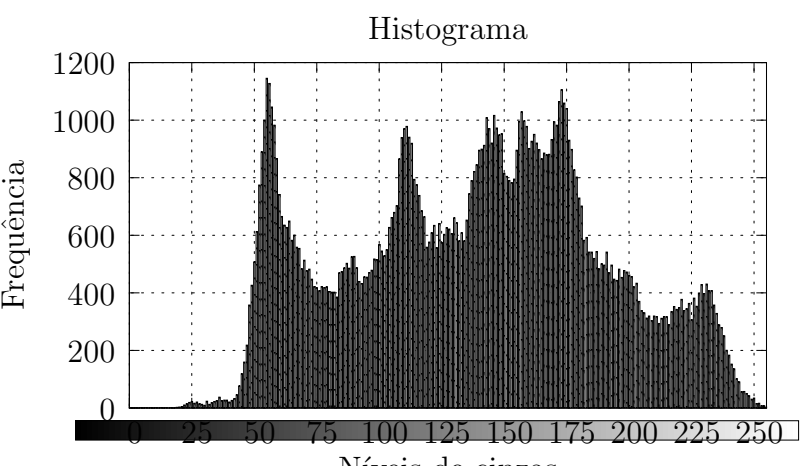

(b)

Figura 6.18: Imagem formada pelo modelo $\mathrm{lgr}_{a}$ com raio da pupila $R=1,0 \mathrm{~mm}$. O círculo de confusão é $\rho^{\prime}=0,032 \mathrm{~mm}$.a) Imagem $I^{\prime}$ e b ) histograma de $I^{\prime}$.

Analisando os histogramas das figuras (6.5), (6.5) e (6.5) percebemos que o fluxo de raios de luz incidente na retina aumento com o tamanho da pupila concentrando os respectivos níveis de cinzas das figuras nas regiões da cor branca indicando o aumento de brilho da imagem no centro.

Ao analisarmos os respectivos raios do círculo de confusão $\rho^{\prime}$ percebemos o aumento do "borrão" da imagem $I^{\prime}$ devido as aberrações presentes em $l g r_{a}$.

Arranjamos a Equação (5.38) para obter a razão $\bar{m}$ Seção (5.5) em termos do aumento 


\section{Simulações e resultados}

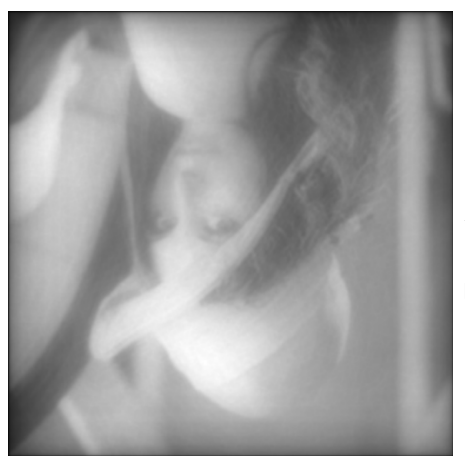

(a)

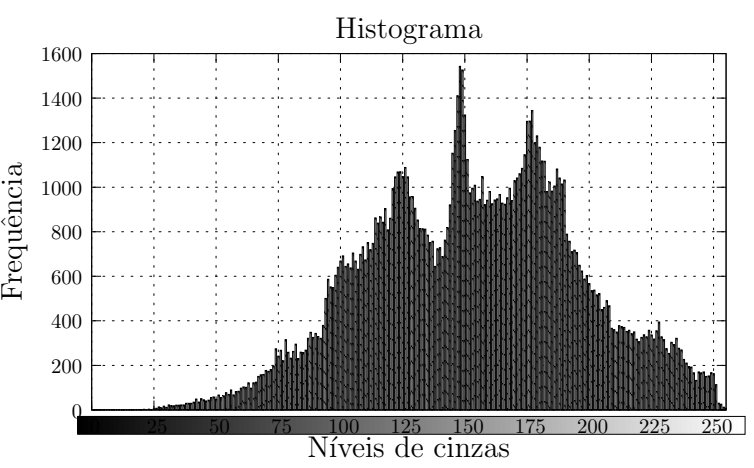

(b)

Figura 6.19: Imagem formada pelo modelo $\operatorname{lgr}_{a}$ com raio da pupila de $R=2,5 \mathrm{~mm}$. O círculo de confusão é $\rho^{\prime}=0,198 \mathrm{~mm}$.a) Imagem $I^{\prime}$ e b ) histograma de $I^{\prime}$.

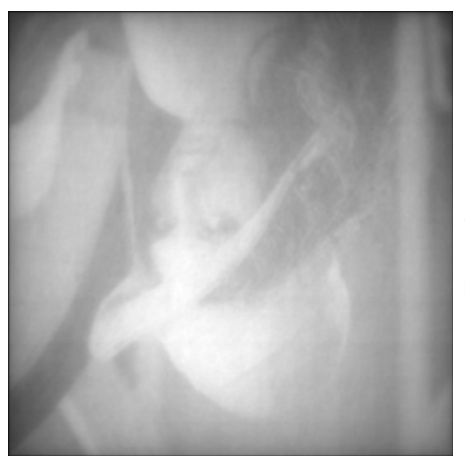

(a)

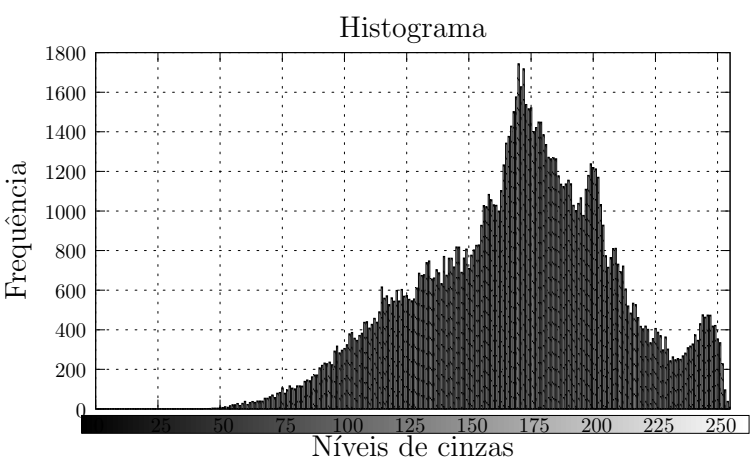

(b)

Figura 6.20: Imagem formada pelo modelo $l g r_{a}$ com raio da pupila de $R=4,0 \mathrm{~mm}$. O círculo de confusão é $\rho^{\prime}=1,125 \mathrm{~mm}$. a) Imagem $I^{\prime}$ e b ) histograma de $I^{\prime}$.

lateral $M$ Equação (2.9) da Seção (2.1.4.2).

$$
\bar{m}=-M \frac{E P}{E^{\prime} V^{\prime}}
$$

Onde $E$ e $E^{\prime}$ são a posição da entrada e saída da calculada na Tabela (6.1) e $V^{\prime}$ é o ponto onde o eixo ótico intercepta a retina e $P$ é a posição de $I$ no eixo $z$.

Em todos os resultados, o tamanho da imagem $h^{\prime}$ é $1,3288 \mathrm{~mm}$ e o qual resulta no aumento lateral $M=\frac{-1,3288 m m}{11,6 m m} \equiv-0,1145$. Para $l g r_{a} E^{\prime} V^{\prime}=21,1312 m m, E P=$ $-144,4414 m m$. A razão $\bar{m}$ calculada pela Equação (6.12) é $\bar{m}=0,7827$. Ao comparar com o valore obtido da Tabela (6.1) encontramos um diferença percentual de apenas $\Delta \bar{m}=1 \%$. 


\subsection{Diagrama de pontos}

O diagrama de pontos $D P\left(\right.$ spot diagram) é uma coleção de intersecções $P_{i}^{\prime}=\left(x_{i}^{\prime}, y_{i}^{\prime}, z_{i}^{\prime}\right) \in$ $S$, com $i=1,2,3, \ldots, N$ entre os raios $l \in C$, onde $C$ é o cone de luz lançado do ponto $P$ no espaço objeto, e a superfície $S \subset \mathbb{R}^{3}$ representa a retina. $D P$ é uma ferramenta importante na análise de sistema ótico em geral e expressa a qualidade do sistema ótico em focalizar objetos pontuais. Os raios de $C$ são lançados e devido à abertura circular da Íris formam um padrão circular em forma de grade quadriculada no plano tangente ao vértice da córnea. O sistema ótico transforma este padrão em um novo padrão na retina. Quando a abertura da Íris é comparável ao comprimento de onda $\lambda$ da luz , o sistema ótico ao focalizar um objeto pontual constrói um padrão circular formado por difração conhecido como airy disc . Nesta situação o padrão gerado por difração produz um "borrão" maior do que aquele produzido pelas aberrações presente no sistema ótico e diminui gradativamente conforme o diâmetro da pupila aumenta. O diâmetro do airy disc é dado por:

$$
D_{a}=1,22 \lambda \frac{f}{d}
$$

onde $f$ é a distância focal e $d$ é o diâmetro da pupila.

O valor $R M S$ (do inglês root mean square) é uma medida quantitativa associado ao diagrama de pontos DP. Ele é calculado através da Equação (6.14). Outra medida comum é o raio do círculo de confusão ou raio geométrico $\rho^{\prime}$ Definição (21).

$$
R M S=\sum_{i} \frac{\sqrt{\left(x_{i}^{\prime}-x_{0}^{\prime}\right)^{2}+\left(y_{i}^{\prime}-y_{0}^{\prime}\right)^{2}}}{N}
$$

Onde $P_{0}^{\prime}=\left(x_{0}^{\prime}, y_{0}^{\prime}, z_{0}^{\prime}\right)$ é a intersecção de $S$ com o raio pupilar $l_{c}$.

Consideramos os diagramas de pontos em duas situações. A primeira $C$ associado ao $D P$ foi lançado de um ponto $P$ no eixo ótico dos modelos e na segunda $C$ foi lançado de um ponto $P$ formando o ângulo visual $\alpha=5^{\circ}$ com o eixo ótico, ver Definição (18). A Figura (6.21),Figura (6.22), Figura (6.23) e Figura (6.24) exibem os diagramas de pontos juntamente com os respectivos airy disc.

Podemos observar que todos os diagramas de pontos diferem do diagrama ideal, que 

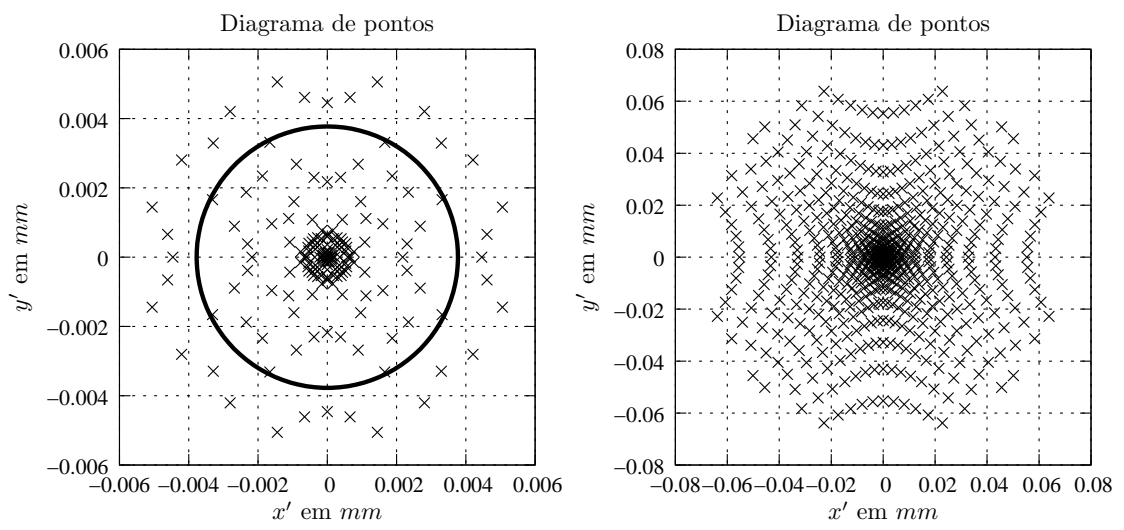

(a)

(b)

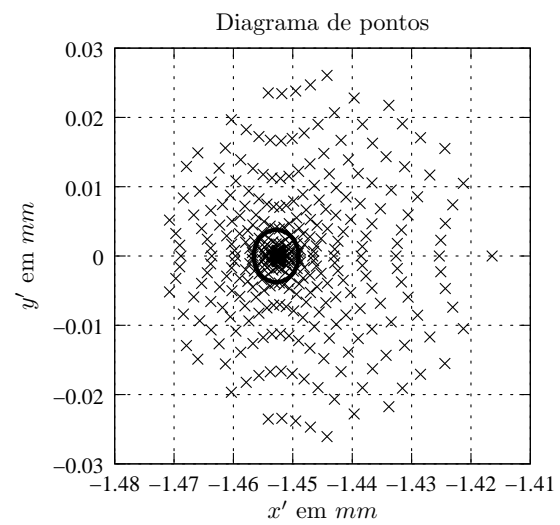

(c)

Figura 6.21: Diagrama de pontos do modelo de $l g r_{u}$ e o padrão airy disc : a) $R=1,0 \mathrm{~mm}$, $R M S=0,0019 \mathrm{~mm}, \rho^{\prime}=0,0053 \mathrm{~mm}$ e $D_{a}=0,0037 \mathrm{~mm}$; b) $R=2,0 \mathrm{~mm}, R M S=$ $0,0250 \mathrm{~mm}, \rho^{\prime}=0,0680 \mathrm{~mm}$ e $D_{a}=0,0019 \mathrm{~mm}$ e c) $R=1,0 \mathrm{~mm}, \alpha=5^{\circ}, R M S=$ $0,0023 \mathrm{~mm}, \rho^{\prime}=0,0010 \mathrm{~mm}$ e $D_{a}=0,0037 \mathrm{~mm}$.

consiste de apenas um ponto em $S$. Note que no modelo lgr para os dois níveis de acomodação, o airy disc é menor que o "borrão" produzido pelo aberração e reforça a idéia de que estes modelos não refletem as aberrações do olho humano. Já no modelo lbr o padrão airy disc prejudica mais a formação da imagem do que o "borrão" provocado pelas aberrações do modelo quando o raio da pupila é $R=1,00 \mathrm{~mm}$. E ao contrário quando o raio é $R=2,00 \mathrm{~mm}$.

Novamente podemos verificar o aumento do $R M S$ e raio geométrico $\rho^{\prime}$ com o aumento do tamanho da pupila. 

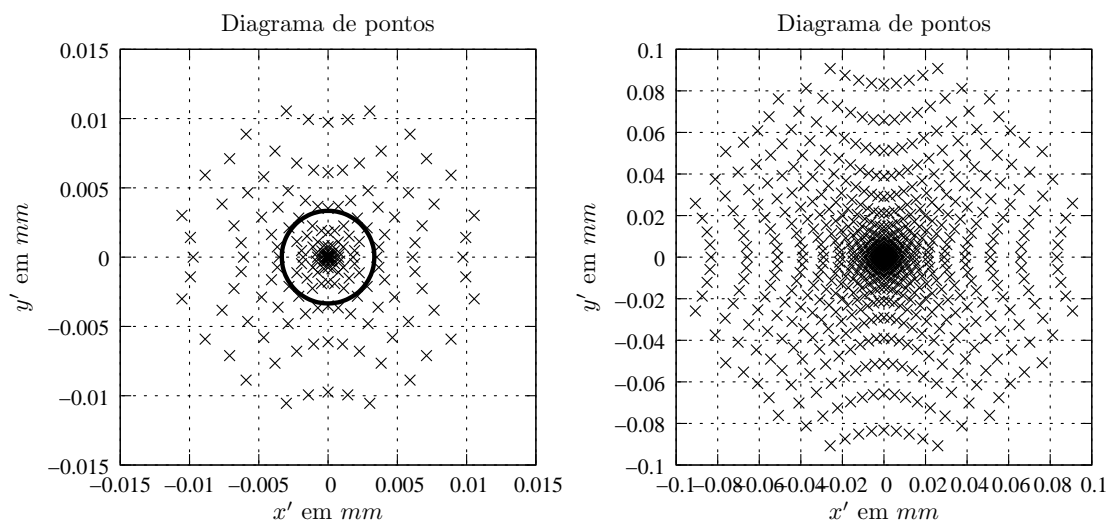

(a)

(b)

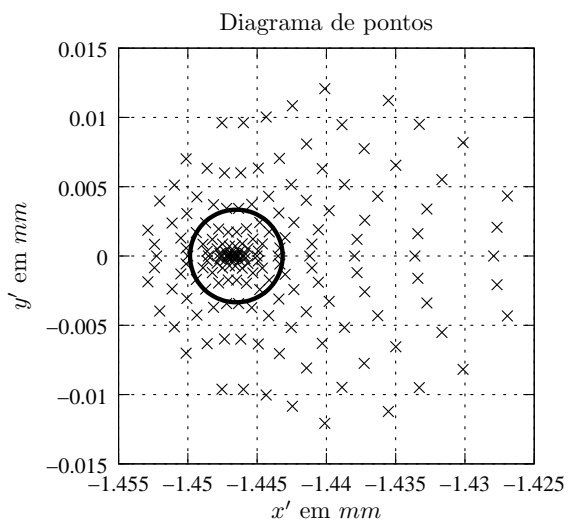

(c)

Figura 6.22: Diagrama de pontos do modelo $\operatorname{lgr}_{a}$ e airy disc : a) $R=1,0 \mathrm{~mm}, R M S=$ $0,0048 \mathrm{~mm}, \rho^{\prime}=0,0110 \mathrm{~mm}$ e $D_{a}=0,0066 \mathrm{~mm}$; b) $R=2,0 \mathrm{~mm}, R M S=0,0373 \mathrm{~mm}$, $\rho^{\prime}=0,0943 \mathrm{~mm}$ e $D_{a}=0,0033 \mathrm{~mm}$ e c) $R=1,0 \mathrm{~mm}, \alpha=5^{\circ}, R M S=0,0058 \mathrm{~mm}$, $\rho^{\prime}=0,0200 \mathrm{~mm}$ e $D_{a}=0,0066 \mathrm{~mm}$.

\subsection{Análise de erros}

Nesta seção fazemos uma breve análise dos erros cometidos pela representação em malha do VEye em relação à modelagem teórico Seção (5.1). Traçamos raios de luz $l$ paralelo ao eixo ótico $z$ à altura $r$ de $z$ na malha $m$ que representa a superfície anterior da córnea do modelo lgr , como descrito na Seção (5.6). O traçado é feito usando-se o Algoritmo (5.2.1.1) e usando o Algoritmo (5.2.1.2). Durante o processo de traçado de raios avalia as normais $\mathbf{N}_{w}$, a intersecção em $\mathbf{W}$, o ângulo de incidência $\theta$ e o de refração $\theta^{\prime}$ de por dois métodos. O primeiro deles através dos cálculos da Seção (5.2.1.1) e o segundo através dos cálculos da Seção (5.2). Então calculamos o ângulo $\gamma$ entre as normais obtidas pelos dois métodos, a diferença percentual entre a coordenada $z$ de $\mathbf{W}, \Delta \theta$ a diferença 


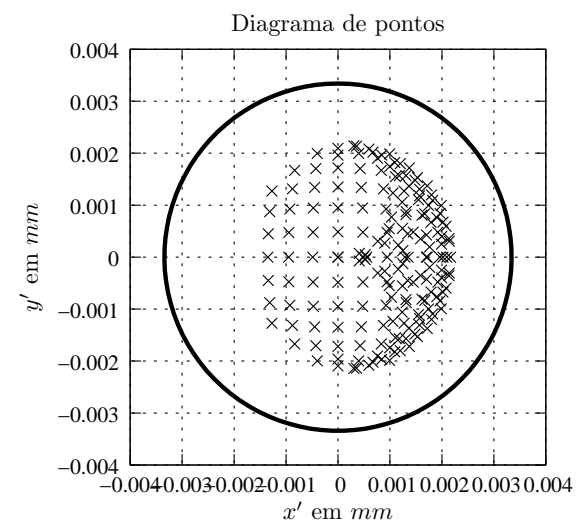

(a)

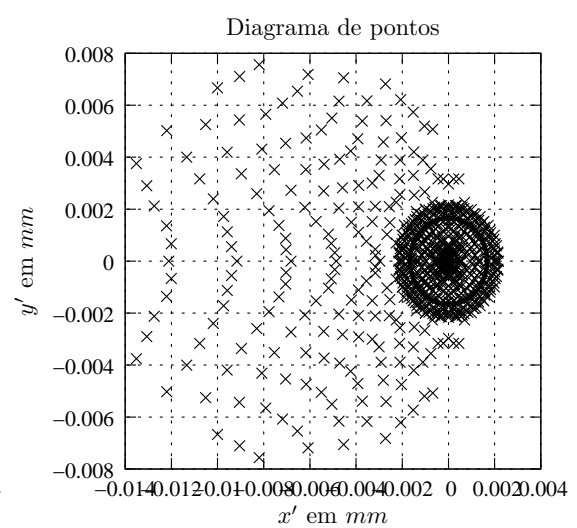

(b)

Figura 6.23: Diagrama de pontos do modelo $l b r \alpha=0^{\circ}$. A circunferência ao centro é o airy disc : a) $R=1,0 \mathrm{~mm}, R M S=0,0017 \mathrm{~mm}, \rho^{\prime}=0,0022 \mathrm{~mm}$ e $D_{a}=0,0074 \mathrm{~mm}$, b) $R=2,0 \mathrm{~mm}, R M S=0,0028 \mathrm{~mm}, \rho^{\prime}=0,014 \mathrm{~mm}$ e $D_{a}=0,0037 \mathrm{~mm}$.

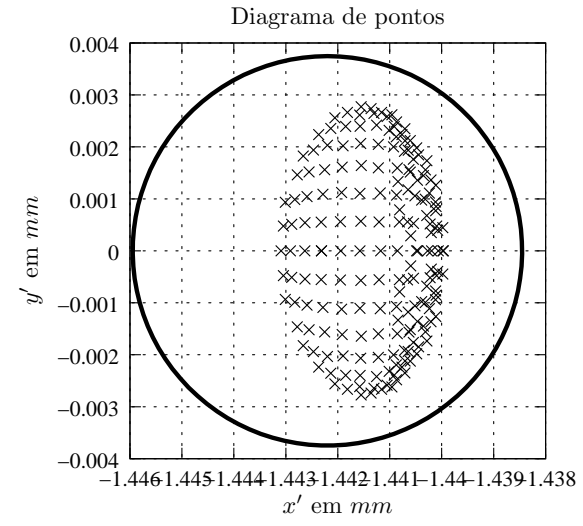

(a)

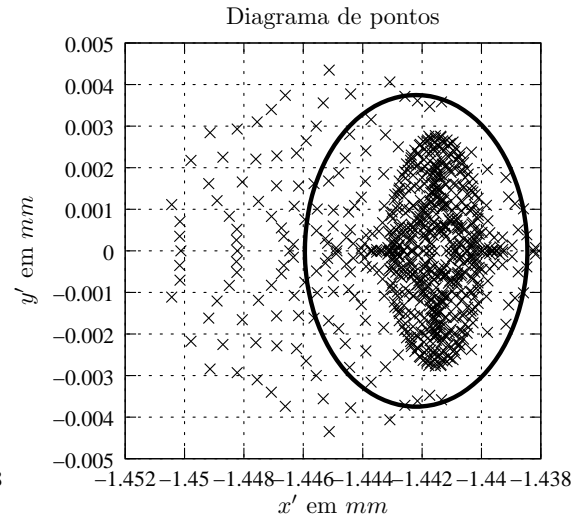

(b)

Figura 6.24: Diagrama de pontos do modelo $l b r \alpha=5^{\circ}$. A circunferência ao centro é o airy disc : a) $R=1,0 \mathrm{~mm}, R M S=0,0020 \mathrm{~mm}, \rho^{\prime}=0,0029 \mathrm{~mm}$ e $D_{a}=0,0074 \mathrm{~mm}$ b) $R=2,0 \mathrm{~mm}, R M S=0,0022 \mathrm{~mm}, \rho^{\prime}=0,0083 \mathrm{~mm}$ e $D_{a}=0,0037 \mathrm{~mm}$.

percentual entre os ângulos de incidência e a diferença percentual $\Delta \theta^{\prime}$ entre os ângulos de refração. Os resultados estão na Figura (6.25). Analisando-os percebemos discrepâncias nas regiões gaussianas da córnea de $l g r$.

Com o objetivo de avaliar como os erros expressos pela Figura (6.26) acunulam quando o traçado é realizado por mais de uma malha, calculamos a aberração esférica dos modelos: $l g r, l b r$ e lot com todas as respectivas superfícies dos modelos sendo representadas por malhas superficias triangulares. O resultado encontra-se na Figura (6.26), juntamente com os respectivos valores de $L S A$ obtidos da Seção (5.6), onde as malhas não foram utilizadas. 


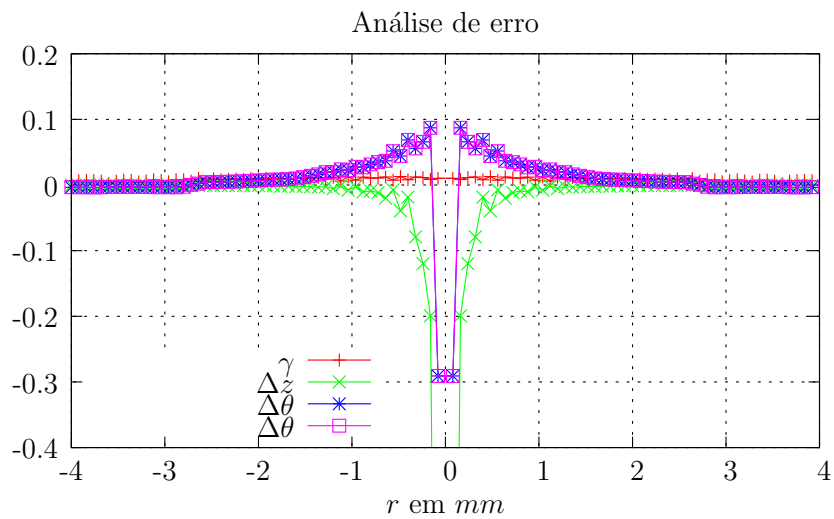

Figura 6.25: Análise de erro cometido pela representação em malha em relação a Equação (5.1) da quádrica no modelo $l g r_{u}$.

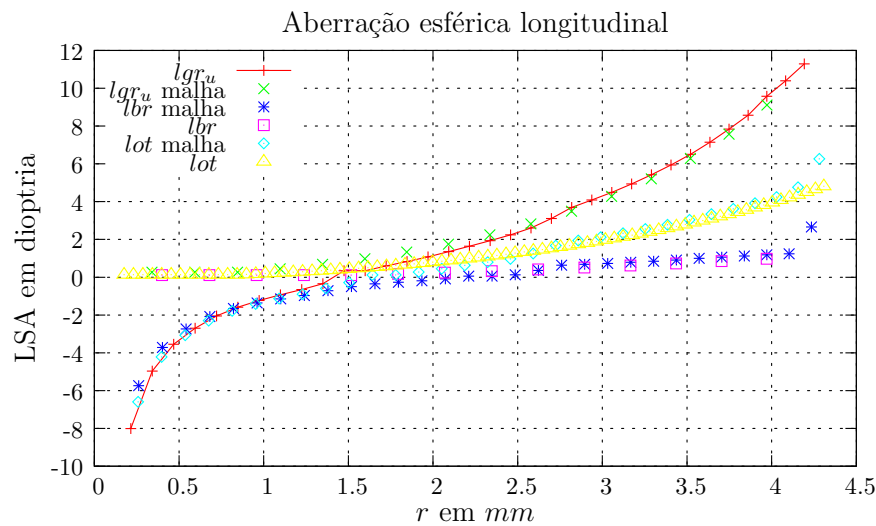

Figura 6.26: Propagação do erro cometido pela representação em malha devido ao acumulo de malhas no traçado ótico.

Na Figura (6.26) vemos que o erro estende-se para fora da região gaussiana chegando até a altura $r=2,0 \mathrm{~mm}$. Sinalizando que as malhas, pelo menos como elas estão sendo feitas, não são uma boa saída para utilizar em modelos em que mais superfícies oriundas de dados in-vivo são utilizadas. 
Simulações e resultados 


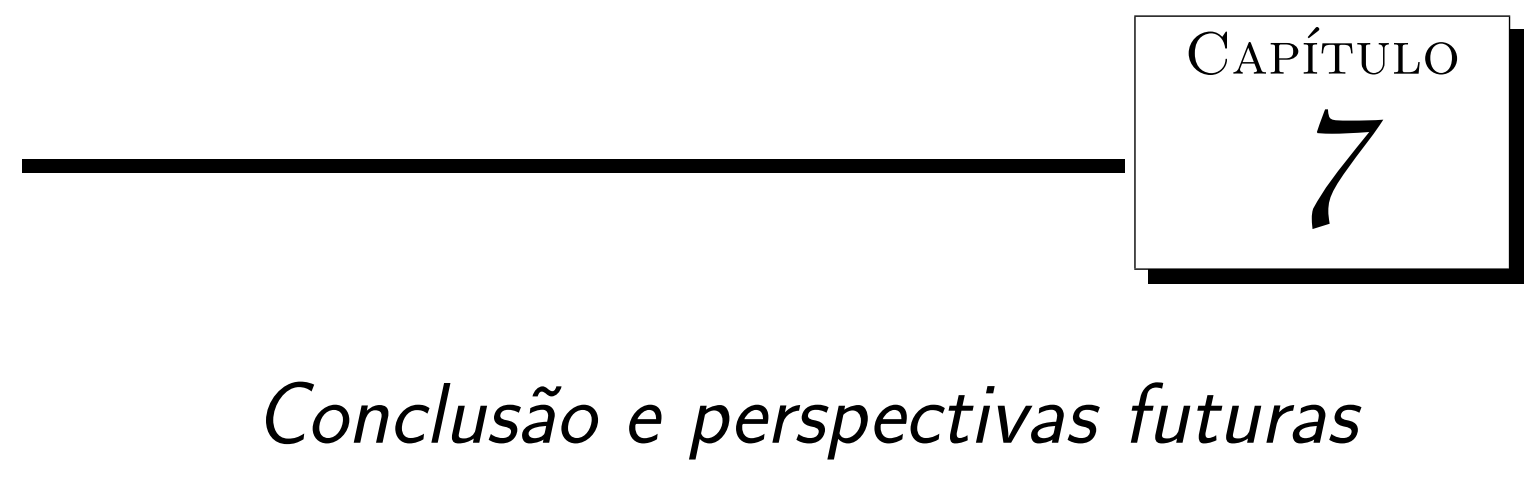

Nesta dissertação propomos um arcabouço capaz de simular os fenômenos óticos e fisiológicos do olho humano inclusive usando dados in-vivo . Estudamos os modelos esquemáticos e fizemos teste que comprovam a eficácia dos modelos em realizar as funções ao qual são propostos. O modelo afásico de Emsley não é visto neste trabalho apesar de ser muito conhecido. Os modelos de gul e lgr refletem o comportamento ótico do olho humano na região gaussiana. Os modelos de lot e koo apresentam resultados de aberração esférica compatíveis ao olho humano. O modelo de nav reproduz o processo de acomodação dentro do seus limites e o modelo de $l b r$ é o modelo que melhor reproduz as propriedades óticas e fisiológicas do olho humano, porém ele não define estados de acomodação.

Na Seção (6.1) calculamos as propriedades gaussianas dos modelos e obtivemos resultados consistentes com a literatura científica. Na Seção (6.2) utilizamos o modelo nav para simular o processo de acomodação do olho humano pois os outros modelos não propõe estados contínuos de acomodação.

A Seção (6.3) exploramos as aberrações dos modelos do ponto de vista da ótica geométrica. Nesta seção calculamos a aberração esférica longitudinal e transversal dos modelos, novamente obtivemos resultados que concordam com os encontrados na litera- 


\section{Conclusão e perspectivas futuras}

tura, ver (16).

Na Seção (6.4) exploramos os modelos do ponto de vista da ótica ondulatória de Fourier. Na Seção (6.4.1) fazemos um teste que valida os algoritmos de ótica ondulatória explicados na Seção (5.7) do VEye . A Seção (6.4.2) aparecem os primeiros resultados usando dados in-vivo .

A Seção (6.5) tem caráter qualitativo e enriquece o entendimento da ótica fisiológica envolvida neste trabalho ao demonstrar o efeito do tamanho da pupila na qualidade das imagens formadas na retina do modelo $l g r_{a}$.

Na Seção (6.7) fizemos uma breve comparação entre o traçado de raio utilizando o algoritmo da Seção (5.2.1.1) e o algoritmo da Seção (5.2.1.2) no traçado de raio. Os resultados indicam que as malhas utilizadas no VEye não geram resultados bons na região gaussiana. O gráfico da Figura (6.26) ilustra a atual limitação que as malhas do VEye proporcionam. Nela repetimos o procedimento da Seção (5.6) para o modelo $l g r_{u}$ em que todas as superfícies refratoras são representadas por malhas no algoritmo de traçado de raio, ver Algoritmo (5.1). Este resultado adverte-nos para os passos futuros do VEye que almeja utilizar todas as superfícies refratoras construídas a partir de dados in-vivo .

Muitos dos trabalhos recentes utilizam aplicações comerciais voltadas para desenho ótico de propósito geral e não permitem um controle detalhado amarrando as mãos do pesquisador. As simulações do VEye é um esforço em aproveitar as informações adquiridas pelos equipamentos modernos de oftalmologia, além de auxiliar o entendimento de sistemas visuais biológicos acabam também em auxiliar a elaboração de sistemas de visão artificial e os projetistas de sistemas óticos. 


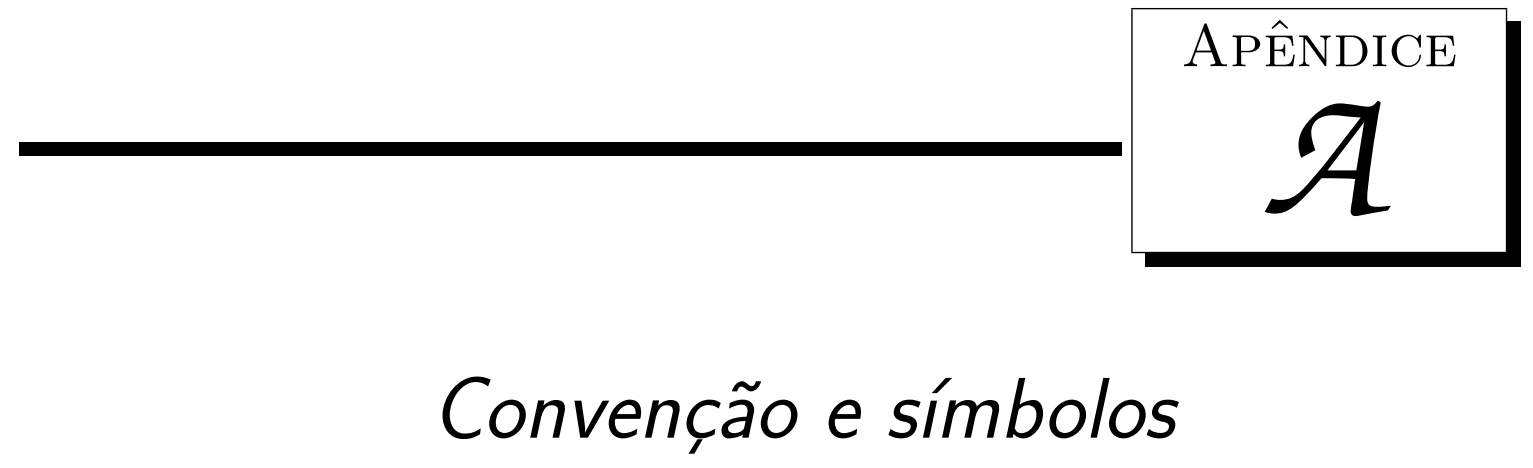

Quando examinamos a formação de imagens e traçados de raios em sistemas óticos é necessário adotar uma convenção de sinal. Adotamos a convenção cartesiana e trigonométrica usual. Distância a esquerda das superfícies são negativas e a direita positivas. Os ângulos são positivos no sentido contrário do relógio e negativos no sentido oposto.

\section{A.1 Notação e sinal de distâncias}

Pontos são representados em letras maiúsculas como em $F$. Distâncias são representadas ou por letras minúsculas como em $f$ ou por duas letras maiúsculas $H F$. No exemplo $H$ e $F$ são pontos e $H F$ é distância medida de $H$ até $F$. Se $F$ está à direita de $H$ então $H F$ é positivo e negativo caso contrário. Ver Figura (2.5). A Figura (A.1) explica a convenção de sinal para os raios de curvatura adotada.

\section{A.2 Unidades e suas abreviações}

A Tabela (A.1) exibe as principais unidades de medidas utilizada neste trabalho e as abreviações associadas a elas. 


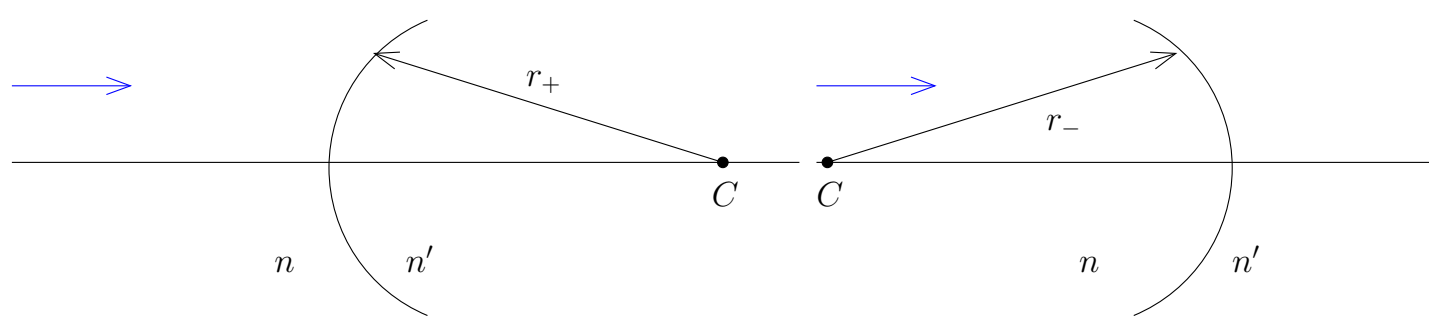

(a)

(b)

Figura A.1: A seta azul indica sentido da luz incidente. Em ambas as figura $n<n^{\prime}$ e $C$ é o centro de curvatura. a) Raio de curvatura positivo $r_{+}$e b ) raio de curvatura $r_{-}$ negativo segundo convenção de sinal adotada.

Tabela A.1: Lista de unidades e símbolos.

\begin{tabular}{ll}
\hline unidade & abreviação \\
\hline$m$ & metro \\
$c m$ & centímetro \\
$m m$ & milímetro \\
$\mu m$ & micron \\
$n m$ & nanometro \\
$D$ & dioptria \\
rad & radiano \\
mrad & miliradiano \\
${ }^{\circ}$ & grau \\
\hline
\end{tabular}

\section{A.3 Modelos e abreviações}

A Tabela (A.2) exibe as abreviações dos modelos esquemáticos do VEye (ver Apêndice (B)).

\section{A.4 Símbolos}

Neste trabalho raios de luz são representados na cor azul e prolongamentos com uma linha pontilhada. As setas indicam o sentido de propagação. Vetores e matrizes são representados em negrito como em V.

A Tabela (A.3) exibe alguns símbolos e convenções. 
Tabela A.2: Abreviações dos modelos esquemáticos do VEye .

\begin{tabular}{ll}
\hline Abreviação & Modelo \\
\hline$l g r_{u}$ & Le Grand no estado não-acomoado \\
$l g r_{a}$ & Le Grand no estado acomodado \\
$l g r$ & Le Grand nos dois estados: $l g r_{u}$ e $l g r_{a} \cdot$ \\
$g u l_{a}$ & Gullstrand-LeGrand no estado não-acomoado \\
$g u l_{u}$ & Gullstrand-LeGrand no estado acomodado \\
$g u l$ & Gullstrand-LeGrand nos dois estados: $g u l_{u}$ e $g u l_{a} \cdot$ \\
$l o t$ & Lotmar \\
$k o o$ & Kooijman \\
$n a v$ & Navarro \\
$n a v_{A}$ & Navarro no estado de acomodação $A$. \\
$l b r$ & Liou-Brennan \\
$l b r_{h}$ & Modelo $l b r$ com superfície anterior da córnea obtida de dados in-vivo \\
\hline
\end{tabular}

Tabela A.3: Lista de símbolos.

\begin{tabular}{ll}
\hline Símbolo & Descrição \\
\hline$P$ & Ponto no espaço objeto \\
$P^{\prime}$ & Ponto no espaço imagem \\
$<\bullet>$ & Denota valor médio. \\
{$[\bullet]$} & Caminho ótico \\
$\otimes$ & Convolução \\
$\{\bullet\}$ & Denota conjunto \\
$\|\bullet\|$ & Norma Euclidiana \\
$\mathfrak{F}$ & Transformada de Fourier \\
$A$ & Acomodação \\
$D$ & Dioptria \\
$F$ e $F^{\prime}$ & Pontos focais: objeto e imagem. \\
$H$ e $H^{\prime}$ & Pontos principais: objeto e imagem. \\
$N$ e $N^{\prime}$ & Pontos nodais: objeto e imagem. \\
$E$ & Entrada da pupila \\
$E^{\prime}$ & Saída da pupila \\
$f$ e $f^{\prime}$ & Distâncias focais: objeto e imagem. \\
$M_{E}$ & Aumento lateral referente a entrada da pupila \\
$M_{E^{\prime}}$ & Aumento lateral referente a saída da pupila \\
$\bar{m}$ & Razão descrita pela Equação (5.34) \\
\hline
\end{tabular}


Convenção e símbolos 


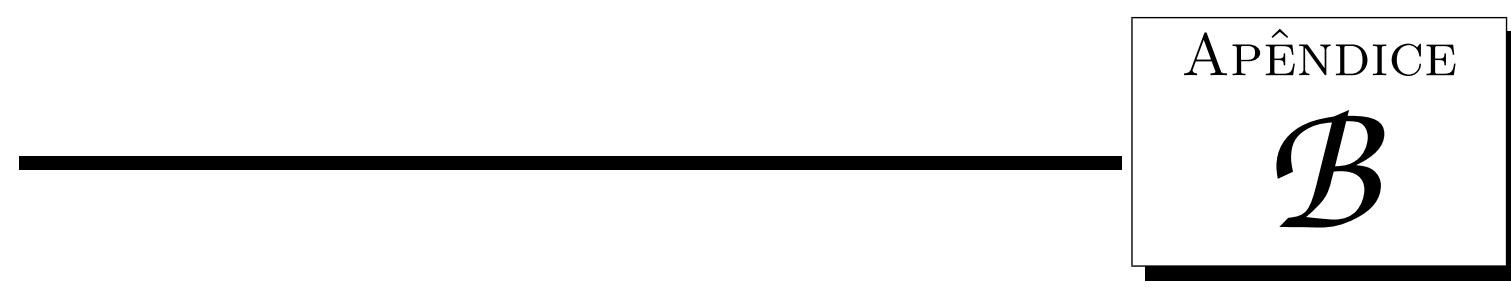

\section{Modelos do olho humano}

Neste apêndice apresentamos os dados que compõe os modelos esquemáticos do olho humano implementado VEye . Eles são construídos com a Equação (5.1). Os modelos paraxiais são: Emsley, Gullstrand-LeGrand e Le Grand. Os modelos esquemáticos finitos são: Lotmar, Kooijman, Navarro e Liou e Brennan.

\section{B.1 Unidades}

Distâncias são dadas em milímetros $(m m)$ e são medidas a partir do vértice da superfície anterior da córnea. Dioptria está em unidades de dioptria $(1 / m)$. Os níveis de acomodação são dados em dioptria e são medidos a partir da superfície anterior da córnea.

Nas próximas seções descrição dos modelos.

\section{B.2 Emsley}

Modelo simples representado por uma única superfície refratora. 


\begin{tabular}{cccccccc}
\hline & & & & & & Dioptrias \\
Meio & $n$ & $R$ & $Q$ & $d$ & Superfície & Componente & Olho \\
\hline Ar & 1,0000 & & & & & & \\
& & 5,555 & 0,000 & & 60,00 & 60,00 & 60,00 \\
Vitreous & $4 / 3$ & & & 22,2222 & & & \\
& & & & & & & \\
\hline
\end{tabular}

\section{B.3 Gullstrand-LeGrand}

Este modelo é uma modificação feita por Le Grand (33) no modelo exato de Gullstrand número 1 (16). Define dois estados de acomodação: não-acomodado e acomodado.

\section{B.3.1 (Não-acomodado)}

\begin{tabular}{lccccccc}
\hline & & & & & & \multicolumn{3}{c}{ Dioptrias } \\
Meio & $n$ & $R$ & $Q$ & $d$ & Superfície & Componente & Olho \\
\hline Ar & 1,0000 & & & & & & \\
& & 7,7 & 0,0 & & 48,83 & & \\
Córnea & 1,376 & & & 0,50 & & & \\
& & 6,8 & 0,0 & & $-5,88$ & & \\
Aqueous & 1,336 & & & 3,10 & & & \\
& & 10,0 & 0,0 & & 5,00 & & \\
Cristalino & 1,4085 & & & 3,6 & & & \\
& & $-6,0$ & 0,0 & & 8,33 & & \\
Vitreous & 1,3360 & & & 17,187 & & & \\
& & & & & & & \\
\end{tabular}




\section{B.3.2 (Acomodado)}

\begin{tabular}{|c|c|c|c|c|c|c|c|}
\hline & & & & & & Dioptrias & \\
\hline Meio & $n$ & $R$ & $Q$ & $d$ & Superfície & Componente & Olho \\
\hline \multirow[t]{2}{*}{ Aqueous } & 1,3374 & & & 2,7 & & & \\
\hline & & 5,33 & 0,0 & & 9,375 & & 70,57 \\
\hline \multirow[t]{2}{*}{ Cristalino } & 1,426 & & & 4,0 & & 33,06 & \\
\hline & & $-5,33$ & 0,0 & & 9,3753 & & \\
\hline
\end{tabular}

\section{B.4 Le Grand}

Este modelo define dois estados de acomodação: não-acomodado e acomodado.

\section{B.4.1 (Não-acomodado)}

Dioptrias

\begin{tabular}{cccccccc} 
Meio & $n$ & $R$ & $Q$ & $d$ & Superfície & Componente & Olho \\
\hline Ar & 1,0000 & & & & & & \\
& & 7,8 & 0,0 & & 48,346 & & \\
Córnea & 1,3771 & & & 0,55 & & 42,356 & \\
& & 6,5 & 0,0 & & $-6,108$ & & 59,940 \\
Aqueous & 1,3374 & & & 3,05 & & & \\
& & 10,2 & 0,000 & & 8,098 & & \\
Cristalino & 1,4200 & & & 4,00 & & & \\
& & $-6,0$ & 0,000 & & 14,000 & & \\
Vitreous & 1,3360 & & & 16,59655 & & & \\
\hline
\end{tabular}




\section{B.4.2 (Acomodado)}

\begin{tabular}{|c|c|c|c|c|c|c|c|}
\hline & & & & & & Dioptrias & \\
\hline Meio & $n$ & $R$ & $Q$ & $d$ & Superfície & Componente & Olho \\
\hline \multirow[t]{2}{*}{ Aqueous } & 1,3374 & & & 2,650 & & & \\
\hline & & 6,000 & 0,000 & & 14,933 & & 67,677 \\
\hline \multirow[t]{2}{*}{ Cristalino } & 1,4270 & & & 4,50 & & 30,700 & \\
\hline & & $-5,500$ & 0,000 & & 16,545 & & \\
\hline
\end{tabular}

\section{B.5 Lotmar (1971)}

Modelo inspirado no modelo de Le Grand no estado não-acomodado. Utiliza superfícies quádricas.

\section{Dioptrias}

\begin{tabular}{|c|c|c|c|c|c|c|c|}
\hline Meio & $n$ & $R$ & $Q$ & $d$ & Superfície & Componente & Olho \\
\hline \multirow[t]{2}{*}{$\mathrm{Ar}$} & 1,0000 & & & & & & \\
\hline & & 7,8 & $-0,286$ & & 48,346 & & \\
\hline \multirow[t]{2}{*}{ Córnea } & 1,3771 & & & 0,55 & & 42,356 & \\
\hline & & 6,5 & 0,000 & & $-6,108$ & & \\
\hline \multirow[t]{2}{*}{ Aqueous } & 1,3374 & & & 3,05 & & & 59,940 \\
\hline & & 10,2 & $-3,06$ & & 8,098 & & \\
\hline \multirow[t]{2}{*}{ Cristalino } & 1,4200 & & & 4,00 & & 21,779 & \\
\hline & & $-6,0$ & $-1,0$ & & 14,000 & & \\
\hline \multirow[t]{2}{*}{ Vitreous } & 1,3360 & & & 16,59655 & & & \\
\hline & & $-12,3$ & 0,00 & & & & \\
\hline
\end{tabular}

\section{B.6 Kooijman(1983)}

Modelo inspirado no modelo de Le Grand no estado não-acomodado. Utiliza superfícies quádricas. 
Dioptrias

\begin{tabular}{cccccccc} 
Meio & $n$ & $R$ & $Q$ & $d$ & Superfície & Componente & Olho \\
\hline Ar & 1,0000 & & & & & \\
& & 7,8 & $-0,286$ & & 48,346 & & \\
Córnea & 1,3771 & & & 0,55 & & 42,356 & \\
& & 6,5 & 0,000 & & $-6,108$ & & \\
Aqueous & 1,3374 & & & 3,05 & & & \\
& & 10,2 & 0,000 & & 8,098 & & \\
Cristalino & 1,4200 & & & 4,00 & & & \\
& & $-6,0$ & $-1,000$ & & 14,000 & & \\
Vitreous & 1,3360 & & & 16,59655 & & & \\
\hline
\end{tabular}

\section{B.7 Navarro}

Navarro propõe um modelo em que às propriedades geométricas dependem do nível de acomodação. As equações abaixo descrevem e são suficientes para construir o modelo.

$$
\begin{aligned}
& R_{3}=10,2-1,75 \ln (A+1) \\
& R_{4}=-6,0+0,2294 \ln (A+1) \\
& d_{2}=3,05-0,05 \ln (A+1) \\
& d_{3}=4,0+0,1 \ln (A+1) \\
& n_{3}=1,42+9 \times 10^{-5}\left(10 A+A^{2}\right) \\
& Q_{3}=-3,1316-0,34 \ln (A+1) \\
& Q_{3}=-1,0-0,125 \ln (A+1)
\end{aligned}
$$

Onde $A$ é o nível de acomodação, ver Capítulo (4). 
Dioptrias

\begin{tabular}{|c|c|c|c|c|c|c|c|}
\hline Meio & $n$ & $R$ & $Q$ & $d$ & Superfície & Componente & Olho \\
\hline \multirow[t]{2}{*}{$\mathrm{Ar}$} & 1,0000 & & & & & & \\
\hline & & 7,72 & $-0,26$ & & 48,705 & & \\
\hline \multirow[t]{2}{*}{ Córnea } & 1,3760 & & & 0,55 & & 42,882 & \\
\hline & & 6,5 & 0,0 & & $-5,983$ & & \\
\hline \multirow[t]{2}{*}{ Aqueous } & 1,3374 & & & $d_{2}$ & & & \\
\hline & & $R_{3}$ & $Q_{3}$ & & & & \\
\hline \multirow[t]{2}{*}{ Cristalino } & $n_{3}$ & & & $d_{3}$ & & & \\
\hline & & $R_{4}$ & $Q_{4}$ & & & & \\
\hline \multirow[t]{2}{*}{ Vitreous } & 1,3360 & & & & & & \\
\hline & & $-12,0$ & 0,0 & & & & \\
\hline
\end{tabular}

Para $A=0,0 D$ :

\begin{tabular}{cccccccc}
\hline Meio & $n$ & $R$ & $Q$ & $d$ & Superfície & Componente & Olho \\
\hline Aqueous & 1,3374 & & & 3,05 & & 60,416 \\
& & 10,2 & $-3,1316$ & & 8,098 & & \\
Cristalino & $(1,42) n_{3}$ & & & 4,00 & & 21,779 & \\
& & $-6,0$ & $-1,0$ & & 14,00 & & \\
Vitreous & 1,3360 & & & 16,40398 & & \\
\hline
\end{tabular}

Para $A=10,0 D$ :

\section{Dioptrias}

\begin{tabular}{cccccccc} 
Meio & $n$ & $R$ & $Q$ & $d$ & Superfície & Componente & Olho \\
\hline Aqueous & 1,3374 & & & 2,930110 & & 71,145 \\
& & 6,00368 & $-3,94688$ & & 16,756 & & \\
Cristalino & 1,438 & & & 4,23979 & & 34,548 & \\
& & $-5,44992$ & $-1,29974$ & & 18,716 & \\
Vitreous & 1,3360 & & & 16,28415 & & \\
\hline
\end{tabular}




\section{B.8 Liou-Brennan}

O modelo de Liou e Brennan é inspirado em dados obtido experimentalmente do olho humano, ver (2). Dos modelos empregados é o unico que utiliza uma distribuição do índice de refração para cada porção do cristalino. Tanto a distribuição anterior $n_{A}$ como a posterior $n_{P}$ são dadas pela Equação (B.1).

$$
n\left(\rho^{\prime}, z^{\prime}\right)=n_{00}+n_{01} z^{\prime}+n_{02} z^{\prime 2}+n_{10} \rho^{\prime 2}
$$

Onde $\rho^{\prime 2}=x^{\prime 2}+y^{\prime 2}$ e $\left(x^{\prime}, y^{\prime}, z^{\prime}\right)$ são um sistema de coordenada centrado em $z_{0}$ no eixo ótico $z$ do modelo e $n_{00}, n_{01}, n_{02}$ e $n_{10}$ são constantes explicadas na Tabela (B.8).

O modelo também define uma pupila deslocada $0,5 \mathrm{~mm}$ para o lado nasal do olho.

\begin{tabular}{|c|c|c|c|c|c|c|c|}
\hline & & & & & & Dioptrias & \\
\hline Meio & $n$ & $R$ & $Q$ & $d$ & Superfície & Componente & Olho \\
\hline \multirow[t]{2}{*}{$\mathrm{Ar}$} & 1,000 & & & & & & \\
\hline & & 7,77 & $-0,18$ & & 48,391 & & \\
\hline \multirow[t]{2}{*}{ Córnea } & 1,376 & & & 0,55 & & 42,882 & \\
\hline & & 6,40 & $-0,60$ & & $-6,250$ & & \\
\hline \multirow[t]{2}{*}{ Aqueous } & 1,336 & & & 3,16 & & & \\
\hline & & 12,40 & $-0,94$ & & 2,581 & & 71,145 \\
\hline \multirow[t]{2}{*}{ Cristalino } & $n_{A}$ & & & 1,59 & 6,283 & & \\
\hline & & $\infty$ & & & & 34,548 & \\
\hline \multirow[t]{2}{*}{ Cristalino } & $n_{P}$ & & & 2,43 & 9,586 & & \\
\hline & & $-8,10$ & 0,96 & & 3,950 & & \\
\hline \multirow[t]{2}{*}{ Vitreous } & 1,3360 & & & 16,23883 & & & \\
\hline & & & 0,0 & & & & \\
\hline
\end{tabular}


Modelos do olho humano

Tabela B.1: Constantes da Equação (B.1) que descreve a distribuição do índice de refração na porção anterior $n_{A}$ e posterior $n_{P}$ do cristalino.

\begin{tabular}{lcc}
\hline & $n_{A}$ & $n_{P}$ \\
\hline$n_{00}$ & 1,368 & 1,407 \\
$n_{01}$ & 0,0049057 & 0,0 \\
$n_{02}$ & $-0,015427$ & $-0,006605$ \\
$n_{10}$ & $-0,001978$ & $-0,001978$ \\
$z_{0}$ & $-3,71$ & $-5,30$ \\
\hline
\end{tabular}




\section{Referências Bibliográficas}

[1] GULLSTRAND A., In the helmholtz's treatise on physiological optics, 3rd ed., Hamburg, Germany, 1909.

[2] LIOU H.; BRENNAN N. A., Anatomically accurate, finite model eye for optical modeling, J. Opt. Soc.of Am. A 14 (1997), 1684-1695.

[3] NONATO L.G.; CASTELO A., A topological for handling triangle insertion and removal into two-dimensional unstructured meshes., Cadernos de Computação do ICMC-USP/São Carlos 2(3) (2002), 221-244.

[4] SCHACHAR R. A., Sclera expansion band procedure reverses presbyopia., Ocular Surgery News Opt (2000), 5.

[5] SMITH G.;PIERSCIONEK B.K.; ATCHISON D. A., The optical modelling of the human lens., Ophtal Physiol. Opt. 11 (1991), 359-369.

[6] Amplitude of accommmodation, http://en.wikipedia.org/wiki/Amplitude_of_accommodation, acesso em 12/01/2008.

[7] LANGENBUCHER A.et al., Ray tracing through a schematic eye containing secondorder (quadric) surfaces using 4 x4 matrix notation, Ophthal. Physiol. Opt. 26 (2006), 180-188.

[8] KOOIJMAN A. C., Light distribution on the retina of a wide-angle theoretical eye, J. Opt Soc Amer 73 (1983), 1544-1550. 


\section{Referências Bibliográficas}

[9] BURDEN R. L.; FAIRES J. D., Análise numérica, Thomson Learning, 2003.

[10] COLIN J. R.; CAMBBELL S.; HIRCHHORN M. D., Zernike expansion of separable functions of cartesian coordinates., Applied Optics 43 (2004), 3963-3966.

[11] BORN M. ; WOLF E., Principles of optics, segunda ed., Pergamon Press, 1970.

[12] HARLE C. E., Geometria diferencial, Institudo de Matemática Pura e Aplicada (IMPA), 1973.

[13] LIANG J. et al., Objective measurement of wave aberrations of the human eye with the use of hartman-shack wave-front sensor., Optical Society of America. 11 (1994), $1949-1957$.

[14] SCHACHAR R. A. et al., The mechanism of accommodation and presbyopia in the primate., Annals of Ophtalmology 27(2) (1995), 58-67.

[15] THIBOS et al.., Accuracy and precision of objective refraction from wavefront aberrations., Journal of Vision 4 (2004), 329-351.

[16] ATCHISON D. A.; SMITH G., Optics of the human eye, Reed Educational and Professional Publishing Ltd, 2000.

[17] SMITH G., The optical properties of the crystalline lens and their significance., Clin Exp Optometry 86(1) (2003), 3-18.

[18] Glut: The opengl utility toolkit, http://pt.wikipedia.org/wiki/OpenGL, Acesso em: 19 de dez. 2007.

[19] HELMHOLTZ H., Physiologic optics, 3rd ed., vol. 1 and 2, Hamburg, Germany, 1909.

[20] EMSLEY H.H., Visual optics, 5th ed., London:Hatton Press Ltd, 1952.

[21] LEMKE C. E.; HOWSON, Equilibrium points od bimatrix games, Journals on Applied Mathematics 12 (1964), 413-423.

[22] NAVARRO R.; SANTAMARÍA J.; BESCÓS J., Accommodation-dependent model of the human eye with aspherics., Optical Society of America A 2 (1985), 1273-1281. 


\section{Referências Bibliográficas}

[23] NOLL R. J., Zernike polynomials and atmospheric turbulence., J. Opt. Soc.of Am 66 (1976), 207-211.

[24] SHARMA A.; KUMARD. V.; GHATAK A. K., Tracing rays through graded-index media: a new method, Applied Optics. 21 (1982), 984-987.

[25] THIBOS L. N., Visual instrumentation:optical design and engerneering principles, 1st ed., McGraw-Hill, 1999.

[26] M. NUSSENVEIG, Curso de física básica: Ótica, relatividade, física quântica., 2a ed., Edgard Blücher, 1998.

[27] Olho humano, http://pt.wikipedia.org/wiki/Olho, Acesso em: 04 de dez. 2007.

[28] Opengl: Open graphics library, http://pt.wikipedia.org/wiki/OpenGL, Acesso em: 19 de dez. 2007.

[29] LIANG J.; WILLIAMS R., Aberration and retinal image quality of the normal human eye, Optical Society of America 14 (1997), 2873-2883.

[30] DORIĆ S., Ray tracing through gradient-index media: recent improvements., Applied Optics 29 (1990), 4026-4029.

[31] DURAN R. S., Modelador e visualizador do sistema visual humano, Master's thesis, Universidade de São Paulo - Instituto de Ciências Matemáticas e de ComputaçãoICMC/USP São Carlos, 2005.

[32] PEDROTTI F. L.; PEDROTTI L. S., Introduction to optics, Prentice-Hall, 1987.

[33] LE GRAND Y.; EL HAGE S.G., Physiological optics, primeira ed., Springer-Verlag, 1980.

[34] GOODMAN J. W., Intrododuction to fourier optics, 2nd ed., McGraw-Hill, 1996. 